ASYLUM MIGRATION TO THE EUROPEAN UNION: PATTERNS OF ORIGIN AND DESTINATION

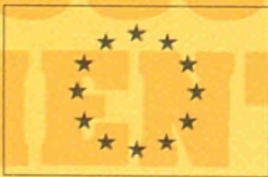

EUROPEAN COMMISSION 
This document has been produced with the financial assistance of the European Commission. The opinions expressed by the authors do not necessarily reflect the position of the European Commission.

A great deal of additional information on the European Union is available on the Internet.

It can be accessed through the Europa server (http://europa.eu.int).

Catatoguing data can be found at the end of this publication.

Luxembourg: Office for Official Publications of the European Communities, 1998

ISBN 92-828-3306-2

(C) European Communities, 1998

Reproduction is authorised provided the source is acknowledged.

\section{Printed in Belgium}




\section{ASYLUM MIGRATION TO THE EUROPEAN UNION: \\ Patterns of origin and destination}

Anita Böcker

Tetty Havinga

Institute for the Sociology of Law

Nijmegen, The Netherlands

1997 
. 


\section{Acknowledgements}

Two years ago, Professor Kees Groenendijk of the Institute for the Sociology of Law (University of Nijmegen) suggested the idea of conducting a study on the geographical distribution of asylum seekers within the European Union. The Secretariat General of the European Commission showed an interest and decided to provide the funding for this study. This research started in February 1995.

The research on which this report is based consists of three parts: a survey of the existing literature, an analysis of the data with regard to asylum applications in the countries of the European Union and interviews with key informants in three countries: Belgium, The Netherlands and the United Kingdom.

We would not have succeeded in finishing this research project without the assistance of many people and institutions. We are grateful to the European Commission for their financial support. Thanks are also due to Thana Chrissantaki of EUROSTAT for providing the data on which this research is based. Ben Pelzer of the Institute for Sociology (University of Nijmegen) conducted the statistical analyses.

The interviews with key informants in The Netherlands were conducted by Thomas Hessels and Tetty Havinga. Thomas Hessels also assisted in the collection of the literature, facts and figures. The key informants in Belgium and the United Kingdom were selected and interviewed by colleagues in these countries. Daniéle Joly of the Centre for Research in Ethnic Relations (University of Warwick) and Mano Candappa were responsible for the interviews in the United Kingdom. Joan Ramakers of the Hoger Instituut voor Arbeid (Higher Institute for Labour Studies, University of Leuven) was responsible for the interviews in Belgium.

Kees Groenendijk deserves special mention. The idea for this study originated with him and he supervised the research project in a stimulating manner. We are grateful to Dennis de Jong for his helpful comments on the research design and the interest he showed in the project. Thanks are also due to Hannie van de Put for the layout of this report and to Lee Ann Weeks for editing the text. Last but not least, we want to express our gratitude to the key informants in the three countries, who shared their knowledge and views with us.

Anita Böcker

Tetty Havinga 


\section{List of Abbreviations}

Abbreviations for countries used in tables and figures

$\begin{array}{ll}\text { B } & \text { Belgium } \\ \text { D } & \text { Germany } \\ \text { DK } & \text { Denmark } \\ \text { E } & \text { Spain } \\ \text { F } & \text { France } \\ \text { GR } & \text { Greece } \\ \text { I } & \text { Italy } \\ \text { IRL } & \text { Ireland } \\ \text { L } & \text { Luxembourg } \\ \text { NL } & \text { The Netherlands } \\ \text { P } & \text { Portugal } \\ \text { UK } & \text { United Kingdom }\end{array}$

Other abbreviations

EFTA European Free Trade Association (current members are Iceland, Liechtenstein, Norway and Switzerland)

EU European Union

EUROSTAT Statistical Office of the European Communities IGC Inter-governmental Consultations on Asylum, Refugee and Migration Policies in Europe, North America and Australia

IOM International Organisation for Migration

NIDI Netherlands Interdisciplinary Demographic Institute

OFPRA Office français de protection des réfugiés et apatrides

UNESCO United Nations Educational, Scientific and Cultural Organization

UNHCR United Nations High Commissioner for Refugees

WVC Dutch Ministry of Welfare, Health and Cultural Affairs 


\section{List of Tables and Figures}

Chapter 2

Table 1: $\quad$ Peterson's typology 12

Table 2: Richmond's typology of reactive migration 12

Chapter 3

Figure 1: Numbers of asylum applications filed in the countries of the European Union and in Germany, France, The Netherlands and the United Kingdom, 1985-1994

Figure 2: Numbers of asylum applications filed in the countries of the European Union in 1985-1994, by region of origin of the applicants

Table 1: EU countries ranked according to the ratio of asylum applications to the size of the population

Table 2: EU countries ranked according to the ratio of asylum applications to the GNP per capita

Table 3: Distribution of different regions of origin for asylum seekers in 11 EU countries, 1985-94 (percentages)

Table 4: Nationalities of major groups of asylum applicants for different EU countries, 1985-94

Table 5: Top five nationalities of applicants seeking asylum in the European Union by year of application

Table 6: Most important destination countries for asylum seekers from the 44 largest countries of origin in the years 1985-94

Appendix 1

Table 1: Asylum applications in EU member states by country of nationality, 1985-1994

Table 2: Distribution of the asylum applications across countries of nationality for the different EU member states (percentages), 1985-1994 
Appendix 2

Table 1: Availability of information pertaining to country of nationality for asylum seekers per EU member state

Table 2: Which persons are included or excluded in the figures on asylum seekers

Appendix 3

Table 1: Scores for the different combinations of country of origin and country of destination on our measure of disproportionality $\mathrm{D}_{\mathrm{od}}$ (relative over- or underrepresentation

Table 2: Results of the statistical analyses

Appendix 6

Table 1: Rank ordering of factors according to importance for determination of the country of asylum 


\section{Contents}

Chapter 1 The destination of asylum movements:

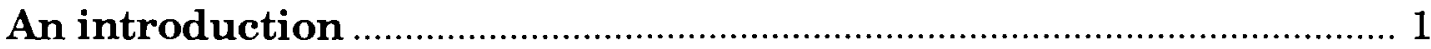

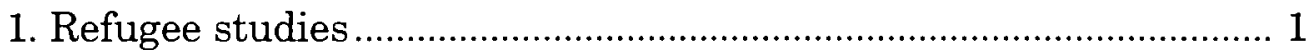

2. Aim of the research project and research questions........................ 2

The concept of asylum seeker ..................................................... 2

The concept of choice .................................................................. 4

Research questions...................................................................... 5

3. Research methods ...................................................................... 5

Survey of the existing literature …………………………........ 5

Analysis of available statistics .................................................... 6

Interviews with key informants.................................................. 7

4. Plan of the study............................................................................ 10

Chapter 2 The destination of asylum movements:

Theoretical perspectives and available data ...................................... 11

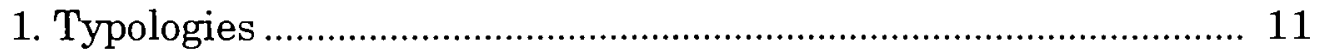

2. Factors causing, directing and shaping migration flows.............. 14

Push-pull factors....................................................................... 14

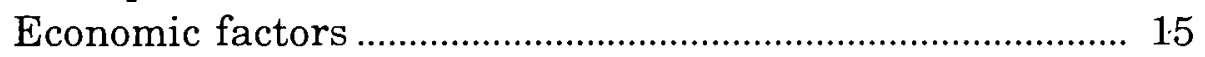

Historical-political factors....................................................... 16

Social factors ........................................................................ 17

The migration-systems approach ............................................ 18

3. Available data on refugees and asylum seekers ........................... 18

Empirical research on the choice of the country of

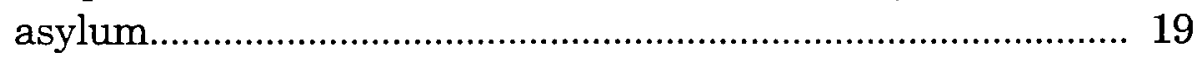

4. Analytical framework....................................................................... 23

Links between countries of origin and countries of

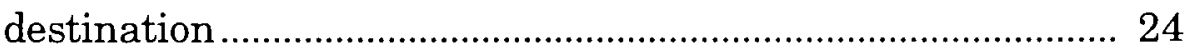

Characteristics of countries of destination (either real or perceived by asylum seekers and their 'agents')............... 24

Events during flight .................................................................. 25

\section{Chapter 3 Patterns of origin and destination:}

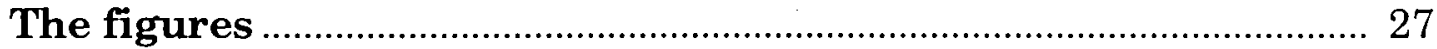

1. Origins and destinations: The general pattern ………………...... 27

Destination countries ................................................................. 28

Factors determining the distribution within the

European Union ..................................................................... 29

Regions and countries of origin ................................................ 31 
2. Origins and destinations: Specific patterns .................................... 33

The importance of former colonial ties..................................... 37

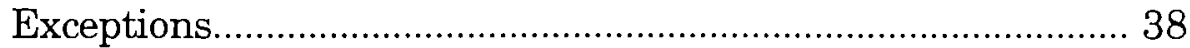

Other cases (with no colonial ties)............................................ 39

Results of a multivariate analysis .............................................. 40

3. Changes in the patterns of origin and destination.......................... 41

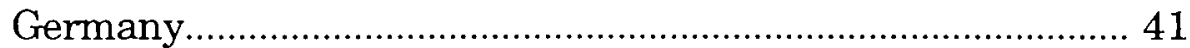

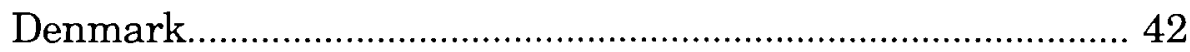

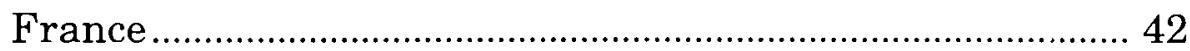

The Netherlands ...................................................................... 43

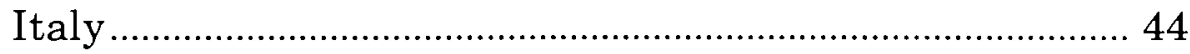

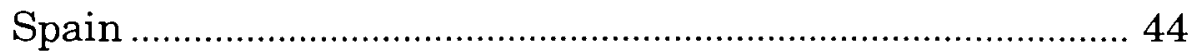

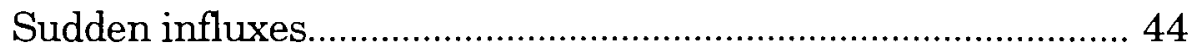

Conclusion .......................................................................... 45

Chapter 4 Key informants on factors influencing the

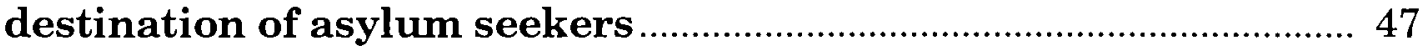

1. Do asylum seekers have a choice of country?.............................. 48

2. Ties between country of origin and country of destination........... 52

Colonial links............................................................................ 52

Language and culture ……………………………………...... 55

Friends, family and existing community .................................. 56

Political ties between countries …………………………….... 58

Trade, travel and religion........................................................... 59

3. Characteristics and image of the countries of destination.......... 60

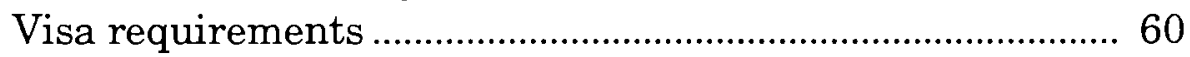

Asylum procedure and recognition rates ............................... 62

Reception facilities and the right to work pending a

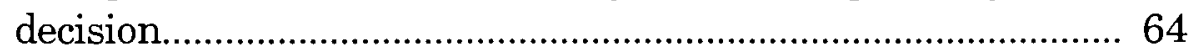

Economic opportunities............................................................. 69

Human-rights reputation.......................................................... 70

5. Events during the flight .................................................................. 71

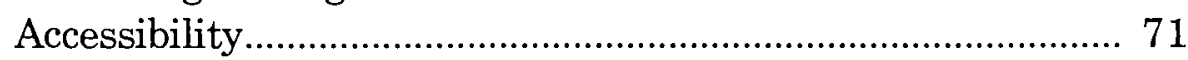

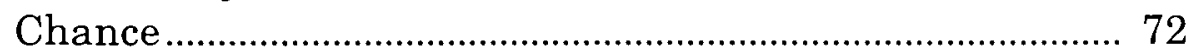

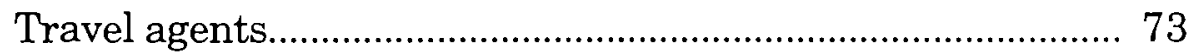

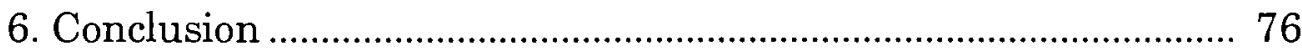

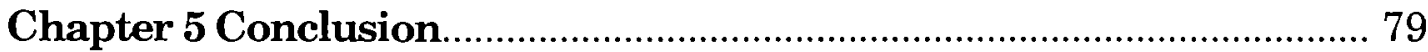

1. Country of asylum by choice or by chance? ……………………..... 79

2. Links between country of origin and country of

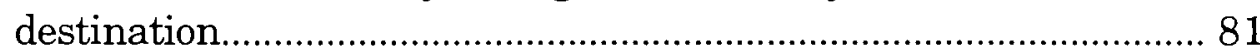

Three important links ............................................................. 81

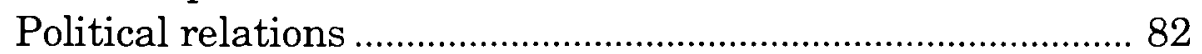


Minimal importance of religion, cultural exchange and

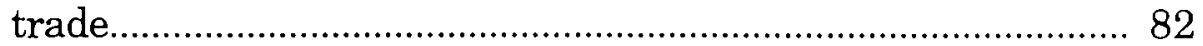

3. Characteristics and image of countries of destination .............. 83

Rumours ............................................................................. 83

Democratic image .............................................................. 84

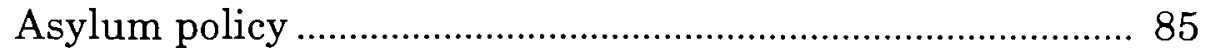

Economic opportunities ..................................................... 86

4. Events during the flight..................................................... 87

Geographical situation: Germany and the United

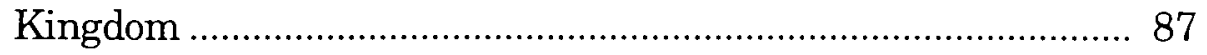

Travel agents ............................................................... 88

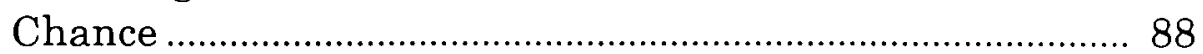

5. Some closing theoretical considerations ................................... 89

6. Some final remarks on policy................................................. 90

Appendix 1: Statistics with regard to asylum applications ..................... 93

Appendix 2: Notes on the statistics used in this study.......................... 99

Appendix 3: Results of the statistical analyses.................................... 101

Appendix 4: List of key informants and information on the interviews..................................................................................... 107

Appendix 5: Topic list used for the interviews with key informants ........ 111

Appendix 6: Rank ordering of factors by key informants...................... 113

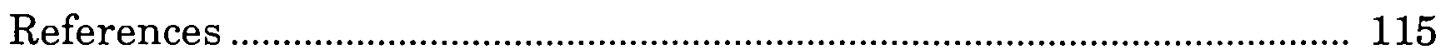


$\rightarrow$ 


\section{Chapter 1}

\section{The destination of asylum movements: An introduction}

During the last decades, asylum policy has become an issue in political debates all over Europe. The governments of most European countries have been confronted with a rising number of individual asylum seekers from a large number of countries. The governments and politicians in these European countries wonder whether their countries may be too attractive for asylum seekers. All countries have the fear of taking in too large a share of the asylum seekers when compared to neighbouring countries. All countries have tried to limit the number of asylum applications by tightening asylum policy, introducing visa requirements and border checks, and creating presumably less favourable conditions for the reception of asylum seekers. The fact that the European Commission supported this research project indicates a growing communal concern for the harmonisation of asylum policy and a fair distribution of the burden among the European countries. With these considerations in mind, we examined the factors determining the destination for possible asylum.

\section{Refugee studies}

Refugees and the global refugee problem have traditionally been studied from two perspectives. First, from the legal perspective of international law, with a focus on the role of the United Nations High Commissioner for Refugees (UNHCR), the legal definition of refugee, the concept of nonrefoulement and the rights of resident refugees (Grahl-Madsen 1983; Hailbronner 1992; Melander 1990; Scheinman 1983). Second, from the perspective of the integration of refugees within the country of (re)settlement (e.g., housing, medical problems, voluntary agencies, participation in the labour market) (Daley 1993; Hammar 1993; Kuhlman 1994; Postel and Boekhoorn 1993).

In the last decade, these perspectives have been supplemented by studies into three other aspects of the refugee problem:

- the causes of refugee migration (Hakovirta 1986, 1991; Richmond 1993; Suhrke 1995; Zolberg, Suhrke and Aguayo 1989); 
- financial and other assistance to the countries of first refuge in a conflict region (Gordenker 1983; Kuhlman 1994);

- the refugee policy of a particular country or group of countries (Caestecker 1992; Hakovirta 1986; Kuiper 1992; Scanlan and Loescher 1983; Ten Doesschate 1993).

The focus of the present study is on yet another aspect of the refugee problem: the patterns of destination for refugees. Ramakers (1995) suggests that migration scholars should try to explain why so many Pakistani, Indian and Ghanese asylum seekers arrive in Belgium as these migration patterns cannot be explained by colonial history or geographical proximity. This question has not attracted much systematic attention, however. Only a limited number of studies have addressed the patterns of origin and destination for asylum seekers, and primarily the political and social conflicts accounting for the flow of refugees have been analysed in the majority of these studies.

Analyses of the conditions causing refugee flows, possible modalities for aid to the countries of first refuge in conflict regions, the conditions facilitating integration and resettlement in the country of refuge and the concept of refugee itself are assumed to contribute to the solution of the global asylum problem. We also consider the patterns of destination for asylum seekers to be worthy of study because a number of implicit assumptions are commonly made with regard to this subject in political debates all over Europe. Asylum policy is frequently based on the assumption that most 'asylum seekers are in fact economic migrants' or 'asylum seekers are attracted by our lenient asylum policy'. In the field of refugee studies and migration theory, moreover, traditional migration theory and research has been criticised for not paying much attention to the reasons for migration to a particular country or region.

\section{Aim of the research project and research questions}

As already stated, the aim of the present research project is to shed greater light on the choice of country of refuge for asylum seekers. The central question is which factors determine the country of application for asylum; in other words, which factors determine the direction of asylum movement?

\section{The concept of asylum seeker}

Certain migration scholars have attempted to classify all kinds of international migrations within a single typology (e.g., Peterson 1970). Such typologies are constructed on the basis of the causes of the migration movement, the migrant's motives or both. In this kind of typology, for 
example, refugees are considered to be involuntary, forced migrants and their movement to be caused by political factors.

The concept of asylum seeker is defined in a more legal sense in the present study. The term asylum seeker is reserved for persons filing a formal request for asylum. ${ }^{1}$ This means, on the one hand, that migrants who seek political refuge without formally applying for asylum are omitted from consideration. On the other hand, migrants who do not really want refuge but file an application for such refuge in order to circumvent normal immigration procedures are included. ${ }^{2}$

Sociologically, the distinction between asylum seekers, or refugees, and other migrants, for instance labour migrants, is not very clear. A sharp separation of economic from political causes of migration is also misleading because many migration movements are the result of mixed causes (Menjivar 1993; Suhrke 1995).

If refugees are easily admitted on other grounds to a country and allowed to settle without applying for asylum, they will probably not file an application for asylum. According to Blaschke (1989), for example, the majority of the people fleeing to Germany from Turkey in the early 1960s and after the coup in 1971 did not apply for asylum. A more recent example is Italy. Up until 1990, it was simply not possible for persons from non-European countries to apply for asylum in Italy. The result was high numbers of undocumented immigrants from countries in the Third World such as Cape Verde, Bangladesh, Somalia, the Philippines, Senegal and Sri Lanka living in Italy (Snowden 1993). Some of these migrants were undoubtedly seeking protection from prosecution.

When no possibility exists for admittance as a labour migrant, in contrast, potential migrants may apply for asylum in order to circumvent the normal immigration procedures and become a legal part of the labour force. As Widgren (1989: 602) states:

'Beyond any doubt, the majority of Poles, Turks and Yugoslavs now applying for asylum would prefer to apply for labor permits, if that option would exist'. ${ }^{3}$

1 In discussing the literature, we may refer to the concepts used by other authors. In some of these studies, however, the concepts of asylum seeker and refugee are not clearly distinguished. When the term refugee is used, for example, it is not always clear that reference is being made to persons with a request for asylum which has been accepted.

2 In the quantitative part of this study, we had to rely on available statistical data and could not take the distinction between formal asylum seekers and those people seeking political refuge into consideration. In the qualitative part of this study, we sometimes make reference to this discrepancy. With regard to the information from the interviews, the respondents used more or less their own definitions.

3 Widgren suggests that a preference for a labour permit excludes a justified claim for recognition as a Convention refugee. This rather common assumption is clearly incorrect. 
The tightening of immigration controls may thus result in a rising number of asylum applications. Migrants may also apply for asylum as a way to legalise their stay in the country for the duration of the asylum procedure. During that time, they can work or look for opportunities to emigrate to some other country. According to a staff member of the Belgian emigration office of the International Organisation for Migration, many Romanians requested asylum in Belgium in order to apply for emigration at the Canadian Embassy in Brussels. In such a way, their stay in Belgium during the processing of their emigration file for Canada is legalised (Caestecker 1995:13). Another illustration of the flexible and changing boundary between refugees and labour migrants is the British recruitment of displaced persons in German and Austrian camps after the Second World War for work (Kay and Miles 1992).

\section{The concept of choice}

The usual definition of refugees and asylum seekers as involuntary migrants often carries the theoretical implication of being pawns. Their movements are a more or less mechanical reaction to political forces, political conflicts, violence and war. This approach has met with criticism. For instance, Hansen (1981:190) has criticised Kunz for neglecting the significance of decision making on the part of refugees:

'Although some people flee in blind panic or without any forethought, my assumption is that, to most refugees, flight and the destination are chosen as the result of more deliberation.'

It can nevertheless be assumed that the destination of flight is not a conscious, rational choice between alternative destinations in most cases. The level of acuteness is probably important (cf. Johansson 1990) with no time for preparation or anticipation of the flight in some cases. When the flight is acute, the choice of a particular country may be purely coincidental from the perspective of individual asylum seekers: they came to a particular country because a plane was available, they managed to get travel documents, someone recommended the country or someone made the travel arrangements for them. The asylum seekers either may or may not have a preference for a particular country, but even with a particular preference may end up in another country. For example, many Ugandese refugees invited to come to The Netherlands in 1972 would have preferred to go to the United Kingdom; many Vietnamese refugees in the 1980 s would have preferred to go to the United States or Canada rather than The Netherlands (Postel and Boekhoorn 1993:15-17, 86). In these cases where the asylum seekers do not themselves have a real choice, we are still interested in the factors determining the destination of their flight. This means the motives of the asylum seekers at a micro level and the factors determining the direction of asylum flows at the macro level. 
We assume the problem to be complex. Goodwin-Gill (1990:16) speaks of 'the multiple dimensions of forced migration movements' and the reasons for flight in particular. We will not attempt to attribute the direction of refugee movements to a single factor. We assume, rather, a number of factors to contribute to the final destination of the flight.

\section{Research questions}

Our central question can be specified in the following manner:

- Are asylum seekers from particular countries of origin randomly distributed among the European Union countries or are there specific patterns of origin and destination?

- Which factors appear to explain (changes in) these patterns?

- To what extent is the country of destination a deliberate choice by asylum seekers?

\section{Research methods}

This research project consists of three parts.

- A survey of the literature and in particular publications based on empirical research with a view to those factors influencing the destinations for asylum.

- An analysis of the data available on asylum seekers in the European Union member states since 1985.

- Interviews with key informants in three EU member states: The Netherlands, Belgium and the United Kingdom.

\section{Survey of the existing literature}

A survey of literature was conducted in order to identify the factors influencing the destination of asylum seekers. In particular, empirical research reports were considered. It proved to be difficult to find literature on the subject. We looked for relevant publications in the Journal of Refugee Studies, International Migration Review, International Migration Bulletin, various bibliographies (e.g., Davies 1990; Joly 1988; WVC 1991, 1992 ) and some on-line bibliographical data bases. In addition, we used information from the Migration News Sheet and reports from the International Organisation for Migration. The more general and theoretical literature on asylum seekers and migration was also considered but not systematically. The aim of this part of the research project was not to present an exhaustive review of the literature but to identify the various factors which have been put forward to explain the patterns of origin and destination for asylum seekers. We did not use reports of investigations by the police and immigration authorities into asylum seekers' itineraries, forgery of travel documents or trafficking. 


\section{Analysis of available statistics}

In this part of the research project, we focused on the member states of the European Union as countries of destination and restricted our analyses to the period 1985-94. In this period, over three million asylum applications were filed in the member states of the European Union. Although this figure is much higher than the figure for the preceding decade, the member states of the European Union still receive only a fraction of all asylum seekers. Most refugees remain in the Third World - in countries near the country which they fled. According to figures from the UNHCR, the world refugee population counted 19 million people at the end of 1992; 23\% lived in Europe and less than 7\% in the European Union.

In the period after 1985, so-called spontaneous asylum seekers made up a relatively large proportion of those persons seeking asylum in Western Europe. In the earlier period, most of the refugees were so-called invited refugees. In these cases, some organisational and procedural structures influenced the distribution of refugees among the countries of resettlement. For example, the countries of asylum often laid down criteria and conditions which the refugees should meet in order to be accepted. The UNHCR and sometimes representatives of the countries for resettlement send officials to refugee camps in order to select refugees for resettlement. In the period 1968-82, The Netherlands received 8,600 invited refugees and registered 9,300 spontaneous asylum applications (Ten Doesschate 1993: 206).

Our analysis is based on data provided by EUROSTAT with regard to the number of asylum applications in the European Union (see Appendix 1, Table 1). The data pertain to the years 1985-94 and the then $12 \mathrm{EU}$ member states: Belgium, Denmark, France, Germany, Greece, Ireland, Italy, Luxembourg, Netherlands, Portugal, Spain, United Kingdom. Reliable data on applications filed before 1985 were not available. Some countries also did not provide statistics for all ten of the years covered by our study, or they did not specify applications by country of origin (nationality) of the asylum seekers.

The available statistics were used to detect existing patterns of destination. We then tried to explain these patterns by relating them to available indicators of ties between countries of origin and countries of destination. Examples of such indicators are proximity and ease of access, the existence of historical and cultural (linguistic) links or the number of persons from a particular country already living in the country of destination. Some of the variables which we had in mind at the outset of this research proved to be particularly difficult to quantify. For example, we did not succeed in finding reliable and complete information with regard to (changes in) air routes and visa obligations. 
It is important to keep in mind that the figures provided by EUROSTAT can only be taken as a rough indication of the patterns of origin and destination for asylum seekers. This is in part due to differences in counting and in part due to incomplete data from the member states. ${ }^{4}$

- The statistics on asylum applications do not always include all persons seeking asylum. Some countries do not count dependent children or accompanying spouses as separate applications while others do.

- Some asylum seekers file multiple applications, either in the same country or in different countries.

- Some countries include invited refugees or quota refugees in their statistics while others do not.

- As already mentioned, it is crucial for our research that the countries of origin or nationalities of the asylum seekers be specified. This specification is not available for all years and all countries of destination. Specific data are not available for Ireland and in the earlier years for Greece, Italy, Spain and Belgium. Specification is also missing for a large number of applications in 1994 for most of the EU countries. The number of unspecified asylum seekers varies between countries. For instance, in the German statistics a substantial number of the asylum applications is unspecified with regard to country of origin/nationality; the residual category varies between 4,500 in 1987 and 53,000 in 1993. This means, for example, that there may have been hundreds or even thousands of Somalian asylum seekers in Germany while the statistics show none.

- Even if the country of origin is specified, it may not be sufficient for explaining the patterns of destination. Asylum seekers from Turkey, Iran and Iraq include an unknown number of Kurdish people. The statistics do not differentiate between people from the northern and the southern part of Somalia. The links between the various communities and the countries of destination obviously vary, and the factors explaining the movements of the different asylum seekers might very well differ as well.

The preceding observations lead us to conclude that the statistics on asylum applications broken down by country of asylum and country of origin/nationality of the asylum seeker provide only rough and sometimes inaccurate data. This is not ideal for an analysis of the patterns of destination for asylum seekers, but it is the best information available.

\section{Interviews with key informants}

A number of key informants from three EU countries were finally interviewed. The primary source for information with regard to the choice of the country of asylum is, of course, the actual asylum seeker him/herself. We initially considered a survey of asylum seekers from a select number

4 A more detailed overview of the available data is provided in Appendix 2. 
of countries of origin in two different countries of refuge. However, this idea was dropped after examining the methodological and technical problems involved in the organisation of such a survey. For one thing, interviewing a sufficient number of asylum seekers in two different countries is a costly and time-consuming enterprise. Even if we had limited ourselves to a single country of refuge, such a survey would have exceeded the budget and schedule set for this research project. Actual asylum seekers are also probably reluctant to answer questions regarding their reasons for coming to this particular country and their itineraries, moreover. This means that the quality of the information gathered would simply not justify such high costs.

A second possibility was to analyse the files on asylum applications. We nevertheless preferred interviewing key informants because the official files obviously contain information gathered for a specific purpose. Immigration officers interview asylum seekers in order to prepare a decision with regard to their request. Asylum seekers cannot speak freely under such circumstances and presumably tell their story to maximise the chances of a favourable decision.

\section{Selection of the three research countries}

It was clear from the start that The Netherlands should be one of the countries in this study. The researchers are Dutch, which enables them to conduct the interviews personally without the assistance of interpreters or fellow researchers. What's more, The Netherlands has received a substantial number of asylum applications from very different countries of origin over the years. Just why people from those countries go to The Netherlands is nevertheless not obvious.

In Brussels, it was suggested that Belgium be included in the research. Belgium seemed to be an interesting country because The Netherlands and Belgium are similar in several respects (i.e., both small countries, both participating in the Benelux), but remarkably different with regard to the number of asylum applications, asylum policy and the country of origin for the asylum seekers.

As the third country, we chose a country with a large number of asylum applications, either Germany, the United Kingdom or France. The groups of asylum seekers going to France greatly resemble those fleeing to Belgium. Hence, we decided not to choose France. Germany would be a very interesting country to study because the majority of asylum applications in the European Union are filed in Germany and Germany receives asylum seekers from almost every country of origin. Asylum seekers from Eastern Europe are strongly represented, presumably because of the long border with Eastern Europe. We nevertheless decided not to include Germany because in Germany the central question seems to be why so many asylum seekers come to that country rather than why asylum seekers 
from a particular country of origin come to Germany. In addition, we expected interviews with key informants in Germany to be complicated by the fact that Germany is a federal state and the associated variation across the Länder. This left the United Kingdom with a high representation of African and Asian countries among the asylum applications. People from some former British colonies do not appear to flee primarily to the United Kingdom which is contrary to what one might expect. Research in the United Kingdom thus appeared to be interesting.

\section{Selection of key informants}

Interviews were conducted with 15 key informants in each of the three countries. Among the key informants were persons working in refugee associations, organisations providing assistance to asylum seekers, lawyers, immigration officers and interpreters. Informants were asked to give their personal opinions; they were not interviewed as a representative of the organisation. In selecting the key informants, we used the following criteria.

- We looked for persons with extended knowledge of why asylum seekers may come to the host country.

- The informant should have (had) face-to-face contact with a large number of asylum seekers.

- There should be as much variation as possible among the key informants in each country. This includes the kind of experience with the asylum seekers and the particular group of asylum seekers; the major countries of origin should be represented.

- A significant number of the key informants should be refugees themselves.

The positions of the key informants interviewed in the three research countries are listed in Appendix 4.

\section{Interviews}

The interviews were conducted in the Dutch, English or Flemish language and then transcribed. On the average, the interviews lasted between one-and-a-half and two hours. The interview included questions with regard to the most likely country of asylum, important determinants of the destinations of asylum seekers, possible reasons for refugees from a particular country applying more or less often for asylum in this European country rather than another, and specific asylum policies. The interviews started with open questions and later focused on particular factors which might explain the patterns of origin and destination for the asylum seekers in the relevant country. ${ }^{5}$

5 See Appendix 5 for a list of the topics addressed during the interviews with the key informants. 
The respondents were asked to answer the questions based on their own experiences with asylum seekers. Some respondents only had knowledge of asylum seekers from a particular country of origin while others had broader knowledge. The respondents also had only knowledge of those asylum seekers who actually came to their country; only in rare cases did the interviews reveal information on asylum seekers who went to some other country. During the interview, the respondents usually answered clearly on the basis of their knowledge of the motives (and stories) of asylum seekers or on the basis of their own opinions.

\section{Plan of the study}

In the next chapter, the results of a survey of the literature for factors which have been put forth as possible explanations for the existing patterns of origin and destination for asylum seekers will be presented. A tentative list of factors is presented for use in the other parts of this research project.

In Chapter Three, we present the results of an analysis of the statistics on asylum applications filed in the countries of the European Union in the years 1985-94. We first describe the patterns of origin and destination which could be discerned from these data. We then examine to what extent the observed differences between these countries can be explained by those factors isolated as potentially important. It should be noted that quantitative data from all countries of origin and destination are not available for all of these factors.

Chapter Four is based on the interviews with the key informants in Belgium, The Netherlands and the United Kingdom. We start with a discussion of whether the asylum seekers actually chose the country of destination or just happened to arrive in that country. We then discuss the specific categories of factors distinguished in Chapter Two.

In Chapter Five, we summarise the findings of our research and try to reach some general conclusions with regard to our central research question: What factors determine the destination of asylum movements? In closing, some remarks on the political consequences of this study will also be provided. 


\section{Chapter 2}

\section{The destination of asylum movements: Theoretical perspectives and available data}

In this chapter, the available information on the direction of refugee and other migration flows is surveyed. We first examine the literature on refugees and asylum seekers. Although this field of studies has expanded during the last decade, studies paying special attention to the patterns of origin and destination for asylum seekers are scarce. We therefore examined the wider field of international migration studies which has tended to focus on economic migrants, as well.

\section{Typologies}

Particularly in the earlier migration literature, many attempts have been made to develop a typology to encompass all types of migrants or migration flows. Peterson's (1970) typology is probably the best known. To date, many references have been made to it. Peterson's typology is based on two criteria. The first criterion refers to the 'function' of migration or the migrant's motive:

'Some persons migrate as a means of achieving the new. Let us term such migration innovating. Others migrate in response to a change in conditions, in order to retain what they have had (...). Let us term such migration conservative' (1970:53).

The second criterion refers to the causes of migration (the 'migratory force' or 'activating agent'). Peterson distinguishes the following causes: 'primitive migration' caused by nature (ecological circumstances); migration forced or impelled by the state (or its equivalent); 'free migration' resulting from the (economic) aspirations of the migrant; and mass migration as the outcome of collective behaviour. In Table 1, the typology based on these two criteria is presented.

Contrary to most older typologies, Peterson's typology appears to have retained its usefulness. His distinction between 'conservative' and 'innovative' migration is still used in recent studies although the labels may sometimes differ ('reactive' versus 'proactive' or 'involuntary' versus 'voluntary' migration). Later typologies have mostly been confined to one of Peterson's types (e.g., migration caused by economic or migration caused 
by political factors). This is in part because scholars examining labour migration flows, on the one hand, and those examining refugee flows, on the other hand, have formed more or less separate circuits. ${ }^{1}$

Table 1: Peterson's typology

\begin{tabular}{|c|c|c|c|c|}
\hline \multirow[t]{2}{*}{ Relation } & \multirow[t]{2}{*}{ Migratory force } & \multirow{2}{*}{$\begin{array}{c}\text { Class of } \\
\text { migration }\end{array}$} & \multicolumn{2}{|c|}{ Type of migration } \\
\hline & & & Conservative & Innovating \\
\hline Nature and man & Ecological push & Primitive & $\begin{array}{c}\text { Wandering } \\
\text { Ranging }\end{array}$ & $\begin{array}{l}\text { Flight from } \\
\text { the land }\end{array}$ \\
\hline State (or equiva- & Migration & Forced & Displacement & Slave trade \\
\hline lent) and man & policy & Impelled & Flight & Coolie trade \\
\hline Man and his norms & $\begin{array}{l}\text { Higher } \\
\text { aspirations }\end{array}$ & Free & Group & Pioneer \\
\hline Collective behaviour & $\begin{array}{c}\text { Social } \\
\text { momentum }\end{array}$ & Mass & Settlement & $\begin{array}{c}\text { Urbaniza- } \\
\text { tion }\end{array}$ \\
\hline
\end{tabular}

Source: Peterson (1970:65).

A recent example of a typology of refugee movements is Richmond's (1993) typology of reactive migration. In this typology, Peterson's distinction of conservative versus innovative migration is replaced with that of 'reactive' versus 'proactive' migration. All reactive migration is then considered refugee migration. Richmond furthermore distinguishes between primary determinants of particular kinds of reactive migration (such critical events as the outbreak of war destroying the capacity of a population to survive) and secondary factors increasing the probability of migration (e.g., inequalities in wealth between different countries). The combination of the two kinds of factors leads to the typology delineated in Table 2.

Table 2: Richmond's typology of reactive migration (primary determinants are listed horizontally, secondary determinants vertically)

\begin{tabular}{lccccc}
\hline psychological & Political & Economic & Environmental & Social & Bio- \\
Political & 1 & & & & \\
Economic & 6 & 10 & 14 & 4 & 5 \\
Environmental & 7 & 11 & 15 & 19 & 22 \\
Social & 8 & 12 & 16 & 20 & 24 \\
Bio-psychological & 9 & 13 & 17 & 21 & 25 \\
\hline Source: Richmon
\end{tabular}

Source: Richmond (1993:18).

1 In addition to theoretical considerations, this may also be due to pragmatic and/or political considerations (adherence to common legal and political distinctions). 
It is clear that Richmond's concept of refugee migration is far more inclusive than conventional definitions; his typology lists no less than 25 types of reactive migration. Only in types one to nine are political factors involved either as primary or secondary determinants of movements. ${ }^{2}$

While Richmond distinguishes between 'reactive' and 'proactive' migrants and considers all reactive migrants to be 'refugees', he emphasises the continuum between proactive and reactive migration.

'Under certain conditions the decision to move may be made after due consideration of all relevant information, rationally calculated to maximize net advantage (...) At the other extreme, the decision to move may be made in a state of panic facing a crisis situation which leaves few alternatives but escape from intolerable threats. Between these two extremes, many of the decisions made by both 'economic' and 'political' migrants are a response to diffuse anxiety generated by a failure of the social system to provide for the fundamental needs of the individual, biological, economic and socia.' (Richmond 1993:10).

Thus, the large majority of international migrants fall somewhere between the two extremes. They have some freedom in deciding whether to move or not and in the choice of destination, but this freedom may be constrained.

In Richmond's conceptualisation, politically motivated migrants who move 'in an anticipatory stage' are proactive migrants and not refugees (cf. Richmond 1993:11). Richmond is referring, here, to the work of Kunz $(1973,1981)$ who distinguishes between 'anticipatory' and 'acute' refugee movements. In Kunz's conceptualisation, however, both types of movements count as refugee movements. In contrast to other migrants, refugees are involuntary migrants who move in response to 'push' factors (i.e., factors driving them away from their home countries). Voluntary migrants are responding to 'pull' factors (i.e., factors attracting them to somewhere else). Kunz then observes that:

'Educated, alert and well-to-do as anticipatory refugees generally are, had they been under the influence of 'pull' there are good reasons to believe that they would have become voluntary migrants earlier' (1973:132).

Johansson (1990) elaborates on the distinction made by Kunz between anticipatory and acute refugee movements but does not agree that refugees only respond to push factors. According to Johansson, pull factors are important to all refugee movements, because

'nobody would willingly leave his home country for another country in which he perceives his predicament to be the same, or even more difficult' (Johansson 1990: 248).

2 See Suhrke (1995) for a more elaborate discussion of Richmond's typology. 
Pull factors are certainly more important for anticipatory than acute refugees as the former have more time to plan than the latter and are not immediately compelled to become refugees. In addition, anticipatory refugees typically have more information on possible countries of refuge and a clearer idea of their destination than acute refugees (Johansson 1990: 244).

\section{Factors causing, directing and shaping migration flows}

Migration is a highly diverse field of study. There is no integrated body of theory. The many different theories, models and approaches can be classified in various ways. One possible way of classifying is according to the type of migrant flow they attempt to explain. As already observed, for example, there is little cross-reference between scholars concerned with labour-migration flows, on the one hand, and those concerned with refugee flows, on the other hand. Another possible way of classifying is according to region. There are more or less separate circuits of scholars concentrated on a specific region or migration system (e.g., the MexicanUS migration system, rural-urban migration in Africa or East-West migration in Europe).

Yet another possible classification is according to academic discipline. For instance, anthropologists and economists tend to approach migration in rather different ways. The two disciplines pose different questions and use different methods for the collection and analysis of data. Anthropologists are primarily interested in individual migrants and their social environments (e.g., households and social networks). Their focus is on individual migrants as active decision-makers. Economists and econometrists, in contrast, take migration flows at the regional, national or international level as the unit of analysis. Geographers have traditionally been most concerned with the question which interests us here, namely: the (spatial) patterns of origin and destination associated with international migration (cf. White and Woods 1980:1).

In the following, no attempt is made at an exhaustive review of the literature on international migration. Rather, an attempt is made to list the various factors which have been put forward to explain the incidence of international migration and, more specifically, the spatial patterns of migration. ${ }^{3}$

\section{Push-pull factors}

Migration theory has been dominated for a long time by the so-called push-pull paradigm. The essence of this paradigm was formulated by

3 For a state-of-the-art review of international migration theory, see European Commission (1994) and Van der Erf and Heering (1995). 
Ravenstein in a paper with the ambitious title The Laws of Migration (1885). The most important of Ravenstein's 'laws' with respect to our topic are as follows:

- most migration tends to be across short distances;

- the volume of migration increases with the development of industry and commerce;

- the direction of migration is mainly from agricultural to industrial areas (rural-urban); and

- most long-distance migration is to the major industrial and commercial centres.

While Ravenstein's laws stem from an analysis of the demographic statistics for a particular country (England) in a particular historical period (the late nineteenth century), they have remained key elements within the push-pull paradigm. Rephrased in the idiom of push-pull paradigm, Ravenstein's laws state that migration flows are conditioned by push factors (driving people away from their place of origin) and pull factors (attracting them to somewhere else) with distance acting as an intervening variable.

\section{Economic factors}

Ravenstein stressed the importance of economic disparities between the sending and receiving areas for migration. Another law of his is, in fact, that the major causes of migration are economic. The echo of Ravenstein's laws can still be heard in recent analyses of the patterns of (labour) migration. In commenting on a series of world maps containing (labour) migration flows for 1960, 1970 and 1980, for example, King concludes:

'The common pattern here is clear: migrants move from areas of rural overcrowding, underemployment and limited peasant horizons to adjacent or not-too-distant countries where industrial, mining or service-sector growth provides higher incomes and the promise of a better life' (1993:18).

The patterns of migration thus reflect the geography of economic disparities between countries. King also notes that this explanation of international migration flows using predominantly economic push-pull concepts nevertheless has its flaws. It does not explain, for instance, why much of the migration from northern Africa is channelled to France. Nor does this predominantly economic explanation account for the preponderance of Yugoslavs in Germany but not in Belgium or The Netherlands (1993:20).

Most of the adherents to the push-pull paradigm have tended to concentrate on economic (labour) migrants. Their models occasionally include social and political push-pull factors (e.g., political (in)stability). Attention is primarily paid to economic factors, however. The level of 
analysis varies. In macro-economic models, migration is the outcome of wage differentials between the sending and receiving areas. In micro-econoinic models, migration is the outcome of individual cost-benefit calculations. Weighing against the benefit of an expected increase in income, which is a function of wage differentials and employment rates, are the actual costs of migration (e.g., travel costs and opportunity costs or income foregone while looking for work). Some scholars also include psychological costs (e.g., the costs related to leaving one's family; learning to read, write and speak a new language; adapting to a new culture). These costs typically increase with distance; however,

'There is some doubt about the significance of geographical distance on its own: in terms of migration impact the social or cultural distance moved (unmeasurable though these may be in practice) are arguably of greater importance' (White and Woods 1980:18).

In some of the micro-economic models, therefore, the propensity to migrate is assumed to decrease with increasing social and cultural distance.

\section{Historical-political factors}

In the 1980s, the push-pull paradigm met with a wave of criticism. The assumption that migration flows spontaneously arise from the sheer existence of economic inequalities was considered particularly untenable. It was pointed out, for example, that the post-war labour migration to Western Europe did not arise out of economic disparities alone but also out of a history of prior contact between the sending and receiving countries:

'In general, the emergence of regular labour outflows of stable size and known destination requires the prior penetration by institutions of the stronger nation-state into those of the weaker sending ones' (Portes and Böröcz 1989:608).

While traditional push-pull models are thus limited to push factors in the sending areas and pull factors in the destination areas with distance acting as an intervening variable, authors such as Portes and Böröcz also focus on possible historical-political links between sending and destination areas. When these linkages are considered, for example, the pattern of post-war labour migration into Western European countries can be seen to clearly reflect previous colonial bonds. Fassmann and Münz (1992:467) speak of the 'privileged recruitment' of migrants. Part of the demand for labour in countries such as Britain, France and The Netherlands has been met by migrants from their former colonies. A similar role is played by ethnic Germans from Central and Eastern Europe and the former Soviet Union in Germany and by Finns in Sweden. 
The historical-political dimension thus leads to recognition of a variety of links (former colonial ties, cultural and linguistic similarities, political and trade relations, capital flows) between the countries of origin and destination. Consideration of the historical-political dimension also focuses attention on the institutional context for such international movements. In Western Europe, for example, much of the labour migration to France, Germany and the Benelux was regulated by a series of bilateral agreements. More recently, attention has been focused on the attempts of destination countries to regulate migration flows and an analysis of African emigration in this light is illustrative. While former mother country France used to be the only country of destination in Europe for Sahelian migrants, they started to explore other destinations in Europe in part as a response to tightening immigration control in France. The result is increasingly multipolar migration flows from the Sahel (Adepoju 1995).

\section{Social factors}

Another development in migration theory is to view migration as essentially a socially-driven process. There is a growing body of literature on the role of 'chain migration' and 'migrant networks' which are personal networks connecting migrants, non-migrants, return migrants and potential migrants in the areas of origin and destination; this may be via kinship, friendship or shared community origin (cf. Boyd 1989). These networks clearly facilitate and encourage further migration by providing information and assistance to potential migrants. In other words, new movements are directed to destinations where earlier migrants from a community have settled:

'More migrants move to a particular place because that is where the networks lead, and because that is where the social structure affords them the greatest opportunities for success. As more migrants arrive, the range of social connections is further extended, making subsequent migration to that place even more likely' (Massey et al. 1987:153).

The areas of origin and destination are thus linked through a self-sustaining process of chain migration which includes family reunification but also the migration of more distant relatives and nonrelatives. This process may eventually become more important than the economic conditions (income and employment disparities) which originally gave rise to the flow of migration. ${ }^{4}$ The findings of individual community studies also show coincidence to often play a role in the initial phase of a migration flow: the migration often starts with a single 'pioneer' in search of work or a single employer in search of workers.

4 See, for instance, Böcker (1995) on the continuing migration of Turks to Western Europe after the recruitment stop. 


\section{The migration-systems approach}

The above review mainly pertains to the literature on labour migration. The literature on refugee movement, which will be considered in the next section, mainly pertains to political factors. Most recently, a new approach has arisen, the so-called migration-systems approach, which attempts to place (among other things) both types of migration within a single analytical framework (e.g,. Koser 1995a).

This systems approach incorporates many of the theoretical notions summarised above. A migration system or network is conceptualised as:

'a network of countries linked by migration interactions whose dynamics are largely shaped by the functioning of a variety of networks linking migration actors at different levels of aggregation' (Kritz, Lim and Zlotnik 1992:15).

One of the premises of this approach is that migration constitutes just one of the linkages between countries of origin and destination and that it should thus be examined within the context of the other linkages. Another premise is that it is necessary to integrate different levels of analysis in order to identify the mechanisms responsible for the translation of macro-level forces into the determinants of migration at the microlevel of individual decision-makers (cf. Kritz, Lim and Zlotnik 1992; Bilsborrow and Zlotnik 1995). Unlike most other approaches, thus, the systems approach does not focus on a particular set of factors or a particular level of analysis. It incorporates, rather, a range of factors and integrates micro-, macro-, and meso-levels of analysis. In addition, it focuses attention on the temporal dimension of migration by considering it a dynamic process. All of this obviously implies the use of different methods and techniques for the collection of data. In practice, moreover, there are not as yet many empirical studies relying on such a systems approach (cf. Schoorl 1995).

\section{Available data on refugees and asylum seekers}

The direction or destination of migration does not constitute a central theme in the wider field of migration studies. This is even more the case with regard to the literature on refugees and asylum seekers. Most research in this expanding field of study has been focused on the legal and political aspects of asylum and the problem of refugee integration (see Chapter One). Nevertheless, we found a number of studies paying systematic attention to the question of why asylum seekers request asylum in particular countries.

In some studies, an attempt is made to analyse (changes in) the geographic patterns of asylum flow. This involves an analysis of statistics with regard to refugee movement and an attempt to explain this move- 
ment. A recent example of this type of study is Hovy (1993). One of Hovy's findings is that historical and related (cultural, linguistic) ties between the countries of origin and destination are a major determinant of the destination of asylum movement: former colonial powers tend to receive disproportionately larger numbers of applicants from regions containing their former overseas colonies. Hovy also observes that sudden changes in the destinations of asylum movements can often be attributed to the imposition of visa requirements by one of the receiving countries. Incidental factors such as rumours about a country's lenient admission policy also appear to play a role (Hovy 1993:224-225). ${ }^{5}$

In addition, there are a number of studies based on empirical research paying systematic attention to the question why asylum seekers request asylum in particular countries. In the following, we first discuss these studies. Next we will discuss a number of studies in which this question is not dealt with systematically, but which nevertheless contain relevant data.

\section{Empirical research on the choice of the country of asylum}

In a few recent studies, special attention has been paid to the question of why asylum seekers sought asylum in a particular country. The first study is one by the Canadian researcher Barsky (1994) in Québec. This study is based on in-depth interviews with 56 asylum seekers from the former Soviet Union (directly or through Israel), Peru and Pakistan. Barsky's central question pertained to the asylum seeker's choice of Québec and Canada for refuge, and the following factors were considered: the asylum seeker's knowledge of Canada's record with regard to exile; the site of Montreal airport in relation to international aviation routes; perceived or known characteristics of Canadian and Québec society; personal characteristics of the asylum seeker; natural barriers; airport and visa restrictions; and 'safe third country' legislation.

A relatively large number of the asylum seekers from Peru had not planned to come to Canada until they had begun their journey. The refugees from Pakistan and the former Soviet Union had, in contrast, more often chosen Canada prior to the start of their journey. The choice of the province Québec for Peruvian asylum claimants was found to be the result of the presence of family members in Canada, perceived affinities between the cultures and the French language, the perception that Canada will accept an asylum request and pure chance. The choice of Canada by the Pakistani asylum claimants appeared to be determined by the recom-

5 Other studies and publications commenting on the statistics with regard to refugees and asylum seekers in a rather ad hoc and/or speculative manner also exist. See, for instance, the International Migration Bulletin (various issues); UNHCR (1994) or Ramakers (1995). These studies tend to attribute changes in the number of asylum applications to measures taken in the receiving countries alone. 
mendations of travel agents and indications from immigration officials and the Pakistani community in New York that the U.S. does not accept claims from Pakistani while Canada does. The choice of Canada for asylum claimants from the former Soviet Union (and Israel) was the result of a perception of Canada as an immigration country, a multicultural country and a non-nationalistic country resembling their country of origin (in climate, geography and level of education) and also the existence of a Russian or Ukrainian community in Canada. For the claimants entering Canada via Israel, no visa requirement, their knowledge of the refugee process and the presence of friends or family in Quebec/Canada also proved to be important. Barsky's study clearly shows the factors important for the choice of country for asylum to be different for different countries of origin.

A second particularly relevant study is one by Hulshof c.s. (1992) ${ }^{6}$ on asylum seekers in The Netherlands. This study is based on a survey of asylum seekers from five of the largest countries of origin in The Netherlands: Ethiopia, Ghana, Iran, Romania and Somalia. The interviews were conducted with 677 asylum seekers and included a few questions explicitly directed at the choice of The Netherlands as the country of refuge.

Most of the refugees happened to arrive in The Netherlands by coincidence. While $60 \%$ of the interviewed asylum seekers came to The Netherlands by chance, $36 \%$ deliberately chose The Netherlands. The latter group consisted of Romanians and Iranians in particular. Coming to The Netherlands by chance means that someone else arranging the journey decided the country of destination or that The Netherlands was the first or only country of destination because of access, for example, to travel documents. A deliberate choice is based on the presence of family members ( $7 \%$ of the respondents), practical circumstances during the journey $(2 \%)$ or other considerations such as a positive image of The Netherlands or the presence of compatriots. Compatriots in The Netherlands or another European country appeared to constitute an important source of information for asylum seekers.

In another Dutch study by Doornhein and Dijkhoff (1995), the records on asylum applications from the immigration authorities were analysed. The motives of the asylum seekers to go to The Netherlands were the main concern of these authors. Almost 1,200 files - randomly chosen from the applications filed between 1983 and 1992 - were included in the analyses. In $30 \%$ of those files, the asylum seeker had ended up in The Netherlands by chance. Taking the entire travel story into account, $63 \%$ had explicitly chosen The Netherlands, $23 \%$ had not chosen The Netherlands and 14\% had partly chosen The Netherlands (1995:55-56).

See for an abridged English translation of this research: Brink and Pasariboe 1993. 
In the older literature we found only one study concerned with the motives of the refugees fleeing to Western Germany from Soviet bloc countries (Flight Motivations of Refugees 1963). In this study, exploratory interviews were held with refugees from Czechoslovakia, Hungary, Poland and Eastern Germany in 1961. The wish for family reunification was a motive mentioned by 8 to $15 \%$ of the refugees interviewed. About $5 \%$ were attracted by better economic circumstances.

\section{Empirical data from other (case) studies}

In addition to the aforementioned studies paying systematic attention to the factors determining the destination of asylum flows, a few other refugee studies also provide some information relevant to our subject.

Several case studies on refugee movements within Africa have shown refugees to tend to go to a place where they have relatives or where there is a history of (labour) migration. ${ }^{7}$

In a study of Haitian refugees in the United States, Stepick and Portes (1986) observe that Haitian labour migrants traditionally went to the Dominican Republic or Cuba. When Papa Doc came into power and many Haitians felt the need to flee, however, they went in large numbers to the United States. The United States became a favoured destination for Haitian refugees even though they were not granted the status of political refugees. Because of the status of Haiti as a friendly nation within the US sphere of influence and a fear that granting asylum to Haitians could trigger similar outflows throughout the Carribean, the US authorities tried to portray the Haitian exodus as an exclusively economic phenomenon.

At the same time, asylum seekers from Cuba in the United States were routinely accorded the status of political refugees because of the symbolic significance of their rejecting the Cuban regime. ${ }^{8}$ The same held

7 Hansen (1981: 192) states with regard to Angolan refugees in Zambia that 'a common theme through many refugees' histories was that they had directed their flight to arrive where their kinfolk lived.' Freund and Kalumba (1986) interviewed Angolan and Zairian refugees in Zambia, and they observed continued migration between Zaire, Angola and Zambia because of kinship networks. Kuhlman (1994) studied Ethiopian and Eritrean refugees in Sudan and observed a pattern of frequent migration in this region. He suggests that refugees from the lowlands and not refugees from the highlands went to Sudan because of the shorter distance and the same Islamic religion. Daley (1993) states that Banyarwanda refugees in Western Tanzania were received heartily because of political sympathy with their anti-colonial struggle, because of family and friendship ties on the other side of the border and because of a history of labour migration.

8 Since 1980, the United States has not wanted Cuban refugees and imposed all kinds of restrictions and obstacles (Scanlan and Loescher 1983; Zucker 1983). See Rystad (1990) on the influence of US foreign policy on US refugee policy. 
for people fleeing from Eastern Europe to the Western world before the Iron Curtain fell (Goodwin-Gill 1990:34).

Studies on the resettlement of invited refugees from refugee camps show a high proportion to actually not choose the country of resettlement. For example, Liebkind (1993) found only $3 \%$ of the Vietnamese refugees in his research to be resettled in Finland by choice; the majority of his respondents would have preferred an English-speaking country. The Vietnamese and Ugandese refugees in The Netherlands also did not come here by choice (Postel and Boekhoorn 1993). ${ }^{9}$ Tenhula (1991) wrote an oral history of South-Asian refugees from Vietnam, Laos and Cambodia in the United States and found their coming to the US to not be by choice. They either landed there because of evacuation by the US army in April 1975 or US acceptance of resettlement when they were in a refugee camp. Many of the refugees had, however, cooperated with the US army in their country of origin and identified with the American style of democracy.

According to Hakovirta (1991:60-61), geographical factors can certainly influence refugee flows. Oceans, mountains, deserts and jungles make flight difficult while passable roads to a neighbouring country make things easy. The impact of the geographical situation should nevertheless not be overestimated. Refugees from Cuba, Haiti, Vietnam and the Philippines are known to flee long distances across an open sea. Hakovirta also points out that European countries with large numbers of migrant workers tend to be more kind to refugees than other countries.

It also seems to be something of a rule that the greater the number of migrant workers the greater the number of refugees, though it is hard to tell whether this is due more to the choice of the refugees themselves than to the political decisions of the governments concerned.'(1991:100-101).

A study on Transylvanian refugees in Hungary (Sik 1992) describes how large numbers of Romanians wanting to go to the West came as tourists to Hungary for the first Formula-1 racing match to be held in Eastern Europe in August 1987. As such countries as Austria and Sweden refused to accept Romanian passports without valid visa, these Transylvanians were forced to remain in Hungary. A group of Transylvanian refugees in Hungary is also known to have travelled to the Austrian border because of rumours that family reunification would be easier there. This case reveals three crucial factors: opportunities or lack thereof to cross the border (Formula-1 race; checks at the Austrian border), visa requirements (necessary travel documents and opportunities to circumvent these requirements) and perceptions of the opportunity for family reunification.

9 Vietnamese refugees were picked up by Dutch ships at sea or came from refugee camps in Thailand and Malaysia. Ugandese refugees preferred the United Kingdom but could not wait. 
In a study on Iranian asylum seekers in The Netherlands (Koser 1995b), the majority of the respondents were bound to have relatives in Europe before they left Iran. Those who had relatives could not always contact them before leaving, however. Moreover, only a few of the respondents actually had relatives in The Netherlands. For those who did, the presence of these relatives was the main reason for applying for asylum in this country. Those respondents without relatives in The Netherlands reported that they had chosen this country because of its (allegedly) lenient asylum policy, or that their arrival in The Netherlands was determined by the routes used by the 'smugglers' involved in their flight. With just one exception, the journeys of the respondents had been organised by specialised agents who provided false passports and made travel arrangements. As a result of tightening immigration controls in Western European countries, asylum seekers have also reported increasing dependence on such 'smugglers' or 'traffickers' (Koser 1996).

\section{Analytical framework}

On the basis of the above literature study, we decided to distinguish three groups of factors:

- links between the country of origin and the country of destination;

- characteristics of the country of destination (either real or as perceived by the asylum seekers and their 'agents'); and

- events during the flight.

In the literature on voluntary or economic migration, attention is either focused on the links between the countries of origin and destination (1) or on the pull factors attracting migrants to a particular country of destination (2). Our review of the literature with regard to refugees and asylum seekers showed a third group of factors to be of major importance: events during the flight or journey (3). This group of factors is not just about events but also about the various actors and factors which may somehow determine the destination of the asylum seekers. Such factors also seem to be of greater importantance for asylum seekers than for other migrants because refugees or asylum seekers tend to have less time to plan, to weigh alternatives, to wait for the most favourable opportunities to obtain the necessary permits. They are less likely than economically motivated migrants to make a personal cost-benefit calculation and, on the basis of this calculation, possibly decide against migration.

From the literature on refugees and asylum seekers it might be concluded that chance is the most important determinant of their destination. This is what several studies based on interviews with individual asylum seekers report: many asylum seekers just happened to arrive in 
the country of destination without a preference for any particular country or actually having made a choice. Nevertheless, it should be noted that events considered chance from the perspective of the individual asylum seeker may be (and often are) the result of forces working at the macrolevel. Take, for example, the case of an asylum seeker stopped at Schiphol Airport in The Netherlands on his way to Canada. For the individual, this is a matter of chance (bad luck); at a macro-level, being stranded in The Netherlands is the result of explicit measures taken by the Canadian government to reduce the influx of undesired migrants (carrier sanctions and pre-flight checks).

In our research, different levels of analysis are combined. Chapter Three is based on an analysis of the available statistics and thus predominantly concerned with factors at the macro-level. Chapter Four is based on interviews with key informants in three countries of destination within the European Union and thus more concerned with the micro-level of individual decision-makers.

Our analytical framework includes the factors listed below.

\section{Links between countries of origin and countries of destination}

- former colonial ties

- linguistic ties or similarities

- cultural ties or similarities (e.g., exchange of students, mass culture connections)

- migration links (existing refugee or immigrant communities)

- political relations (including both formal relations between governments and informal relations between, for example, political parties or movements)

- economic relations (trade, investments, development aid)

\section{Characteristics of countries of destination (either real or perceiv- ed by asylum seekers and their 'agents')}

- economic characteristics (indicators such as GNP per capita, unemployment rate and - more difficult to measure - economic opportunities for asylum seekers)

- relevant policies (including visa policy and general asylum policy as well as specific policies towards particular groups of asylum seekers; recognition rates including general rates and rates for specific nationality groups; rights enjoyed by asylum seekers during the determination procedure including access to the labour market; etc.

- image of the country of destination (human rights reputation; more generally viewed as an attractive, rich and/or liberal country; etc.). 


\section{Events during flight}

- geographic proximity

- air routes

- activities of 'travel agents' (i.e., persons or organisations who help asylum seekers to leave their country of origin and make travel arrangements)

- barriers, controls and checks 


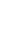




\section{Chapter 3}

\section{Patterns of origin and destination: The figures}

Since 1985, over 3 million persons have applied for asylum in the member states of the European Union. The European countries experience this as a burden, particularly when it comes to the costs involved in the reception of these asylum seekers and the determination procedures related to their applications, but the fact is that most refugees remain in Third World countries near the country which they fled. According to figures from the UNHCR at the end of 1992, the world refugee population counted 19 million people with $23 \%$ living on European territory and less than 7\% in the European Union (UNHCR 1993: 149-153). Only three European countries rank among the top fifty countries when the ratio of refugees to the size of the total population is considered: Denmark (30th), Germany (33rd) and Luxembourg (42nd). When the ratio of refugees to the average GNP per capita is considered, only Germany ranks among the top fifty countries and then only as 42nd (UNHCR 1993: 154-155).

The above UNHCR rankings relate to refugees. For most industrialised countries, this means only (invited) quota refugees and asylum seekers who have been recognised as refugees in the sense of the Geneva Convention. The figures analysed in this chapter, in contrast, relate to asylum applications. The analyses in this chapter are restricted to the years 1985-94 and the then 12 EU member states.

\section{Origins and destinations: The general pattern}

From 1983 to 1992, the number of asylum applications filed in European countries increased more or less steadily. The year 1992 was a peak with 570,000 applications filed in EU countries and 127,000 in EFTA countries. ${ }^{1}$ Since then, the numbers have declined. In France, the peak in the number of applications already occurred in 1989. In Greece, the peak occurred one year later. And in the United Kingdom, Switzerland, Austria and Italy the peak occurred in $1991 .^{2}$ In Germany, Sweden and Fin-

1 Unless otherwise stated, the figures in this chapter were provided by EUROSTAT.

2 New peaks occurred in Switzerland in 1993 and the United Kingdom in 1994. However, the numbers filed in these years were considerably lower than in 1991. 
land it was in 1992. In Belgium, Denmark, Norway, Portugal, Spain and Switzerland, the peak occurred in 1993. Finally, the number of applications filed in The Netherlands reached its peak in 1994.

The decreasing number of asylum applications is a worldwide and not specifically European phenomenon. Canada has seen the numbers drop since 1993, and the United States has seen this since 1995 (cf. IGC 1995). In some countries, the numbers dropped very sharply. For instance, the number of applications filed in Germany in $1994(127,210)$ was less than one third of the number filed in $1992(438,191)$. The French figures, in contrast, show a gradual decline from a maximum of 61,422 applications in 1989 to 25,964 in 1994. Though the decline is mostly attributed to policy measures, the events and developments in the countries of origin also seem to be relevant. For instance, the decline in the number of asylum seekers from former Yugoslavia can be attributed to changing conditions in Bosnia-Herzegovina and the other Yugoslavian successor states.

Figure 1: Numbers of asylum applications filed in the countries of the European Union and in Germany, France, The Netherlands and the United Kingdom, 1985-1994

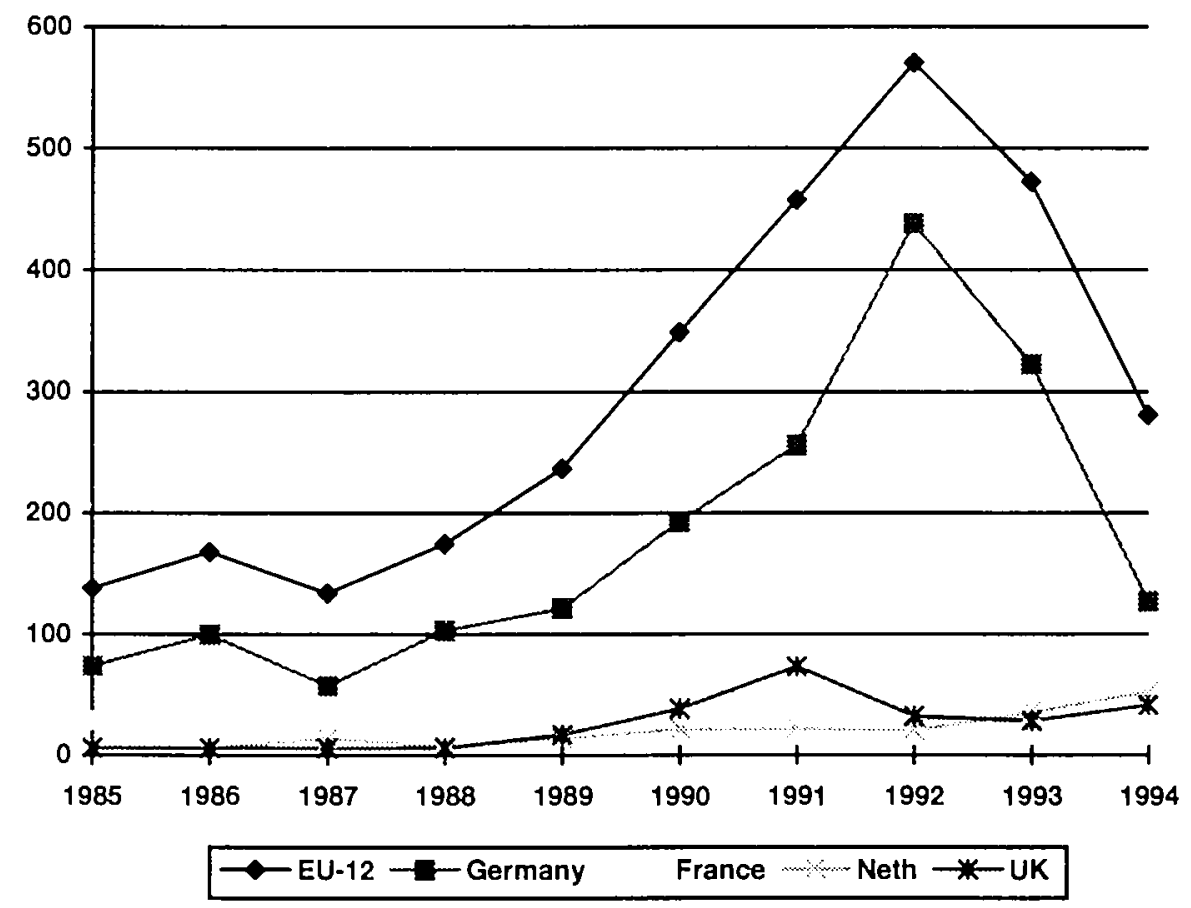

\section{Destination countries}

Throughout the period 1985-94, Germany was the most important country of destination within the European Union. Germany received an aver- 
age $64 \%$ of all applications. ${ }^{3}$ In the peak year of 1992 , Germany received over $75 \%$ of all the applications filed in the European Union. In 1993-94, after the introduction of a new asylum law, the German share dropped to $45 \%$.

France was the second most important country of destination within the European Union with 13\% of all applications in the years 1985-1994. As the numbers in Germany went up, however, the French proportin went down. In the second half of the $1980 \mathrm{~s}$, France received $15 \%$ to $25 \%$ of the total asylum flow to Europe. In 1992-1994, this share had dropped to less than 10\%. In 1992, moreover, the United Kingdom received more asylum applications than France; in 1993 and 1994, The Netherlands was the second largest destination country after Germany (and followed by the United Kingdom).

Belgium and Denmark also received substantial numbers of asylum applications. With regard to the latter country in 1987, both the number of applications and the country's share of the European total dropped sharply. Between 1987 and 1993, the annual number of applications increased once again, but Denmark's share of the European total remained low (fluctuating between $1 \%$ and $3 \%$ ). Spain's share of the European total tends to be of a similar size.

Italy and Greece received smaller numbers of applications than most of the other countries in the European Union. ${ }^{4}$ Peaks nevertheless occurred in in both countries in particular years. Italy received more than $8 \%$ of all applications filed in Europe in 1987, and Greece received about 5\% of all applications in 1987 and in 1988. Finally, Portugal, Luxembourg and Ireland received only very small numbers of asylum applications between 1985 and 1994.

\section{Factors determining the distribution within the European Union}

The countries receiving the largest numbers of asylum applications (Germany, France, The Netherlands and the United Kingdom) are also clearly the most highly populated and richest countries within the European Union. These same countries recruited foreign labourers in the period 1960-75 while Spain, Portugal, Italy and Greece were the sending countries. The country with the lowest number of applications, Ireland, has also been a country of emigration for a long, long time.

When the countries of the European Union are ranked according to the ratio of asylum applications to the size of the population or the average GNP per capita, it becomes clear that a simple linear relation does not

3 Since 1984, Germany has been the country receiving the largest number of asylum applications in the world. The second largest asylum country is the United States; the third is France (UNHCR 1993: 157).

4 The figures for Italy and Greece should be examined with caution because these countries did not have official asylum procedures until quite recently. 
Table 1: EU countries ranked according to the ratio of asylum applications to the size of the population

\begin{tabular}{|l|r|r|r|}
\hline Country & $\begin{array}{l}\text { Number of } \\
\text { asylum applications } \\
\begin{array}{l}1985-94 \\
\text { (in thousands) }\end{array}\end{array}$ & $\begin{array}{l}\text { Population } \\
\text { 1989 } \\
\text { (in thousands)* }\end{array}$ & $\begin{array}{l}\text { Ratio of asylum } \\
\text { applications } \\
\text { to population }\end{array}$ \\
\hline \hline 1 Germany & 1726.0 & 62000 & $1: 35.9$ \\
\hline 2 Netherlands & 194.3 & 14800 & 76.2 \\
\hline 3 Denmark & 64.0 & 5100 & 79.7 \\
\hline 4 Belgium & 94.3 & 9900 & 105.0 \\
\hline 5 France & 361.9 & 56200 & 155.3 \\
\hline 6 United Kingdom & 166.3 & 57200 & 344.0 \\
\hline 7 Luxembourg & 1.1 & 400 & 363.6 \\
\hline 8 Greece & 14.8 & 10000 & 675.7 \\
\hline 9 Spain & 52.4 & 38800 & 740.5 \\
\hline 10 Italy & 35.0 & 57500 & 1642.9 \\
\hline 11 Portugal & 4.4 & 10500 & 2386.4 \\
\hline 12 Ireland & 0.7 & 3500 & 5000.0 \\
\hline
\end{tabular}

* Source: Statistical Yearbook United Nations 1988/89. Statistics with regard to asylum applications were provided by EUROSTAT, 1995.

Table 2: EU countries ranked according to the ratio of asylum applications to the GNP per capita

\begin{tabular}{|l|r|r|r|}
\hline Country & $\begin{array}{l}\text { Number of } \\
\text { asylum applications } \\
\begin{array}{l}1985-94 \\
\text { (in thousands) }\end{array}\end{array}$ & $\begin{array}{l}\text { GNP* per capita } \\
\text { (in US dollars) }\end{array}$ & $\begin{array}{l}\text { Ratio of asylum } \\
\text { applications } \\
\text { to GNP per capita }\end{array}$ \\
\hline \hline 1 Germany & 1726.0 & 18980 & 90.9 \\
\hline 2 France & 361.9 & 17000 & 21.3 \\
\hline 3 Netherlands & 194.3 & 15260 & 12.7 \\
\hline 4 United Kingdom & 166.3 & 14910 & 11.2 \\
\hline 5 Belgium & 94.3 & 15450 & 6.1 \\
\hline 6 Spain & 52.4 & 9800 & 5.3 \\
\hline 7 Denmark & 64.0 & 20840 & 3.1 \\
\hline 8 Greece & 14.8 & 5420 & 2.7 \\
\hline 9 Italy & 35.0 & 15060 & 2.3 \\
\hline 10 Portugal & 4.4 & 4310 & 1.0 \\
\hline 11 Ireland & 0.7 & 9770 & 0.1 \\
\hline 12 Luxembourg & 1.1 & 17500 & 0.1 \\
\hline
\end{tabular}

* Source: Statistical Yearbook United Nations 1988/89. Statistics with regard to asylum applications were provided by EUROSTAT, 1995.

exist between these variables and the volume of applications filed in the country (see Tables 1 and 2). For example, the number of applications filed in France was twice the number filed in the United Kingdom and ten times the number filed in Italy despite the rather small differences in GNP per capita and even smaller differences in the sizes of the populations for the three countries. The rankings again show Germany to receive an extremely large proportion of the total volume of asylum applications filed in the European Union even if the size of its population size 
and GNP per capita are taken into consideration. In order to explain the disproportionate number of applications for asylum in Germany, it is often pointed out that the concept of asylum laid down in the German Constitution and up until 1993 was broader than the concept used in most other European countries (see, for example, Hovy 1993: 210). However, the recognition rate in Germany (i.e., the proportion of asylum seekers actually recognised as refugees) is lower than in most other European countries. Another explanation for Germany's disproportional share of the total volume of applications filed in the European Union might be the accessibility of the country across land from Central and Eastern Europe. However, many asylum seekers from outside Europe presumably arrive by plane.

\section{Regions and countries of origin}

Nearly $40 \%$ of the applications in the years 1985-1994 were filed by Europeans; almost $20 \%$ were filed by Africans; and applicants from Asia (including the Middle East) accounted for over $30 \%$ of the applications (see Table 3 below).

Table 3: Distribution of different regions of origin for asylum seekers in 11 EU countries, 1985-94 (percentages)

\begin{tabular}{|l|r|r|r|r|r|r|r|}
\hline & Europe & Africa & \multicolumn{1}{|c|}{ Asia } & Mid-East & America & \multicolumn{1}{|c|}{$\begin{array}{c}\text { state- } \\
\text { less/ } \\
\text { unspec. }\end{array}$} & \\
\hline \hline D & 52.0 & 11.7 & 15.3 & 17.2 & 0.0 & 3.7 & 100 \\
\hline F & 10.8 & 38.1 & 28.3 & 18.5 & - & 0.4 & 100 \\
\hline NL & 31.2 & 27.6 & 18.1 & 19.2 & 2.3 & 1.6 & 100 \\
\hline UK & 6.9 & 30.2 & 18.0 & 9.7 & 0.7 & 34.5 & 100 \\
\hline B & 26.2 & 30.1 & 14.9 & 7.4 & 0.7 & 20.7 & 100 \\
\hline DK & 36.5 & 10.5 & 11.3 & 26.8 & 0.0 & 14.5 & 100 \\
\hline E & 27.9 & 16.8 & 5.8 & 4.7 & 23.1 & 21.8 & 100 \\
\hline I & 45.3 & 10.2 & 1.0 & 1.5 & 0.2 & 41.9 & 100 \\
\hline GR & 0.2 & 3.0 & 0.2 & 28.5 & 0.0 & 68.1 & 100 \\
\hline P & 50.5 & 42.9 & 4.5 & 0.9 & 0.2 & 1.0 & 100 \\
\hline L & 48.4 & 21.4 & 11.3 & 16.3 & 2.6 & 0.1 & 100 \\
\hline total & 38.6 & 18.2 & 16.5 & 16.2 & 1.3 & 8.9 & 100 \\
\hline
\end{tabular}

* Based on statistics provided by EUROSTAT, 1995. In some cases, the annual totals were not broken down by region of origin or country of nationality. This is the case for Ireland throughout the whole period 1985-1994 (also see Appendix 2).

Between 1985 and 1992, there was a steep rise in the number of European applicants. As a result, the proportion of European applicants increased from $10 \%$ in 1985 to $57 \%$ in 1992 . Following the introduction of 'safe countries of origin' legislation in most EU member states in 1992 or thereafter, the number of asylum seekers from Central and Eastern 
Europe underwent a sharp decrease. In 1994, their share of the total of applications was no more than $33 \%$.

In 1985 and 1986, a large proportion of the applicants seeking asylum in the EU came from South and East Asia (30\% and particularly from Sri Lanka, India and Pakistan). Since 1987, the Asian share has ranged between $13 \%$ and $17 \%$; the number of Asian applicants again peaked in the early 1990s, but the peak in the European numbers was considerably higher.

Up until 1990, approximately $25 \%$ of the applicants seeking asylum in the EU came from the Middle East (and particularly from Turkey, Iran and Lebanon). Although the absolute numbers remained fairly stable, their relative share has declined to between $8 \%$ and $14 \%$. The proportion of applications from Africans has fluctuated between $13 \%$ and $22 \%$. Only a small proportion of the applicants seeking asylum in the EU in the years 1985-94 were from Latin America (between 1\% and 2\%).

Figure 2: Numbers of asylum appications filed in the countries of the European Union in 1985-1994, by region of origin of the applicants

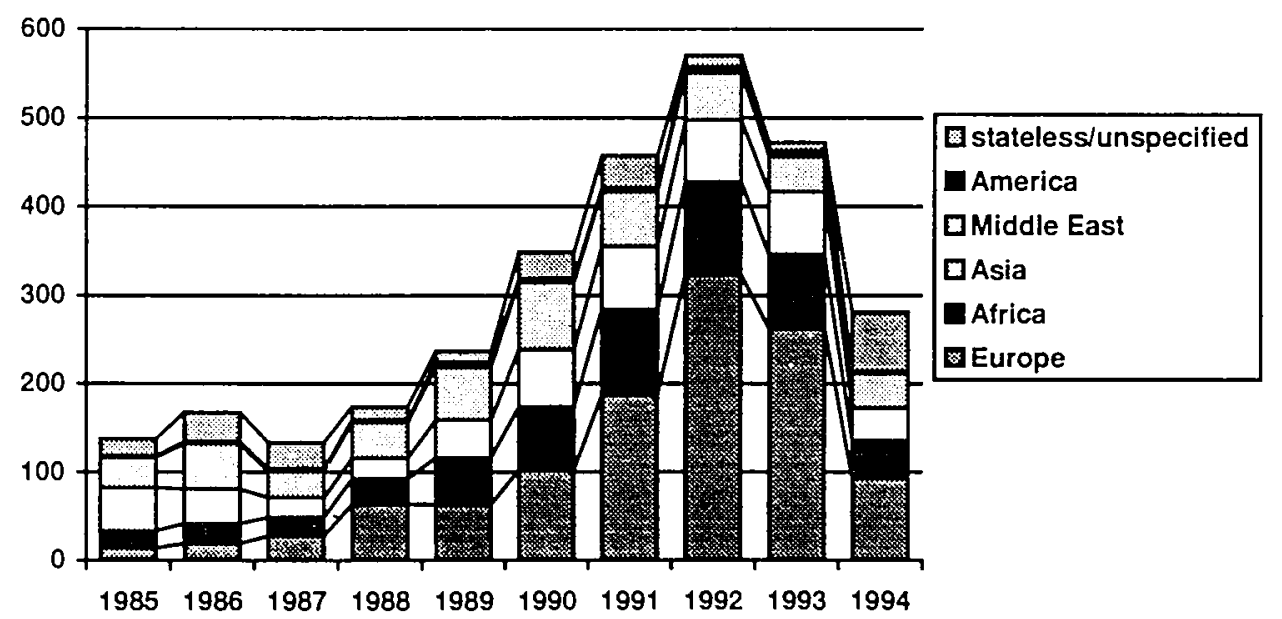

In most EU countries, a small number of nationalities account for the majority of the asylum applications (see Table 4 below). For all twelve countries considered together, asylum seekers from seven countries accounted for more than 50\% of all the applications filed between 1985 and 1994: Yugoslavia, Romania, Turkey, Poland, Sri Lanka, Iran and Bulgaria. 


\section{Origins and destinations: Specific patterns}

The asylum seekers from the different regions and countries in the world are not distributed evenly across the EU countries. In Germany, Portugal, Luxembourg and Italy, about $50 \%$ of all asylum applications are filed by Europeans (while the European share of the total asylum flow to the European Union amounts to no more than $40 \%$ ). Asylum seekers in Portugal, France, the United Kingdom, Belgium and The Netherlands originate relatively often from Africa. The share of asylum seekers from Asia is high for France and very low for all of the Southern European countries. The proportion of asylum seekers from the Middle East is high in Greece and Denmark while Spain receives relatively many applications from Latin Americans (see Table 3).

Closer examination of the specific patterns of origin and destination clearly shows that the asylum seekers from a particular country of origin in many cases tend to go to a particular country within the European Union. In Table 6, the most important destinations for applicants from the 44 largest countries of origin in the years 1985-1994 are presented. ${ }^{5}$

As can be seen from Table 6, almost all of the asylum seekers from Mali (90\% to 100\%) filed their applications in France. The same holds for applicants from five additional countries of origin. Almost all of the asylum seekers from Uganda filed their applications in the United Kingdom; almost all of the Surinamese applied for asylum in The Netherlands; and almost all of the asylum seekers from the Dominican Republic applied in Spain. In eight out of these nine cases, moreover, the country of origin is a former colony of the asylum country. ${ }^{6}$ It is important to note that in all of these cases the numbers are relatively small: Mali ranks 24th among the major countries of origin for asylum seekers, and the Dominican Republic ranks 44th. All nine of these countries of origin are also not listed in the German statistics. This means that part of the asylum migration from these countries may have had Germany as a destination.

There are even more cases where the vast majority (over 75\%) of the asylum seekers from a particular country of origin have gone to a specific country within the European Union. The asylum seekers from Yugoslavia and five other Central and Eastern European countries have filed their applications predominantly in Germany.

5 The analyses in the remainder of this chapter will be restricted to these top 44 countries. Each of these countries accounted for over 3,000 asylum applicants in the 12 EU countries during the years 1985-94. Together, these countries accounted for almost $99 \%$ of the applications filed in the EU.

6 Cape Verde is the one exception. Although Cape Verde was a Portuguese colony, almost all of the Cape Verdian asylum seekers have gone to France. 
Table 4: Nationalities of major groups of asylum applicants for different EU countries, 1985-94

\begin{tabular}{|c|c|c|c|c|}
\hline $\begin{array}{l}\text { Country of } \\
\text { potential asylum }\end{array}$ & $\begin{array}{l}\text { Country of } \\
\text { nationality }\end{array}$ & $\begin{array}{l}\text { Number } \\
\text { (in thou- } \\
\text { sands }\end{array}$ & $\%$ & cum. $\%$ \\
\hline \multirow[t]{6}{*}{ EU total } & $\begin{array}{l}\text { (ex-)Yugoslavia } \\
\text { Romania }\end{array}$ & $\begin{array}{l}485 \\
330\end{array}$ & $\begin{array}{l}16 \\
11\end{array}$ & $\begin{array}{l}16 \\
27\end{array}$ \\
\hline & Turkey & 264 & 9 & 36 \\
\hline & Poland & 133 & 5 & 41 \\
\hline & Sri Lanka & 125 & 4 & 45 \\
\hline & Iran & 115 & 4 & 49 \\
\hline & Bulgaria & 90 & 3 & 52 \\
\hline \multirow[t]{3}{*}{ Germany } & $\begin{array}{l}\text { (ex-)Yugoslavia } \\
\text { Romania }\end{array}$ & $\begin{array}{l}400 \\
273\end{array}$ & $\begin{array}{l}22 \\
15\end{array}$ & $\begin{array}{l}22 \\
38\end{array}$ \\
\hline & Turkey & 175 & 10 & 47 \\
\hline & Poland & 106 & 6 & 53 \\
\hline \multirow[t]{6}{*}{ France } & $\begin{array}{l}\text { Turkey } \\
\text { Zaire }\end{array}$ & $\begin{array}{l}61 \\
38\end{array}$ & $\begin{array}{l}17 \\
11\end{array}$ & $\begin{array}{l}17 \\
26\end{array}$ \\
\hline & Sri Lanka & 27 & 7 & 34 \\
\hline & Vietnam & 19 & 5 & 39 \\
\hline & Romania & 18 & 5 & 44 \\
\hline & Mali & 17 & 5 & 48 \\
\hline & Angola & 14 & 4 & 52 \\
\hline \multirow[t]{9}{*}{ United Kingdom } & $\begin{array}{l}\text { Sri Lanka } \\
\text { (ex-)Yugoslavia }\end{array}$ & $\begin{array}{l}20 \\
12\end{array}$ & $\begin{array}{l}8 \\
5\end{array}$ & $\begin{array}{r}8 \\
13\end{array}$ \\
\hline & Zaire & 12 & 5 & 17 \\
\hline & Turkey & 12 & 5 & 22 \\
\hline & Somalia & 11 & 5 & 27 \\
\hline & Pakistan & 11 & 4 & 32 \\
\hline & India & 9 & 4 & 35 \\
\hline & Angola & 8 & 3 & 38 \\
\hline & Ghana & 8 & 3 & 39 \\
\hline & Uganda & 7 & 3 & 41 \\
\hline \multirow[t]{5}{*}{ Netherlands } & $\begin{array}{l}\text { (ex-)Yugoslavia } \\
\text { Somalia }\end{array}$ & $\begin{array}{l}33 \\
20\end{array}$ & $\begin{array}{l}17 \\
10\end{array}$ & $\begin{array}{l}17 \\
28\end{array}$ \\
\hline & Iran & 16 & 8 & 37 \\
\hline & Sri Lanka & 13 & 7 & 43 \\
\hline & Romania & 9 & 5 & 48 \\
\hline & Iraq & 9 & 4 & 53 \\
\hline \multirow[t]{4}{*}{ Denmark } & $\begin{array}{l}\text { (ex-)Yugoslavia } \\
\text { Iran }\end{array}$ & $\begin{array}{r}19 \\
8\end{array}$ & $\begin{array}{l}26 \\
10\end{array}$ & $\begin{array}{l}26 \\
36\end{array}$ \\
\hline & Iraq & 5 & 7 & 43 \\
\hline & Somalia & 5 & 6 & 50 \\
\hline & Lebanon & 5 & 6 & 56 \\
\hline
\end{tabular}




\begin{tabular}{|l|l|r|r|r|}
\hline Belgium (1988-94) & Zaire & 14 & 12 & 12 \\
& Romania & 14 & 12 & 24 \\
& (ex-)Yugoslavia & 9 & 7 & 32 \\
& India & 8 & 7 & 38 \\
& Ghana & 8 & 7 & 45 \\
& Turkey & 6 & 6 & 51 \\
\hline Spain (1988-94) & Poland & 10 & 15 & 15 \\
& Peru & 5 & 11 & 25 \\
& Romania & 3 & 5 & 33 \\
& Dominican Rep. & 3 & 4 & 38 \\
& Senegal & 3 & 4 & 42 \\
& China & 2 & 3 & 49 \\
& Cuba & 2 & 3 & 52 \\
\hline
\end{tabular}

Based on statistics provided by EUROSTAT, 1995.

The countries of origin appear to be rather stable. Comparison of the annual top five countries of origin for the years 1985-94 (see Table 5 below) nevertheless reveals a gradually shifting list. While only one country (Turkey) consistently figures in the top five, the total number of countries ranking among the top five is still only eleven.

Table 5: Top five nationalities of applicants seeking asylum in the European Union by year of application

\begin{tabular}{|c|c|c|c|c|c|}
\hline & 1 & 2 & 3 & 4 & 5 \\
\hline $\begin{array}{l}1985 \\
1986 \\
1987 \\
1988 \\
1989 \\
1990 \\
1991 \\
1992 \\
1993 \\
1994 \\
\end{array}$ & $\begin{array}{l}\text { Sri Lanka } \\
\text { Iran } \\
\text { Turkey } \\
\text { Poland } \\
\text { Turkey } \\
\text { Romania } \\
\text { (ex-)Yugosl. } \\
\text { (ex-)Yugosl. } \\
\text { (ex-)Yugosl. } \\
\text { (ex-)Yugosl. }\end{array}$ & $\begin{array}{l}\text { Iran } \\
\text { Turkey } \\
\text { Poland } \\
\text { Turkey } \\
\text { Poland } \\
\text { Turkey } \\
\text { Romania } \\
\text { Romania } \\
\text { Romania } \\
\text { Turkey }\end{array}$ & $\begin{array}{l}\text { Turkey } \\
\text { Poland } \\
\text { Iran } \\
\text { (ex-)Yugosl. } \\
\text { (ex-)Yugosl. } \\
\text { (ex)Yugosl. } \\
\text { Turkey } \\
\text { Turkey } \\
\text { Bulgaria } \\
\text { Romania } \\
\end{array}$ & \begin{tabular}{|l} 
Poland \\
Lebanon \\
Sri Lanka \\
Iran \\
Sri Lanka \\
Lebanon \\
Albania \\
Bulgaria \\
Turkey \\
Sri Lanka
\end{tabular} & \begin{tabular}{|l|} 
Lebanon \\
Sri Lanka \\
(ex-)Yugosl. \\
Sri Lanka \\
Zaire \\
Poland \\
Bulgaria \\
Zaire \\
Algeria \\
Iran \\
\end{tabular} \\
\hline
\end{tabular}

Based on statistics provided by EUROSTAT, 1995.

It is obvious that political developments in the regions of origin affect the asylum flows. Asylum seekers from former Yugoslavia started to arrive in 1987 and their numbers increased drastically between 1991 and 1993 when the war was most intense. Algerian applicants started to arrive in 1992 and 1993, after the army took control and a state of emergency was imposed. 
Table 6: Most important destination countries for asylum seekers from the 44 largest countries of origin in the years 1985-94

\begin{tabular}{|c|c|c|c|}
\hline $\begin{array}{l}\text { Country of } \\
\text { origin }\end{array}$ & $\begin{array}{l}\text { Total } \\
\text { number of } \\
\text { applications }\end{array}$ & $\begin{array}{l}\text { More than } 90 \% \text { of } \\
\text { applications made } \\
\text { in one country }\end{array}$ & \\
\hline Mali** $^{* *}$ & 16,865 & $\mathrm{~F}^{*}$ & \\
\hline Cambodia** $^{* *}$ & 8,416 & $\mathrm{~F}^{*}$ & \\
\hline Haiti** & 6,999 & $\mathrm{~F}^{*}$ & \\
\hline Mauritania** & 4,877 & $\mathrm{~F}^{*}$ & \\
\hline $\operatorname{Laos}^{* *}$ & 4,353 & $\mathrm{~F}^{*}$ & \\
\hline Cape Verde** & 4,035 & $\mathrm{~F}$ & \\
\hline Uganda $^{* *}$ & 7,017 & $\mathrm{UK}^{*}$ & \\
\hline Surinam** & 3,712 & $\mathrm{NL}^{*}$ & \\
\hline \multirow[t]{2}{*}{$\begin{array}{l}\text { Dominican } \\
\text { Republic } \\
\end{array}$} & 3,135 & $E^{*}$ & \\
\hline & & $\begin{array}{l}75-90 \% \text { of appli- } \\
\text { cations made in one } \\
\text { country }\end{array}$ & $\begin{array}{l}\text { More than } 90 \% \text { of } \\
\text { applications made in the } \\
\text { following countries }\end{array}$ \\
\hline Yugoslavia & 485,047 & $\mathrm{D}$ & $\mathrm{D}, \mathrm{NL}$ \\
\hline Czechoslovakia & 15,595 & $\mathrm{D}$ & $\mathrm{D}, \mathrm{NL}$ \\
\hline Hungary & 11,329 & $\mathrm{D}$ & $\mathrm{D}, \mathrm{NL}$ \\
\hline Afghanistan & 52,661 & $\mathrm{D}$ & $\mathrm{D}, \mathrm{NL}$ \\
\hline Bulgaria & 90,457 & $\mathrm{D}$ & $\mathrm{D}, \mathrm{B}$ \\
\hline Romania & 330,407 & $\mathrm{D}$ & $\mathrm{D}, \mathrm{F}, \mathrm{B}$ \\
\hline Poland & 133,370 & $\mathrm{D}$ & $\mathrm{D}, \mathrm{E}, \mathrm{F}$ \\
\hline Lebanon & 70,215 & $\mathrm{D}$ & $\mathrm{D}, \mathrm{DK}, \mathrm{NL}$ \\
\hline Albania** & 23,297 & $\mathrm{I}$ & $\mathrm{I}, \mathrm{F}$ \\
\hline Peru** $^{* *}$ & 9,098 & $\mathrm{E}^{*}$ & $E^{*}, F$ \\
\hline Guinea** & 1,719 & $\mathrm{~F}^{*}$ & $\mathrm{~F}^{*}, \mathrm{~B}$ \\
\hline \multirow[t]{2}{*}{ Syria** } & 3,661 & NL & $\mathrm{NL}, \mathrm{B}, \mathrm{DK}$ \\
\hline & & $\begin{array}{l}\text { 60-75\% of appli- } \\
\text { cations made in one } \\
\text { country }\end{array}$ & $\begin{array}{l}\text { More than } 90 \% \text { of } \\
\text { applications made in the } \\
\text { following countries }\end{array}$ \\
\hline Vietnam & 66,221 & $\mathrm{D}$ & $\mathrm{D}, \mathrm{F}^{*}$ \\
\hline Turkey & 264,491 & $\mathrm{D}$ & $\mathrm{D}, \mathrm{F}, \mathrm{UK}$ \\
\hline Algeria & 27,068 & $\mathrm{D}$ & $\mathrm{D}, \mathrm{F}^{*}, \mathrm{NL}$ \\
\hline Iran & 115,154 & $\mathrm{D}$ & $\mathrm{D}, \mathrm{NL}, \mathrm{DK}, \mathrm{UK}$ \\
\hline Nigeria & 43,773 & $\mathrm{D}$ & $\mathrm{D}, \mathrm{UK}^{*}, \mathrm{~B}, \mathrm{NL}$ \\
\hline Sudan** & 3,509 & $\mathrm{UK}^{*}$ & $\mathrm{UK}^{*}, \mathrm{NL}$ \\
\hline \multirow[t]{2}{*}{ Senegal*** } & 8,802 & $\mathrm{~F}^{*}$ & $\mathrm{~F}^{*}, \mathrm{E}$ \\
\hline & & $\begin{array}{l}40-60 \% \text { of appli- } \\
\text { cations made in one } \\
\text { country }\end{array}$ & $\begin{array}{l}\text { More than } 90 \% \text { of } \\
\text { applications made in the } \\
\text { following countries }\end{array}$ \\
\hline Sri Lanka & 124,608 & $\mathrm{D}$ & $\mathrm{D}, \mathrm{F}, \mathrm{UK}^{*}, \mathrm{NL}$ \\
\hline Ghana & 66,215 & $\mathrm{D}$ & $\mathrm{D}, \mathrm{F}, \mathrm{UK}^{*}, \mathrm{~B}$ \\
\hline Pakistan & 57,879 & $\mathrm{D}$ & $\mathrm{D}, \mathrm{UK}^{*}, \mathrm{~F}, \mathrm{~B}$ \\
\hline India & 66,544 & $\mathrm{D}$ & $\mathrm{D}, \mathrm{UK}^{*}, \mathrm{~B}, \mathrm{~F}$ \\
\hline Ethiopia & 31,054 & $\mathrm{D}$ & $\mathrm{D}, \mathrm{UK}, \mathrm{NL}, \mathrm{I}^{*}$ \\
\hline Togo & 8,160 & $\mathrm{D}$ & $\mathrm{D}, \mathrm{UK}, \mathrm{B}, \mathrm{NL}$ \\
\hline USSR & 34,811 & $\mathrm{D}$ & $\mathrm{D}, \mathrm{NL}, \mathrm{F}, \mathrm{DK}$ \\
\hline
\end{tabular}




\begin{tabular}{|l|r|l|l|}
\hline Colombia** & 3,982 & $\mathrm{~F}$ & $\mathrm{~F}, \mathrm{UK}, \mathrm{NL}$ \\
\hline Angola** & 30,459 & $\mathrm{~F}$ & $\mathrm{~F}, \mathrm{UK}, \mathrm{NL}, \mathrm{E} / \mathrm{B}$ \\
\hline Zaire & 81,309 & $\mathrm{~F}$ & $\mathrm{~F}, \mathrm{~B}^{*}, \mathrm{UK}, \mathrm{D}$ \\
\hline Bangladesh & 8,668 & $\mathrm{~F}$ & $\mathrm{~F}, \mathrm{NL}, \mathrm{B}, \mathrm{UK}$ \\
\hline Chili** & 3,383 & $\mathrm{~F}$ & $\mathrm{~F}, \mathrm{E}^{*}, \mathrm{~B}, \mathrm{NL}$ \\
\hline China & 23,336 & $\mathrm{~F}$ & $\mathrm{~F}, \mathrm{NL}, \mathrm{D}, \mathrm{E}, \mathrm{UK}$ \\
\hline Somalia** & 42,211 & $\mathrm{NL}$ & $\mathrm{NL}, \mathrm{UK}^{*}, \mathrm{DK}, \mathrm{I}^{*}$ \\
\hline Liberia** & 5,067 & $\mathrm{NL}$ & $\mathrm{NL}, \mathrm{B}, \mathrm{E}, \mathrm{F}$ \\
\hline & & & $\begin{array}{l}\text { More than 90\% of the } \\
\text { applications made in the } \\
\text { following countries }\end{array}$ \\
\hline Iraq $^{* *}$ & & & GR, NL, DK, UK \\
\hline
\end{tabular}

Based on statistics provided by EUROSTAT, 1995.

* Country of origin is in this case a former colony, protectorate or mandated territory of the country of destination.

** Relevant country of origin is not listed within the German statistics.

The same holds for applicants from Lebanon and Afghanistan. Similarly, the vast majority of Albanians have sought refuge in Italy. Peruvians have typically sought refuge in Spain, Guineans in France, and Syrians in The Netherlands.

Given that Germany has received $60 \%$ of all applications filed in the European Union, it is not surprising to note that Germany has been the most important country of destination for applicants from 20 of the 44 largest countries of origin. France has been the most important destination for applicants from 14 countries; all of these countries are located outside Europe and seven are former colonies. The Netherlands was the main destination for asylum seekers from four countries (Surinam, Syria, Somalia and Liberia). Surprisingly, the United Kingdom was the most important destination for applicants from only two of its former colonies (Uganda and Sudan). Spain, too, was the main destination for asylum seekers from two former colonies (Dominican Republic and Peru). Italy was the main destination for one country (Albania), and Greece was similarly the main destination for one country (Iraq). Finally, Belgium and Denmark received substantial numbers of applications but did not constitute the main country of destination for any country of origin.

\section{The importance of former colonial ties}

Historical ties are certainly likely to play an important part in the above patterns. The relatively high number of Africans in Portugal, France, the United Kingdom, and - of these countries to a lesser extent - Belgium may be explained by the colonial past of these countries in Africa. The same holds for the relatively high number of Asians in France and the relatively high number of Latin Americans in Spain. However, the relative number of Asian applications in the United Kingdom is not particularly higher than in other countries, although the most important countries of origin in Asia (Sri Lanka, India and Pakistan) are former British 
colonies. The high share of Africans in The Netherlands (with The Netherlands being the main destination for Somalis and Liberians) also cannot be attributed to historical ties.

When the colonial ties between the countries of origin and destination are systematically examined, it becomes clear that such ties almost always result in overrepresentation (i.e., the share of asylum seekers from the former colonies applying to the relevant EU country being larger than the share applying elsewhere in the European Union). In most cases with colonial ties, additional linkages may attract asylum seekers to the former mother country as well. The language of the former mother country is the official language in most former colonies. In many cases, migration networks have been built up between the countries and the former mother country is home to a large immigrant population from the former colony. Most of the emigrants from India, Pakistan and Bangladesh in Europe, for instance, are living in the United Kingdom while France is home to almost all of the emigrants from Laos and Cambodia. In the 1970s, France invited relatively large numbers of Vietnamese, Laotian and Cambodian refugees who were staying in camps in Hong Kong and Thailand to come to France (cf. Black 1993: 90). When students are sent abroad to complete their studies, they also tend to go to the former mother country. Almost all Malinese, Senegalese, Mauritanian, Guinean and Togolese students in Europe, for instance, are studying in France while by far the majority of the students from Nigeria, Sudan and Uganda can be found to be studying in the United Kingdom (UNESCO 1986). In addition, most Third World countries do not have regular flights to all of the countries in Western Europe; flights to the former mother country almost always exist, however. Colonial ties also often lead to preferential visa treatment with nationals from former colonies not needing a visa to enter the former mother country. ${ }^{7}$

\section{Exceptions}

There are many reasons for colonial ties to result in a certain degree of overrepresentation. There are nevertheless a few cases where the former mother country receives a disproportionally small proportion of the flow of asylum seekers from a former colony. For instance: Lebanon was once a French protectorate and the French language is still very much spoken in that country, but only $1 \%$ of all the asylum applications coming from Lebanese nationals are filed in France. Other cases in point are Syria and Togo (former mandated territories of France), Afghanistan (former British protectorate) and Cape Verde (former colony of Portugal).

In some cases where asylum seekers from a particular country are found to go in relatively large numbers to the former mother country,

7 The EU member states have been harmonising their visa policies since 1986, however. 
their overrepresentation in other European countries is still larger. Somalia is a case in point. Both the United Kingdom and Italy (the former colonial powers in Somalia) have a relatively large share of the asylum flow from Somalia, but The Netherlands has a much larger share (in both absolute numbers and relative to the Dutch share of the total asylum flow to Europe). Similarly, Indians, Ghanaians and Nigerians are somewhat overrepresented in the United Kingdom, but their overrepresentation in Belgium is much larger. Other cases in point are Bangladesh (overrepresentation in the United Kingdom less than in Belgium and France); Iraq (overrepresentation in the United Kingdom less than in Greece, Denmark and The Netherlands); Ethiopia (overrepresentation in Italy less than in Greece); Senegal (overrepresentation in France less than in Spain).

These exceptions are difficult to explain. For example, the recognition rate (i.e., proportion of asylum seekers obtaining full refugee status or temporary protection) for Somalis in The Netherlands (43\%) is much higher than in Italy (9\%), but much lower than in the United Kingdom (95\%). Similarly, recognition rates for Indians, Ghanaians and Nigerians in Belgium are extremely low. Thus, differences in recognition rates cannot explain these exceptional patterns of asylum seekers going to a country other than the mother country. These exceptions cannot be explained by air connections either. Between Belgium and Ghana, for example, regular flights simply do not exist.

\section{Other cases (with no colonial ties)}

The large share of Europeans in Germany can presumably be explained by historical ties as well. Historically, Germany has received large numbers of refugees from Central and Eastern Europe. A history of labour migration to Germany exists particularly in the case of Poland and Germany grants far more scholarships to students from Central and Eastern Europe than any other EU country (UNESCO 1986). Germany is clearly the nearest country in the European Union for most Central and Eastern European asylum seekers. Also, asylum seekers from Soviet bloc countries have often received preferential treatment in Germany: they have frequently been allowed to stay (tolerated) even when their asylum applications were rejected (cf. Hailbronner 1994: 26).

With regard to the high share of Europeans in Italy, it is important to note that this is almost completely accounted for by Albanians. Given the long history of migration between these two countries, it is not surprising that Italy constitutes the main destination for Albanian asylum seekers. Parts of the Albanian coast were once colonised by Venetians and (Southern) Italy is home to a large Albanian-speaking minority. In addition, Italy is relatively easy to reach from Albania. The disproportionately small number of non-European asylum seekers in Italy, in contrast, can be at- 
tributed to Italy's application of the 1951 Geneva Convention with a geographical limitation. Up until 1990, only Europeans could apply for asylum in Italy.

Greece is the nearest country in the European Union for many asylum seekers from the Middle East and particularly those using Turkey as a transit country. This may explain why Greece is the most important destination for Iraqis. The high share of Middle Eastern applicants in Denmark is more difficult to explain. Other Nordic countries (and particularly Sweden) also receive large numbers of asylum seekers from the Middle East.

\section{Results of a multivariate analysis}

It is clear that colonial and other historical ties between the countries of origin and destination play a role in asylum movement. The importance of these ties on should nevertheless not be overrated.

In a multivariate regression analysis (see Appendix 3), we explicitly attempted to assess the influence of a number of factors. The following variables were included in the analysis: the presence or absence of colonial ties between the country of origin and the country of destination; the presence or absence of language ties; the presence or absence of geographical proximity; the presence or absence of (important) trade relations; and the number of nationals from the country of origin on scholarship in the country of destination.

When examined separately, the first three variables (colonial ties, language ties, geographic proximity) appeared to have an effect although a limited one. Multiple regression analysis identified colonial ties as the most important predictor of the country of destination (Beta .318). The effect of language ties was found to be much smaller, and the remaining variables were found to have hardly any effect at all. All five of the variables considered together explained no more than $17 \%$ of the total variance ( $\mathrm{R}$ Square .169).

It is important to note that, with the exception of colonial and language ties, the variables included in the analysis could only be operationalised very roughly. This is because of uncomparable or missing data. Due to missing data, moreover, the following variables could not be included in the analysis: recognition rates (i.e., the proportion of asylum seekers receiving a positive decision on their application); size of the existing immigrant communities; and the presence or absence of regular flights between the country of origin and the country of destination. In a number of cases where the asylum seekers from a particular country of origin were overrepresented for a specific country of destination, we examined whether high recognition rates, sizeable immigrant communities or regular flights from the country of origin might play a role and found this not to be the case in most instances. 


\section{Changes in the patterns of origin and destination}

When the patterns of origin and destination are compared for separate years, it becomes clear that the patterns have been constantly changing. For some of the more remarkable shifts, we tried to determine whether the following factors might account for the change of pattern: measures taken in the receiving country in order to reduce the influx of asylum seekers; measures taken in a neighbouring country; and decisions on previous applications (e.g., a large number of positive decisions in the year preceding the change). A clear relation to one (or a combination) of these factors was only found in a limited number of cases.

\section{Germany}

It is interesting to note that in quite a number of the cases where the number of asylum seekers from a particular country suddenly rises, a simultaneous rise in the proportion going to Germany can also be observed. Put differently, Germany tends to receive a large portion of the increase. Up until 1989, for instance, France received about 20\% of all Romanian applications; as the number of Romanians deciding to move abroad increased (1990-93), Germany's share increased to over 90\% (and France's dropped to 2-3\%). In the case of Bulgaria and Nigeria, a similar pattern of change can be observed. In the case of the Vietnamese, too, the proportion filing an application in Germany increased. Up until 1989, the majority of the applicants went to France; after 1989, the annual number of applications in France remained relatively stable while the number of Vietnamese asylum seekers applying to Germany rose steeply. The explanation in this case is quite simple, however: the applications in Germany were filed by Vietnamese already living there. They were originally recruited as guestworkers by the former GDR and applied for asylum when their contracts were not renewed (shortly before the reunification of Germany).

In 1993-94, a steep drop in the number of applications for asylum in Germany occurred. In the case of Romanians and Bulgarians the decline was even sharper, (presumably) because these countries (along with a number of other countries in Central and Eastern Europe and in Africa) were considered safe countries of origin since June 1993. As the drop in other EU countries was less sharp, Germany's share of the asylum flow from Romania and Bulgaria was reduced.

In a number of other cases, the asylum flow initially directed at predominantly Germany, increasingly went to other EU countries. In 198586 , for instance, nearly $90 \%$ of the Indian applications were filed in Germany; in 1987, however, this proportion was only $35 \%$. Similarly, the proportion of Ghanaians filing in Germany dropped from $60-70 \%$ in 1985-86 to less than $20 \%$ in 1987 . In both cases, the flow initially shifted to The 
Netherlands (with 1987 as a peak year) and later to other countries (particularly Belgium and the United Kingdom).

\section{Denmark}

With regard to Denmark, a peak in the annual number of applications in 1986 followed by a sharp reduction one year later was already observed. Closer examination showed the 1986 peak to be mainly due to a once-only rise in the number of Sri Lankan and stateless (Palestinian) applicants. The number of applications from other Mid-Eastern countries (Lebanon, Iran, Turkey) had already started to decline in 1986 after Denmark (and Sweden) concluded an agreement with the GDR and, in effect, restricted asylum seekers arriving on board Interflug planes in East Berlin from further travel to Denmark and Sweden without a visa (Migration News Sheet, November 1985, February 1986). As a result, Denmark's share of the Lebanese asylum flow to Europe fell from almost $40 \%$ to $4 \%$; its share of the Iranian flow from $19 \%$ to $6 \%$; and its share of the Turkish flow from $8 \%$ to less than $1 \%$. At the same time, the German share and, in the case of Turkey, the French share increased. 8

\section{France}

In France, the numbers have similarly decreased since 1990. Particularly in 1992, there was a sharp reduction. Among the nationalities most affected were again the Turks (the proportion of Turkish asylum seekers going to France fell from over $30 \%$ in 1990 to $5 \%$ in 1992) but also a number of African (Angolans), Asian (Vietnamese) and Latin American (Peruvians) nationalities. The Turkish and Vietnamese asylum flows were increasingly directed at Germany, while the Angolan flow was directed at the United Kingdom and the Peruvian flow at Spain. The decrease in France since 1989 may be explained by a number of factors. Both in 1990 and 1991, large numbers of Turkish and Angolan asylum seekers received a negative decision from France. In 1991, France introduced visa requirements for a number of countries, including Angola. Between 1989 and 1992, moreover, a series of restrictive measures were taken. In October 1991, it was decided that asylum seekers would be no longer authorised to work while waiting for the decision on their application. This restriction may explain the sharp drop in the numbers in 1992 , but the 1989 peak remains difficult to explain.

8 The Greek share presumably increased as well. At the end of 1986 , there were reports of a rise in the number of applicants from the Middle East using Turkey as a transit country. It had reportedly become more difficult for these nationalities to fly to East Berlin and cross over to West Berlin (Migration News Sheet, November and December 1986). However, we could not check this because the Greek figures for the years 1985-88 are not broken down by country of nationality. 


\section{The Netherlands}

For The Netherlands, 1987 was a peak year. In 1987, over $10 \%$ of all the applications filed in the European Union were filed in The Netherlands. In other years, the country's share of the EU total was around 5\%. The number of applicants from Ghana, Zaire, India and Pakistan showed a particularly strong increase. With regard to the Zairese applicants, such an increase can be assumed to be an after-effect of the death of a Zairese asylum seeker at the Brussels airport in January 1987 (Migration News Sheet, March and April 1987). This does not explain the similar increases in the numbers of applicants from other countries, however. The number of applications filed by Ghanaians, Indians and Pakistanis in Germany dropped in 1987 when the FRG reached an agreement with the GDR to reduce the influx of asylum seekers through East Berlin; the asylum seekers from these countries reportedly started to go to The Netherlands as a result of such restriction.

The 1987 peak was followed by a once-only drop in the number of applications filed in The Netherlands in 1988. The same nationalities which contributed to the 1987 peak now showed a sharp decline. In addition, the number of applicants from Turkey underwent a threefold reduction.

In 1994, the number of applications filed in The Netherlands reached yet another peak and the country's share in the yearly EU total amounted to almost 19\% (as opposed to 4\% in 1992 and 8\% in 1993). The rise in the proportion of asylum seekers filing in The Netherlands can be attributed to the already decreasing numbers in the other EU countries. At the same time, there was a large influx to The Netherlands from Eastern Europe (former USSR, former Yugoslavia, Romania), the Middle East (Iran, Afghanistan, Iraq) and Africa (Somalia, Zaire, Algeria, Angola). It has been suggested that many of the Somalis waiting for a decision in other European countries left for The Netherlands when the Dutch authorities, in an operation aimed at eliminating backlogs, granted residence permits to thousands of Somalis who had already been tolerated in The Netherlands for four to five years (Migration News Sheet, January 1993). In 1992-93, many Iranian and Iraqi applicants received a positive decision as well. For most of the other nationalities, however, the large influx observed in 1994 cannot be attributed to a large number of positive decisions in the previous year. The explanation put forth by the Dutch government (the State Secretary of Justice) is that asylum seekers who would previously have applied in Germany did so in The Netherlands because The Netherlands had not as yet taken measures to restrict potential asylum seekers from entering the country and the asylum procedure (cf. International Migration Bulletin, November 1994). 


\section{Italy}

It has already been observed that Italy received more than $8 \%$ of all the applications filed in Europe in 1987. This is reportedly due to the rising number of Polish applicants with easy access to Italy as a result of numerous pilgrimages to the Vatican. Other European countries had also already taken measures to reduce the influx of Poles (Migration News Sheet, September 1987) $)^{9}$.

\section{Spain}

Particularly in 1990-92, Spain's share of the asylum flow from a number of countries showed a marked increase. For instance, the proportion of Senegalese asylum seekers going to Spain increased from $13 \%$ in 1989 to $30 \%$ in $1990-91$ and $66 \%$ in 1992 . The increase in the proportion of Peruvian asylum seekers applying to Spain was even stronger: from $4 \%$ in 1989 to $47 \%$ in 1990 and about $90 \%$ in 1991 and 1992 . In both cases, a simultaneous decline in the relative numbers for France can be observed. In 1993-94, Spain also experienced an influx of Chinese asylum seekers. In 1992, less than $1 \%$ of all Chinese applications were filed in Spain; in 1993 this proportion was $23 \%$; and in 1994 it was $30 \%$. Again, a simultaneous decline in the proportion of Chinese going to France can be observed. It appears that these nationalities started to explore other destinations for asylum in response to worsening conditions (e.g. tightening asylum policies) in France and that the neighbour, Spain, constituted a natural option. ${ }^{10}$

\section{Sudden influxes}

Finally, there are numerous cases where the flow of applicants from a particular country can be observed to re-direct itself towards a specific country within the European Union for a relatively short period of time. In the first three weeks of August 1986, for instance, over 900 Sri Lankans (Tamils) arrived in Denmark to apply for asylum (Migration News Sheet, September 1986). A total of 2,752 Sri Lankan applications were filed in Denmark in 1986 (nearly 30\% of the annual EU total); in contrast, a total of 300 applications were filed in 1985 ( $1 \%$ of the EU total). Similarly in Belgium, there was an influx of hundreds of Chinese asylum

9 We were again unable to check this information because the Italian figures for the years 1985-89 are not broken down by country of nationality. It is interesting to note a sharp increase in the number of Polish applicants in Spain in 1990. The majority were reportedly catholics claiming religious persecution at home (Migration News Sheet, January 1991).

10 See Adepoju (1995:196) who also observes that Sahelian emigrants are increasingly exploring other destinations in response to the worsening situation in France (tightening immigration restrictions; xenophobic reactions to immigrants; changes in employment conditions). Within Europe, they appear to be going to Spain, Italy, Belgium and Germany. 
seekers in the space of three days in August 1989 (Migration News Sheet, September 1989). As a result, Belgium received over $30 \%$ of all applications filed by Chinese nationals in the European Union in 1989 (and less than $2 \%$ in 1988). In May of 1989, about 1,200 (Kurdish) Turks arrived in the United Kingdom (Migration News Sheet, June 1989). This means that more than 2,400 Turkish applications were filed in the United Kingdom in 1989 and represents seven times the number of applications filed in 1988. The number of applications filed by Turks in all of the EU countries, in contrast, only underwent a two-fold increase.

When the sudden increase cannot be attributed to worsening conditions in the country of origin, there is a tendency among policy makers and the press to attribute the increase to the activities of traffickers. In two of the three above-mentioned cases (the Tamils in Denmark and the Kurdish Turks in the United Kingdom), some of the applicants in fact report payment of large sums of money to middle men who promised to help them settle in Western Europe. In the third case (the Chinese in Belgium), rumours of Belgium accepting Chinese refugees had been spread among the Chinese in The Netherlands, France and Germany.

\section{Conclusion}

Many additional examples could be provided, but it is clear from the foregoing examples that a change in the pattern of asylum origin and destination typically has no clear or simple explanation. Changes in the destinations of asylum flows are often attributed to policy measures and it is assumed that the introduction of measures to reduce the influx of asylum seekers in one country frequently produces rising numbers in neighbouring countries. According to Schilling (1995:264), for example,

'basically, the European countries compete with each other for the lowest influx

Schilling mentions Denmark - Norway (1986-1987) and Germany - The Netherlands (1993-1994) as cases in point.

The effects of both internal and external policy measures should not be overrated, however. Over the last decade, most Western European countries have constantly been taking measures to reduce the influx of asylum seekers. In many cases, however, the asylum statistics simply do not reflect the effects of these measures. In cases where there is an effect, moreover, it often proves to be transient. For example, the introduction of visa requirements in the United Kingdom for Sri Lankans and a number of other nationalities reportedly had some effect in the months following their introduction. One year later, however, the influx of asylum seekers again started to increase (Migration News Sheet, June 1985, September 1986, February 1987). 
The reaction of most European governments to the rising numbers of asylum applications has been to regularly amend their asylum legislation. Although these amendments may produce a temporary decline, the figures can be expected to rise again after a year or so. 


\section{Chapter 4}

\section{Key informants on factors influencing the destination of asylum seekers}

After analysing the statistics with regard to the number of asylum applications between 1985 and 1994, we will now turn to a more qualitative source of information. In The Netherlands, Belgium and the United Kingdom, we interviewed a number of key informants on this topic, ${ }^{1}$ and the results of these interviews are presented here.

The source of the analyses should be kept in mind while reading this chapter. Our key informants were all insiders in one way or another. They had or have different positions and different experiences which may colour their answers. Most of them have only knowledge of asylum seekers coming to the relevant country of destination and in some cases only knowledge of a particular group of asylum seekers. The Netherlands, Belgium and the United Kingdom are all Northern European countries. The experiences of key informants in a Southern European country are probably different. We also found some differences between the three countries of destination considered in this study. These differences stem from the colonial histories of the countries and differences in the asylum-seeking populations and patterns of migration. This suggests that interviews in other Northern countries such as Germany or Denmark could easily have produced different findings as well. Although we tried to capture as much variation as possible within the group of key informants, the selection of the individuals was by chance. Finally, the interviews in the United Kingdom were predominantly with individuals from refugee organisations and refugee communities which means individuals with knowledge of their own group in particular. The interviews in The Netherlands and Belgium, in contrast, were predominantly with individuals with some general knowledge of asylum seekers and specialised knowledge of a particular group. In addition, the informants were supposed to base their answers on their knowledge of the motives and opinions of asylum seekers; the views of the individual respondents were obviously expressed on some occasions, however, instead of the views of the asylum seekers or facts. Despite all these restrictions, the interviews proved to be quite useful. The interviews also produced insider stories concerned with concrete

1 See Chapter 1 and Appendix 4 on the selection of and interviews with the key informants. The topics dealt with in the interview are summarised in Appendix 5. 
situations and thereby highlight the processes behind actual asylum movement.

We will begin with a discussion of the question of just how much choice the asylum seeker has (in the opinion of the key informants) (section one). After that, we will discuss the impact of ties between the country of origin and the country of asylum (section two), the characteristics of the countries of destination (section three) and events during the actual flight and travel which might influence the destination of the asylum seeker (section four). These factors cannot always be clearly separated; some of them overlap and some of them naturally fall together. In this chapter, you will find boxes concerned with asylum seekers from a particular country of origin. These cases are meant to illustrate the impact of the various factors. The case stories also show the complexity of the matter (i.e., the role of a combination and succession of different factors in one and the same asylum movement). Once again, it should be noted that the case stories are limited to the three countries in which the interviews took place. When information from other sources has been used, explicit reference to that source will be made.

\section{Do asylum seekers have a choice of country?}

Do asylum seekers consciously choose the country they apply to for asylum? In this research, it is important to distinguish between asylum seekers who decide to go to a particular country and asylum seekers who happen to arrive in a particular country. The latter can be either because someone else (a travel agent or middleman) determined the destination or because the relevant country was the only country the asylum seeker could go to (availability of transportation and travel documents).

Most of the informants were of the opinion that the asylum seekers do not have much choice in the matter. They simply want to leave the country of origin for a safe place. The accessibility of a country is thus most important.

'There are refugees in Somalia, Ethiopia, countries in serious trouble. Those people just welcome the first opportunity. (...) It is hard to choose in a difficult situation.'

'For a refugee it is not important to which country he goes. It is important how he can leave India. If he gets documents, passport, visa for the Netherlands than he will go to the Netherlands. (...) Asylum seekers do not have any choice in the country they go to.'

Some informants added that asylum seekers will try to go to a particular country when they know someone there. 
'Normally when people seek asylum in Western Europe, they are not spoilt for choices. They are fleeing persecution and they go to the place where they can get a visa. Secondly they go to where they can get support, if for example one has a brother or a sister or a father or a mother in England, yes of course their first choice would be England. (...) It is not choices between countries, but it's how they can go and who is there to go to.'

Other informants pointed out that the destination of the first flow of asylum seekers is often pure chance or coincidence. After the first group has requested asylum, however, others will follow. This is largely due to the connections of the travel agent and/or the desire to join family and friends.

I have the impression that in recent times many asylum seekers have social relations. They really deliberately choose a particular country. Via travel agents and via other relationships they search an opportunity to get in that country.'

Ex-Yugoslavia: Seeking refuge from a civil war in Europe

Rank order of ex-Yugoslavia as country of origin

\begin{tabular}{|l|r|}
\hline EU-12 & 1 \\
\hline Belgium & 3 \\
\hline The Netherlands & 1 \\
\hline United Kingdom & 2 \\
\hline
\end{tabular}

Although ex-Yugoslavia is among the most important countries of origin for all three of the countries of destination examined here, Germany has received by far the most asylum seekers from this country.

There is general agreement among the informants from all three countries of destination, that ex-Yugoslavians generally prefer to go to Germany for a number of reasons. When the conflict broke out, Germany was already home to the largest Yugoslavian immigrant community. Many asylum seekers have or had relatives or friends there. Germany is also preferred because it was the first
European country to recognise Croatia and because it invited large numbers of refugees (larger numbers than any other country). This induced others to seek asylum in Germany as well. Finally, for asylum seekers travelling over land, Germany is easier to reach than the other three research countries.

All the same, ex-Yugoslavians have also come in large numbers to The Netherlands, the UK and Belgium. The key informants in all three countries agreed that where the earlier arrivals ended up was very much a matter of chance. Family links were the basis for later arrivals although their choices were also very much influenced by the current situation and circumstances. According to one of the UK informants: 'You have got people who have brothers, sisters or other relatives in Denmark and they are here, because at the time it was more important to get out to go somewhere than wait to be reunified with your family. The conditions in the camps were just appalling.'

According to the majority of the informants, most asylum seekers simply want to go to Western Europe or North America and do not have a particular preference for a particular country. Some of the Dutch and Belgian informants reported The Netherlands and Belgium to be rather unattrac- 
tive for asylum seekers; many of the asylum seekers would prefer another country.

'60\% of the asylum seekers would prefer asking for asylum in another country [than The Netherlands]. They would rather go to Canada, for example people from the Middle East, from Sri Lanka, Pakistani and Bangla Deshi. People from Eastern Europe prefer Germany. North Africans choose France or Belgium. It has to do with language and cultural influences. (...) Yugoslavs do choose the Netherlands.'

'The reception of asylum seekers in Belgium is really terrible. (...) Most of the asylum seekers I know and even those recognised as refugees want to leave Belgium. They used to live in a community and now they live in a village where they know no one. (...) The reception and the comfort is of minor importance. (...) You are treated as a criminal. It is especially the hostility that bothers them.'

The British respondents report a different view. They are generally of the opinion that the majority of the asylum seekers want to be in the United Kingdom. Only particular groups of asylum seekers may have a desire to go to America.

'I think (...) that people escaping persecution and leaving out of countries (...), their choice may be restricted. On the other hand, on the whole, I think people do get to their country of choice. They do get to the UK because they choose to come here.'

Particularly some of the informants in Belgium and The Netherlands report that asylum seekers may try to choose a different country of destination after their arrival in Western Europe. When leaving the country of origin, asylum seekers do not have much choice of country. Once in a Western European country, they may therefore reconsider their destination. They may decide to travel to another country because they have an acquaintance living there, because they think they will feel more comfortable there, because they have more opportunities to work or study there or because they think they have a greater chance of being accepted as a refugee there. Numerous examples cited in the interviews with the key informants indicate the popularity of Canada and the United States. But particular asylum seekers may want to go to Belgium from Germany, to The Netherlands from Belgium, to the United Kingdom from France and so forth. The asylum seekers sometimes succeed in going to the more preferred country; that country also sometimes remains out of reach.

Some of the informants distinguished different categories of asylum seekers with respect to choice: Some have more choice than others. Some of the informants considered people with a higher education to have more choice because they have greater information on the countries and various options. Other informants pointed out that some asylum seekers can anticipate their flight, collect information and make arrangements while others find themselves in sudden and unexpected danger and simply 
have to flee. Other informants say that the more money you have the more choice you have because some countries are very expensive and money can buy almost anything. The most extreme statement in this respect is that a poor man will simply not succeed in leaving Africa. Because of the more tight controls and visa requirements for major countries of origin, it is virtually impossible to leave a country on your own and you therefore need help to obtain travel documents or to evade border controls. This help is usually expensive, and the travel agent decides where the individual will go to or at least which destinations can be chosen from for what price. Some of the informants were also of the opinion that people from such European countries as Romania and Yugoslavia have a greater choice because of the geographic proximity and thus accessibility of a number of European countries for them.

A preference for a particular country of refuge is presumably based on some knowledge of that country unless the preference is based on a desire to join family and friends. In the following, we will briefly consider what our key informants had to say about the knowledge which asylum seekers appear to have of the country of destination.

According to most of our informants, asylum seekers do not know much about the country of asylum when they arrive. Many asylum seekers have only a notion of Europe or the West or the North in general. When they do differentiate between European countries, this is mostly on the basis of rather vague ideas: Germany as rich and powerful, Scandinavian countries and The Netherlands as particularly humanitarian (respect for human rights), democratic and peace-loving.

Possible sources of information for asylum seekers are earlier arrivals who tend to provide only positive information; radio and television; $;^{2}$ and acquaintance with nationals from the country of asylum which may include development workers, priests, tourists, Unifil soldiers or business partners.

Most asylum seekers have a highly idealised picture of life in Europe although some of them would still have preferred to go to Canada or the United States. Asylum seekers also tend to be quite optimistic about their chances in the country of destination. They assume they will be allowed to stay. They cannot imagine being sent back. And they are often insufficiently informed about reception facilities.

While most asylum seekers tend to have a rather vague and quite rosy picture of life in the asylum country, differences were nevertheless reported by our key informants. Differences may exist between nationality groups. When a group from the country of origin is already settled in the

2 See, for instance, the Box on asylum seekers from Romania elsewhere in this Chapter. 
country of destination, moreover, the asylum seekers may sometimes have information on the asylum procedure. For example, they may know or have grounds to assume that they will not be returned immediately, that the procedure can take years and that they will be allowed to stay pending the decision. Differences related to the level of education may also, as already mentioned, exist.

Some informants also emphasised that asylum seekers gain more (adequate) knowledge of the country where they are staying and neigbouring European countries with time. Some of them may decide to move to another country as a result. For example, several of the informants in The Netherlands thought that the assaults on asylum centres in Germany and the debate on possible changes in German asylum law produced a flow of asylum seekers to The Netherlands from Germany. Several other informants thought that many Somalis had come to The Netherlands from other countries when they heard that the Dutch authorities were granting residence permits to Somalis.

\section{Ties between the country of origin and country of destination}

In the next three sections we will discuss the opinions of the key informants with regard to the impact of the three groups of factors distinguished in Chapter Two on the destination of asylum seekers. In this section, we consider the links between the country of origin and the country of asylum. In the remaining sections, we will consider the characteristics and image of the country of asylum and possibly critical events during the flight.

\section{Colonial links}

A common explanation for the country people turn to when seeking asylum is the ties existing between the country of origin and the country of potential asylum. In the previous chapter, former colonial ties were shown to be the only factor to clearly explain some of the patterns in the statistical data.

The interviews in the United Kingdom and in Belgium showed colonial and historical ties to explain the arrival of asylum seekers from such exBritish colonies as Sri Lanka, Uganda, India, Pakistan or West Africa in the UK and the arrival of asylum seekers from Zaire, Rwanda and Burundi in Belgium. Most of the informants think that colonial ties are important because this means a settled community in the country of destination, possible mastery of the relevant language, familiarity with the culture and perhaps an idealised image of the former mother country. 
Romania: Economic opportunities and a television broadcast

Rank order of Romania as country of origin

\begin{tabular}{|l|r|}
\hline EU-12 & 2 \\
\hline Belgium & 2 \\
\hline The Netherlands & 5 \\
\hline United Kingdom & 18 \\
\hline
\end{tabular}

Whereas Romanians have come in relatively large numbers to Belgium and The Netherlands, the number of Romanian applications in the UK has been rather small. In The Netherlands, 1990 and 1994 were peak years. In Belgium, the influx of Romanian asylum seekers was highest in 1993.

The informants in the UK think that the main reason for few Romanians coming to this country is the relative inaccessibility of the island. Other Western European countries can be reached by land. According to one informant, those Romanians who do arrive in the UK may not have wanted to come specifically to this country: 'The Romanians all seem to come in on container lorries. It seems they wanted to go anywhere and just sort of fell out wherever.'

The Dutch informants think that most Romanians prefer to go to France or Germany. France is preferred because of the language, Germany because of the economic opportunities which are thought to be better there. Several informants pointed out the very high refusal rates for Romanians in The Netherlands. All the same, the Netherlands has nevertheless received a relatively large number of Romanian asylum applications particularly in 1990 and 1994.
One of the Dutch informants who interprets for many Romanian asylum seekers provided the following explanation for the 1990 peak. After the Romanian revolution, The Netherlands was one of the first countries to send aid. In 1989, there was a national collection for Romania. The collection was supported by a television show and this show was broadcast in Romania. Many asylum seekers later recognised the interpreter from this broadcast. Another important factor at the time was the relative ease of obtaining a visa for The Netherlands: the Dutch ambassador was relatively flexible. The influx of Romanians decreased after the Dutch authorities started giving priority to applications from East Europeans. Most Romanian applicants received a negative decision within two weeks after their arrival.

Most of the key informants from Belgium agree that economic opportunities play an important role: asylum seekers are allowed to work pending the decision on their application. They also point out that the number of new arrivals dropped sharply after the introduction of a partial employment ban at the end of 1993 . Other informants point out that many Romanians actually wanted to go to Canada. The Délégation Générale du Québec in Brussels had the reputation of easily issuing visas for Romanians. Many Romanians thus came to Brussels to apply for a visa for Canada. They applied for asylum in Belgium in order to stay there while waiting for a decision on their Canadian visa application. According to one informant, the influx of Romanians to Belgium clearly dropped when the Canadian government decided to process all visa applications in Paris.

Asylum seekers from a former colony may also consider it the duty of the mother country to receive them; Zairians, for example, claim a right to go to Belgium and feel that Belgium is obliged to receive them.

Examples of other European countries where asylum seekers from former colonies appear to go include Algerians going to France and Eritreans going to Italy. 
The Dutch informants did not typically consider colonial and historical ties between the country of origin and the country of destination to be very important. The interviews tended to reflect the specific situation in The Netherlands. With the exception of a small number of Surinamese, the asylum seekers in the Netherlands generally do not originate from a former colony. Some of the informants also pointed to the historical ties of Sri Lanka to The Netherlands.

According to some Dutch informants, asylum seekers may also not want to go to the mother country at times. Ethiopian asylum seekers avoid Italy, Zairians avoid Belgium and some Algerians avoid France because of the ties existing between the authorities in the two countries and the fear that the secret service in their home country might take action in the mother country. Nevertheless, the Dutch informants see only those Zairian asylum seekers who have traveled to The Netherlands and not the large number who have remained in Belgium. Another reason to avoid the mother country may be a tighter asylum policy with regard to former colonies. In this case, the chances of acceptance are minimal as a result of good relations between the governments of the country of origin and the country of asylum. It is also possible that the authorities in the country of asylum strictly limit the admission of asylum seekers from former colonies in order to avoid a possible stream of asylum seekers from former colonies.

In the interviews, we asked the informants to rank the importance of six factors previously identified as possibly influencing the country of destination but then for a restricted number of countries of origin. ${ }^{3}$ As can be seen in Appendix 6, most of the Dutch informants did not consider the factor 'historical, political and cultural ties' to be at all important for the arrival of asylum seekers from former Yugoslavia, Romania, Turkey, Sri Lanka, Lebanon and Ghana.

The Belgian informants rarely considered 'historical, political and cultural ties' to be the most important factor. For Zairian asylum seekers, however, this factor was second most important (next to the presence of fellow countrymen in Belgium). For former Yugoslavian and Turkish asylum seekers, it was considered relatively important. For asylum seekers from Lebanon, Ghana and India this factor was least important.

Only a small number of the UK informants responded to this question, but it seems they consider 'historical, political and cultural ties' to be an important factor for asylum seekers from Sri Lanka and Ghana. For both Sri Lanka and Ghana, the presence of fellow countrymen in Britain was also considered an important factor.

Colonial ties between two countries often imply other kinds of ties as well. European airline companies often maintain direct flights with for-

3 See Appendix 6 for more detailed information with regard to this interview question. 
mer colonies. The educational system in the former colony may resemble that in the mother country and the language of the mother country may be familiar. Former colonial ties mostly implies a history of migration from the former colony to the mother country, labour migration, people going there for educational purposes, mixed marriages and established trade relations. A history of migration also suggests an already settled community in the mother country. It is nevertheless hard, if not impossible, to distinguish these different links between the country of origin and the country of asylum.

\section{Language and culture}

Almost all of the UK informants regard language as an important factor. People from Anglophone countries are more likely to end up in the UK than in non-English speaking countries. Many people all over the world speak English and no other foreign language. Only one UK informant, an immigration law solicitor, expressed a different view:

'Language doesn't seem to be a big issue, virtually everyone I see needs an interpreter anyway.'

The Dutch informants think language is an important factor and that asylum seekers prefer an English-, French-, German- or Italian-language country. The Dutch language makes The Netherlands unattractive. Almost no asylum seeker is familiar with Dutch, and asylum seekers find it a difficult language to learn. Despite such unfamiliarity, large numbers of people ask for asylum in The Netherlands and, for these asylum seekers, factors other than language are obviously more important.

In many of the Belgian interviews, language was simply not discussed. An informant working in a Belgian reception centre nevertheless stressed the importance of language within the country of Belgium itself. Frenchspeaking asylum seekers chose the Walloon provinces in Belgium while the English-speaking asylum seekers chose the Flanders provinces. When Belgian informants talked about the importance of language, they referred to the French language. Language is considered important for asylum seekers from Africa (Rwanda, Ivory Coast, Zaire), Latin America and Vietnam. One Belgian informant nevertheless pointed out that Somalis and Ethiopians would prefer the English language and educational system.

Cultural connections between the country of origin and the country of asylum can accompany colonial links and a history of migration. Colonial and other historical links between a Western European country and a Third World country might also include the educational system in the home country based on a European model. For a specialised or higher education, parents may send their children to the relevant European country. There are sometimes scholarships to pay for such study, and 
these kinds of cultural links might make a specific country particularly attractive for asylum.

Some of the UK informants in particular made reference to (previous) students in the UK from such former colonies as Sudan, Somalia and Nigeria and such other countries as Chile, Iran and Bosnia. An Iranian informant in the UK explained:4

Before the revolution, the UK was a very popular Western country for Iranians to come, as a visitor, as a student or for medical reasons. English is the second language in Iran.

In the interviews in Belgium and The Netherlands, foreign students were only mentioned in a very few cases.

\section{Friends, family and existing community}

For almost all interviewees, the most important factor influencing the country of destination for asylum was reported to be the presence of friends, relatives or countrymen in the country. The presence of a person you know personally in a country is considered to be the number one pulling factor. Asylum seekers try to go to countries where they know an established community exists to give them support. 5 This is a type of chain migration similar to that which occurs for labour. ${ }^{6}$

The UK informants on the average reported the presence of a community of compatriots in the UK to be the most important factor for asylum seekers from Turkey, Sri Lanka and Ghana. The Belgium informants reported the presence of fellow countrymen in Belgium to be the most important factor for asylum seekers from Zaire and Turkey. It was the second most important factor for Sri Lankans and Lebanese and the third most important factor for the other countries of origin. ${ }^{7}$ In the view of the Dutch informants, family, friends and compatriots in the country of destination was the most important factor for asylum seekers from Turkey and Ghana. This factor is also believed to be very important for asylum seekers from former Yugoslavia, together with the Dutch asylum policy and The Netherlands being easy to reach.

In most of the British interviews, established communities in the UK and in London in particular, are referred to.

4 Compare the Box on asylum seekers from Iran elsewhere in this Chapter.

5 This is also reflected in the Boxes included in this Chapter. In all cases, with the exception of Romania, existing communities or presence of family is mentioned as one of the factors influencing the destination of asylum movement. This factor is important for asylum seekers from Ghana, India, Iran, Somalia, Sri Lanka and Turkey.

6 See Chapter 2.

7 For Sri Lanka, travel agents are considered more important; for Lebanon, economic opportunities are considered more important. 
'People prefer to come to Britain, for instance Sri Lankans, Ugandans, Ghanaians, Nigerians, Indians, Pakistani, because of the settled community here."

Other communities mentioned for the UK include the Bangladeshi, (Kurdish) Turks and people from North Somalia. The existence of some of these communities obviously relates to an entire range of links between the two countries resulting in a history of migration.

The Belgian informants also considered the presence of fellow countrymen an important factor. Reference is made to a Zairian community in Belgium. Other Belgian informants mentioned networks of Sikhs, Turks, Pakistani and Poles which enabled fellow countrymen to find work fairly quickly after their arrival.

\section{Turkey: Existing communities}

Rank order of Turkey as country of origin

\begin{tabular}{|l|r|}
\hline EU-12 & 3 \\
\hline Belgium & 6 \\
\hline The Netherlands & 7 \\
\hline United Kingdom & 4 \\
\hline
\end{tabular}

The number of Turkish applicants in the three research countries is small in comparison to those in Germany and France. The proportion of Turks applying for asylum in the UK has steadily increased. Up until 1987, the UK received less than $1 \%$ of the total number of Turkish applications in the EU-12. In 1994 , this proportion was over $8 \%$. The proportion of Turks applying to The Netherlands, in contrast, dropped from between $8 \%$ and $10 \%$ in the years 1985 87 to about $2 \%$ in the years $1988-94$.
The key informants in all three countries think that most Turkish asylum seekers prefer to go to Germany for a number of reasons. Germany is home to the largest Turkish community in Western Europe. It has attracted large numbers of economically and politically motivated Turkish migrants.

According to several informants, Germany's asylum policy also plays a role. The refusal rates for Turkish asylum seekers are very high, but many rejected applicants somehow manage to stay. France is also an attractive asylum country for Kurdish Turks in particular because they have a better chance of obtaining refugee status there - although one of the English informants claims that quite a few Turkish asylum seekers arrive in the UK from France by ferry! There is also general agreement that for those Turks who apply for asylum in the three research countries, relatives or friends already settled there are the main pull factor.

In the Dutch interviews, there was also talk of relatives and friends already living in The Netherlands as refugees or migrant workers. After some people arrived, more people followed. As one Dutch informant pointed out, going to a country which has already accepted your relatives, increases your chances of acceptance by $20 \%$. According to an interpreter working for Romanians as well as Africans in The Netherlands, this factor is not at all important for Romanians as they do not want to meet other Romanians and do not want to help each other.

The existence of an established community in the country of destination is not, thus, considered an advantage by all asylum seekers. An in- 
terviewee in the UK also explains that Angolans were very cautious when they first arrived. Not knowing their political background, Angolans did not trust other Angolans.

\section{Political ties between countries}

The possibility of colonial links inducing asylum seekers to avoid the former mother country has already been mentioned. In general, close political links between the governments of a country of possible asylum and the country of origin make people afraid to ask for asylum in the relevant country of destination. This negative factor is mentioned as an explanation for why people from the Ivory Coast go to Britain and not to France. The French government is even said to have apologised to the government of the Ivory Coast for granting asylum to three people. Zairian asylum seekers assume that the French and Belgians collaborate with the Mobutu regime and do not feel safe in France and Belgium. A Zairian refugee said he actually did not want to go to Belgium because the country is a $100 \%$ supporter of Zairian politics. In the view of a Dutch informant, The Netherlands was a favourite destination for Vietnamese people from Eastern Europe because a Vietnamese Embassy does not exist in The Netherlands. Due to the close political relations between Turkey and numerous European countries, it has also become harder for a Turkish asylum seeker to find acceptance as a refugee. A Dutch informant who is an immigration lawyer explains the decline in applications from Turkish asylum seekers since 1988:

I think that it became more difficult for Turkish people to obtain the status of refugee. Turkey got caught up in European events. Suddenly they signed those treaties on torture and from that moment on it became more difficult to obtain the legal status of refugee.'

In connection with this decline, another Dutch key informant points to the intimate relationship between the Dutch government, NATO and Turkey. According to this informant, The Netherlands was particularly hard on Turkish asylum seekers for exactly this reason. This is also why Turkish asylum seekers prefer other countries of destination such as France.

In addition to the political relation between the governments of the country of origin and the country of asylum, ties with the political opposition in the country of origin can also exert a more positive effect at times. Support for an opposition movement by a Western society or Western government can give asylum seekers the impression that they will be quite welcome in that country. A Dutch informant points to an opposition group in Czechoslovakia, Charta '77, and the strong support of this group in The Netherlands as an explanation for the arrival of numerous asylum seekers from Czechoslovakia. For members of a particular political party 
or organisation, moreover, it can be important that representatives of the political opposition in the country of origin reside in a possible country of asylum. People from Northern Somalia, for example, are said to want to go to London because the resistance movement has its seat there. Some expect the establishment of the so-called Kurdish parliament in exile in The Hague to make the Netherlands more attractive for Kurdish asylum seekers.

The personal flight story of a Kurd from Iraq, one of our key informants in The Netherlands, presents a mixture of the above factors.

\begin{abstract}
We were sure that the Netherlands would not send us back because of their bad relationship with Iraq. We expected to be arrested though. Our flight was via Paris. We were very afraid of being stopped there. Chirac was a friend of Sadam Hussein, we feared being sent back to Iraq. Oil is more important than people. We read in the newspaper that the Netherlands had a conflict with the Arab world and was proIsrael. That is why we expected to be safe there.'
\end{abstract}

\title{
Trade, travel and religion
}

Our informants do not consider religion to be an important factor for the destination of asylum seekers. When asked, only a few could think of any impact. A Belgian informant mentioned Poles saying that they came to Belgium because it is largely Roman Catholic. Two Dutch informants mentioned The Netherlands being a Christian country and the existence of a Ghanaian church in Amsterdam as important for Ghanaian asylum seekers.

Western travellers in the countries of origin may also influence the country of destination. Asylum seekers tend to go to a country they know something about. An encounter with a Dutch journalist, a Belgian missionary or a Canadian priest may motivate an asylum seeker to go to The Netherlands, Belgium or Canada respectively.

Trade and business connections may also have some influence. It seems that asylum seekers from African countries such as Zaire, Ghana and Somalia sometimes travel together with someone who travels regularly between Africa and Europe (Belgium) on business. It is, of course, possible that trafficking in people to Europe is the main business for some of these people. The interviews indicated other types of trade to also be important. A certain level of import and export between the countries may also bring familiarity with the country of destination. As an Iranian informant relates:

Why then the Netherlands? The person hears from his friends or acquaintances about The Netherlands. The Netherlands is more often in the Iranian news - we used to know about only cheese and wooden shoes. Now there is more than that. The contact between the two countries has grown, for example Dutch Volvos are used as taxis in Teheran and it says 'Made in Holland' on the cars so everyone knows Holland.' 
Trade makes a country known all over the world. The Netherlands in particular as a trading country was mentioned for Iran, Somalia and Africa. The UK informants mentioned trade with Lebanon, Somalia, Iran and Bosnia.

Finally, some informants mentioned the guest worker schemes from the 1960s as stimulating later migration from Turkey on an asylum basis. Nevertheless, no informant regarded the economic relations between the country of origin and the country of asylum to be crucial.

\section{Characteristics and image of the countries of destination}

We asked the key informants to comment on the role of a number of characteristics of the countries of refuge. The role of asylum and immigration policies was most elaborately discussed during the interviews. In the following, a distinction is made between the measures and policies which determine the possibilities for entering the country, on the one hand, and the measures and policies which determine possibilities for staying in the country, on the other hand. In addition, attention will be focused on the rights which the asylum seekers either do or do not enjoy pending a decision on their application. In addition to the role of the asylum and immigration policies, the key informants were also asked to comment on the roles of certain other characteristics of the asylum countries, including economic opportunities and the human-rights reputation.

\section{Visa requirements}

Since 1986, the EU member states have developed a common visa policy for most non-EU countries (or so-called third countries). As a result of this common policy, nationals from nearly all countries of origin need a visa for all EU member states. An important exception is Poland. Since 1991, Poles do not need a visa to enter an EU member state. Despite this common visa policy, it may still be easier to obtain a visa from one member state than from another. Asylum seekers or their agents may also find ways to either buy or falsify visas for particular countries.

There was a broad consensus among the key informants that visa requirements and a restrictive visa policy make it far more costly and difficult to travel to a particular destination country. As a case in point, one of the UK informants mentioned Sierra Leone: the flow of asylum seekers fleeing to Britain because of civil war simply stopped when visa requirements were imposed. ${ }^{8}$ According to one of the Dutch informants, Bosnians used to come to The Netherlands on a direct flight from Skopje to an airport in the south of The Netherlands. After the introduction of

8 Asylum applications from Siera Leone are not specified in the UK figures. We therefore do not know if this decline actually occurred. 
visa requirements in July 1992, these flights were discontinued and the influx of Bosnian asylum seekers sharply decreased. 9 The informants also emphasised that the effects of such visa requirements are usually temporary. After some time, the asylum seekers typically find some means of circumventing the requirements.

Asylum seekers who cannot obtain a visa for the country of their choice may end up in any country which they can get a visa for. As a case in point, one of the Belgian informants mentioned the Vietnamese who came to Belgium from refugee camps in South East Asia:

'They were dreaming of France, knew nothing about Belgium, but came to this country because Belgium was the only country issuing visas and this was the only way to get out of the camps."

According to another Belgian informant, Belgium was the only country that issued visas to Iraqis staying in Jordan. Several other informants in Belgium also thought that it was easier to get a visa for Belgium than for France or the US or Canada. This would explain why some asylum seekers ended up in Belgium when they would have preferred to go to another country. Still other informants mention that asylum seekers may buy a ticket to the country for which they have a visa but not necessarily file for asylum there.

A general conclusion among the informants is that visa policies have become increasingly restrictive in all asylum countries and that asylum seekers have been forced as a result to make a detour via countries where it is not so difficult to obtain a visa, enter the country on false documents or use other clandestine means. This mostly requires the help of an agent and a lot of money. Some asylum seekers may end up in a country which they would not have chosen when given alternatives. However, it was repeatedly remarked during the interviews that 'money can buy anything.'

In addition to the imposition of visa requirements, most of the EU countries have adopted carrier sanctions to prevent asylum seekers from entering the country. Many countries also conduct pre-flight checks in particular countries of origin. The key informants from all three countries of destination agreed that, just as visa requirements and more restrictive visa policies, these measures simply make it more costly and difficult to travel to a particular country. In the end, they do not prevent asylum seekers from entering the country. There was also broad consensus on the fact that other factors play a more important role in the choice of the country of asylum, in part because most of the EU countries have taken similar measures.

9 The figures show an increase in the number of Bosnian applications in The Netherlands in 1993. This discrepancy can be explained by The Netherlands initially not allowing Bosnians to apply for asylum. 


\section{Asylum procedure and recognition rates}

Entering a country is one thing; being allowed to stay there is another. The proportion of asylum seekers granted refugee status (or temporary protection) varies both by country of destination and by country of origin. Recognition rates for asylum seekers from the same country of origin sometimes vary widely across different asylum countries. The question is whether a higher recognition rate for particular countries of origin makes an asylum country more attractive for asylum seekers from those countries or not?

The key informants in the UK did not consider recognition rates to be an important factor. The Belgian informants, in contrast, thought that differences in recognition rates may sometimes have an effect. One of the informants pointed out that some Zairians go to The Netherlands because of the low recognition rates in Belgium. Similarly, asylum seekers from Eastern Europe show a preference for the United States and Canada because their chances of being granted refugee status are much higher there than in Western Europe.

Several of the Dutch informants also considered recognition rates to be important. They also pointed out that asylum seekers can sometimes react quite quickly to the decisions on applications in different countries. For example, the influx of asylum seekers from Somalia, Sri Lanka and Iran increased rapidly after the Dutch authorities, in an operation to eliminate backlogs, had granted large numbers of residence permits to earlier arrivals from these countries. Conversely, the influx of asylum seekers from Turkey dropped when most of the Turkish applicants received a negative decision. ${ }^{10}$

The informants agreed that most asylum seekers do not know the difference between a refugee status and temporary protection or even temporary toleration pending a decision on the application. The crucial factor is not the recognition rates themselves but the chances of being allowed to stay. Some Belgian and Dutch informants therefore think that the lengthy asylum procedures used to be one of the main attractions in Belgium and The Netherlands. The Dutch informants also assume that asylum seekers from a number of countries of origin and particularly Somalia have been mainly attracted by the Dutch policy of not deporting people to countries under civil war conditions. ${ }^{11}$

Over the last years, most of the EU countries have introduced special, accelerated procedures for applications filed at the border (in practice, airports) and for manifestly unfounded applications. Most countries have taken additional measures to force rejected asylum seekers to leave the country. As a result, asylum seekers currently run a higher risk of being detained and deported.

10 See the Box on asylum seekers from Turkey elsewhere in this Chapter.

11 See the Box on asylum seekers from Somalia below 


\section{Somalia: Established communities and asylum policies}

Rank order of Somalia as country of origin

\begin{tabular}{|l|r|}
\hline EU-12* & 16 \\
\hline Belgium & 22 \\
\hline The Netherlands & 2 \\
\hline United Kingdom & 5 \\
\hline
\end{tabular}

Somali asylum seekers have come in relatively large numbers to The Netherlands and the UK. Belgium, in contrast, has received only a limited number of Somali asylum seekers. In both The Netherlands and the UK, there was a sharp increase in the number of Somali applications in 1989. In the UK, the numbers have remained fairly stable. In The Netherlands, the numbers increased steeply again in 1992. In the years 1987-89 and 1992-94, The Netherlands received larger numbers of Somali applicants than any other EU country.

The UK informants consider established communities and historical ties to be the most important factors for Somali asylum seekers in the UK. The northern part of Somalia, now the breakaway 'Republic of Somaliland', was a British protectorate for a long time. Communities of northern Somalis have settled in such cities as London, Cardiff and Liverpool. They have settled in the ports of Britain because they are seamen and previously came to work for the navy. When the civil war started in Somalia, many of these already settled migrants had their relatives come over to the UK. For other northern Somalis as well, the communities in Britain were an 'anchor.'

One informant thinks that southern Somalis (from the part of Somalia which used to be an Italian colony) also came to the UK in large numbers because Italy still applied the 1951 Geneva Convention with a geographical limitation and thus only accepted refugees from Europe at the beginning of the civil war in Somalia. Other informants think that Italy was nevertheless an attractive destination for Somalis because of the possibilities of resettlement in the United States, Canada or Australia.

In the case of The Netherlands, the influx of Somalis cannot be traced to historical ties or existing immigrant communities. Several informants observed that Somalis initially did not care where they ended up as long as it was in Western Europe. Some of them ended up in The Netherlands, for example, because they managed to get on a plane in $\mathrm{Ke}$ nya which was going to Amsterdam. Practically all of the Dutch informants agree that The Netherlands later attracted larger numbers of Somalis because of the Dutch asylum policy. As victims of a civil war, Somalis are not returned. Their stay is 'tolerated' for three to five years, and then they are likely to obtain a regular residence permit. Several informants also pointed to the granting of residence permits to large numbers of Somalis in 1992 in an operation to eliminate backlogs. This explains the sharp rise in applications from Somalis in the same year. According to these same informants, many of the later arrivals came from Germany and other European countries. After hearing about Somalis in The Netherlands obtaining a regular residence permit, they also decided to try their luck. Other Dutch informants suggested that the later arrivals were family members and relatives of the earlier arrivals who were predominantly young males.

* Somalia is not listed in the German asylum statistics. We therefore assumed that Somalis do not constitute a major group of asylum seekers for Germany.

Most of the informants think that deportations in particular may have a deterrent effect. As one of the UK informants put it: 
'If large numbers of people from particular countries are returned, then the message will get back there.'

Another UK informant did not agree, however, and observed that Nigerians keep coming to the UK despite high refusal rates and deportations. The Belgian informants did not think that the special procedures imposed at the Zaventem Airport for asylum seekers arriving in Belgium made the country less attractive: they still arrive but no longer by plane. The introduction of a shortened procedure for manifestly unfounded applications in 1993 nevertheless produced a sharp drop in the number of new arrivals in Belgium. Asylum seekers from Ghana and a number of other countries now run a high risk of being sent back or deported after a short stay in Belgium. ${ }^{12}$

Finally, we asked the informants if they thought that the introduction of a new and more restrictive asylum law in Germany in 1992 made other EU countries more attractive for asylum. The informants in Belgium and The Netherlands indeed thought that those asylum seekers who would previously have filed in Germany were now filing in neighbouring countries: 1993 was a peak year for both Belgium and The Netherlands and, according to the key informants, this was mainly due to the reduced attractiveness of Germany.

Some respondents point out that family reunification policy may also influence the number of asylum applications. When family reunification is made impossible or difficult, family members may be inclined to apply for asylum in order to gain access to the country in question. The result of restricted family reunification can thus be an increase in the number of asylum applications.

To conclude: Some of the measures taken by governments to reduce the number of asylum applications appear to have an effect. The key informants in all three countries nevertheless observed that as all of the EU countries adopted similar measures, the effects on the distribution of asylum seekers across Europe are fairly limited. When there is an effect, moreover, it does tend not to last very long. As one of the Belgian informants put it:

'Now one country is somewhat less restrictive, now another country, but in all countries, there has been a tightening of restrictions.'

\section{Reception facilities and the right to work pending a decision}

Arrangements for the reception and housing of asylum seekers pending the decision on their application vary across countries. Some countries, including the Netherlands, have a system of compulsory residence for

12 See the Box on asylum seekers from Ghana elsewhere in this Chapter. 
asylum seekers in reception centres. In these centres, the asylum seekers receive benefits in kind rather than in cash. The policies with regard to the employment of asylum seekers differ across countries as well. In some countries, asylum seekers have the right to work pending the decision on their application; in other countries, there is a ban on the employment of asylum seekers.

\section{Ghana: Chain migration and econo- mic opportunities}

Rank order of Ghana as country of origin

\begin{tabular}{|l|r|}
\hline EU-12 & 12 \\
\hline Belgium (1988-94) & 5 \\
\hline The Netherlands & 10 \\
\hline United Kingdom & 9 \\
\hline
\end{tabular}

All three countries experienced a relatively large influx of asylum seekers from Ghana, but only for a limited period. In 1987, The Netherlands received over $50 \%$ of the total number of applications filed by Ghanaians in the EU-12 in that year. In 1988-90, the proportion going to The Netherlands remained relatively large and the number going to Belgium increased considerably. In 1990 , a sharp increase in the number of Ghanaian applications in the UK also occurred. In 1994, the influx to Belgium underwent a sharp decrease while the number of applications in the UK remained high.

In The Netherlands and the UK, key informants are inclined to regard chain migration (ties with settled communities in the country of destination) as factor number one. In the UK, historical ties between the country of origin and the country of destination are considered a second almost equally important factor. In The Netherlands, the Dutch asylum policy is seen as the second most important factor. The Belgian informants, in contrast, consider economic opportunities to be the most important pull factor for Ghanaians; travel agents and chain migration are considered somewhat less important.
According to the Dutch informants, many Ghanaians have been attracted by the existing Ghanaian community in Amsterdam. One of the Dutch informants recalls that some of the first Ghanaian asylum seekers belonged to a particular religious sect and claimed potential persecution in Ghana. Others claimed their lives were endangered because of a succession conflict in their tribe. It took the Dutch authorities a long time to make a decision, as they were not accustomed to the handling of applications from Ghana. When some of the applicants received a positive decision, this induced larger numbers of Ghanaians to file applications in The Netherlands. Measures taken by the Dutch authorities can perhaps explain the drop in the numbers since 1990. Ghanaian applications were decided upon extra quickly, and few - if any - received a positive decision.

The Belgian informants think that the first Ghanaian asylum seekers came to Belgium by chance or because of travel agents directing their activities to this country. Belgium proved to be attractive because of the lengthy determination procedure and because the asylum seekers were allowed to work pending a decision. All of the Belgian informants agreed that Belgium is no longer an attractive asylum country for Ghanaians because asylum seekers are no longer allowed to work during the initial stage of the determination procedure (and practically all Ghanaian applications are found to be 'manifestly unfounded' at this stage). Rejected applicants also run a much higher risk of being forcibly returned these days. 
Of the three countries in our research, The Netherlands has the most restrictive policy. Pending the (final) decision on their application, applicants must live in reception centres and are not allowed to work. The UK and Belgium have more liberal policies. In the UK, asylum seekers are not housed in centres. They are free to choose their own place of residence and, when necessary, apply for the same assistance as homeless people. In addition, asylum seekers are generally as a rule allowed to work in the UK after six months. In Belgium, too, asylum seekers have the right to choose their own place of residence ${ }^{13}$ and are not obliged to live in reception centres. In addition, asylum seekers used to have free access to the Belgian labour market. Since October 1993, however, they are only allowed to work when their application has been declared admissible (i.e., not manifestly unfounded).

Most of the informants did not consider reception facilities and the right to housing to be a very important factor. The Dutch and Belgian informants agree that the reception facilities in The Netherlands are better than in Belgium. Several Dutch respondents think that asylum seekers are attracted by the quality of the reception facilities in The Netherlands. One of the informants suggested that most of the people with a Benelux visa prefer to file their applications in The Netherlands rather than in Belgium because of the reception facilities in The Netherlands. The Belgian interviewees suggested, in contrast, that Belgium is attractive precisely because the asylum seekers are not obliged to live in a reception centre. One of the informants observed that, every time he visits a centre, people ask him how long they will have to stay there and when they can have their own house. One of the UK informants suggested that Britain is attractive for refugees for similar reasons:

'not because of what the state does for them, but what it does not: they just let you loose, you can go and live anywhere in the community you want, you can basically work, you can basically study, you can carry on some semblance of a normal life until the decision is reached. You do not get this in other European countries.'

Another UK informant thought that Britain might be perceived as more hospitable than France, for example, but doubted whether asylum seekers generally know anything about the benefits they might receive:

'The majority do not really know what is happening here.'

Reception in centres is presumably attractive during the first period after arrival (it certainly sounds good at home: you will have a room, food and

13 In 1995, however, the Belgian authorities introduced a policy of distributing the asylum seekers across Belgian municipalities. As a consequence, asylum seekers are no longer allowed to settle in some of the larger cities. 
be taken care of). Reception centres are also attractive for particular categories of asylum seekers, including families with children, asylum seekers in need of medical care and so-called 'asylum-tourists.' A Dutch informant tells about asylum seekers from Romania:

'The reason the for introduction of the asylum reception centres [implying an accelerated procedure for manifestly unfounded asylum applications, $\mathrm{AB} / \mathrm{TH}]$ is the problem of Romanian back-packers, the holiday-asylum tourists. They came here and basically said that they had heard that you could stay in a reception centre for a while. Isn't that great? You can imagine... That they no longer come here is obvious. The fact that this is now no longer allowed is known in Romania as well.'

\begin{tabular}{l}
\hline India: Economic opportunities, \\
temples and communities \\
Rank order of India as country of origin \\
\begin{tabular}{|l|r|}
\hline EU-12 & 13 \\
\hline Belgium & 4 \\
\hline The Netherlands & 7 \\
\hline United Kingdom & 16 \\
\hline
\end{tabular}
\end{tabular}

Asylum seekers from India have come in relatively large numbers to Belgium and the UK. In 1993, almost 3,000 Indians applied for asylum in Belgium, which was one third of the total number of applications filed by Indians in the EU-12 in that year. The Netherlands experienced a relatively large influx in 1987-88. Since 1989, however, the proportion of Indians applying for asylum in The Netherlands has been rather small.

The key informants in all three countries of destination think that most of the Indian asylum seekers prefer to go to the UK because of historical ties, the fact that the UK is home to the largest Indian community in Europe and the language. Why has Belgium had such a large share of the total volume of Indian asylum applications? The answers from most of the Belgian informants all point in the same direction: networks and economic opportunities. Many of the Indian asylum seekers in Belgium are Sikhs from The Punjab. It is not exactly clear how and when they started coming to Belgium, but many of them ended up working as harvesting hands in the fruit growing region of Sint Truiden. The story goes that the first Sikh asylum seekers were recruited in Germany by a fruit grower from Sint Truiden with contacts there. Apparently, it was not long before the news spread in Punjab and more and more Sikhs were coming to Sint Truiden.

Most of the informants assume that travel agents also played an important part. One informant claims that 'it was an organised business' with 'brokers' in The Punjab recruiting cheap labour for a group of fruit growers in Belgium. However, informants with inside information tell a somewhat different story. Most of the asylum seekers indeed needed travel agents but these agents only organised the journey. The asylum seekers knew of a Sikh community and a temple in Sint Truiden, and they knew that they would be helped there. The importance of communities and temples is also stressed by one of the key informants in The Netherlands, the president of the International Sikh Youth Federation Holland: 'Sikhs are living in every country in the world. New arrivals, when they have nobody here, will ask for the temple and go there first. Every Sikh will help them, our community is very close.'

After the introduction of a partial employment ban in Belgium at the end of 1993 (asylum seekers are no longer allowed to work until their application has been declared admissible), the number of new arrivals in Belgium dropped sharply. 
To conclude, what is unattractive for some asylum seekers makes reception centres attractive for others. Most informants were inclined to relativise the importance of reception policy. As one of the UK informants put it:

'If somebody has family somewhere else, that person will not go to America because of better standards there. They will say: wherever I go, the most important for me is to be safe and to be with my family. So it is marginal.'

Many of the informants consider the right to work to be an important factor. In their opinion, most of the asylum seekers do not like to live on public support; they prefer access to the labour market. According to one of the UK informants, this is what makes the UK one of the most attractive countries within Europe:

'The state interferes less with the refugee's life here.'

Access to the labour market may also be more important for some nationalities than for others. When asked to explain why Indians tend to go to Belgium and not to The Netherlands, informants in Belgium and The Netherlands answered that work seems to be very important for Sikhs (who seem to account for the majority of Indian asylum applications). According to one of the informants, most of the Sikhs in Belgium first arrived in Germany. As they were not allowed to work there, they went to Belgium. Many of the Belgian informants also observed that the 1993 change of policy in Belgium (asylum seekers are now authorised to work only after their application has been declared admissible) produced a sharp reduction in the flow of asylum seekers from a number of countries and most notably India, Nigeria, Ghana and Romania.

As already mentioned, we asked the informants to rank order the importance of six different factors for a limited number of countries of origin. Asylum policy was one of the factors but generally not considered to be the most important. Asylum policy scored higher in the interviews in The Netherlands than in Belgium and the UK. The Dutch informants ranked asylum policy as number two or three for asylum seekers from Yugoslavia, Romania, Turkey and Ghana. The Belgian informants also considered this factor to be relatively important for asylum seekers from Yugoslavia and Romania; in the case of Yugoslavia, they even regarded it as most important. In the UK, asylum policy was considered to be least important and as number five or six for all of the countries of origin under consideration. 


\section{Economic opportunities}

Many interviewees considered (differences in) economic opportunities an important factor. Access to the labour market in part determines economic opportunities. A ban on employment pending a decision clearly restricts the economic opportunities for asylum seekers. When no employment is available for asylum seekers, however, free access will also be of little use to them. When a large informal labour market exists, conversely, a ban on employment will not bother them very much.

According to the Dutch informants, asylum seekers are not attracted to The Netherlands by economic opportunities. There was a broad consensus that asylum seekers do not have a lot of opportunities in The Netherlands because of the ban on employment, on the one hand, and the lack of a large informal labour sector, on the other hand. The key informants in Belgium and the UK, in contrast, see economic opportunities as a factor explaining why some groups tend to apply for asylum in these countries. The Belgian informants again mentioned the Sikhs who occupied a particular niche in the labour market picking fruit in the region around Sint Truiden for some years. ${ }^{14}$ According to one of the UK informants, certain groups of asylum seekers are also drawn to the UK because of the large informal labour sector there.

A number of the informants nevertheless claim that economic opportunities simply do not play a role in the choice of country of destination. Several UK informants pointed out, for example, that the Nigerians and Somalis who manage to arrive in Western Europe were often used to a rather good life at home. One of the informants added that:

'if people really think about economic situations they would not pick Britain as their first choice: we are in a pretty desperate situation and it is very difficult to find work.'

Economic opportunities are also more generally referred to as an explanation for the high number of asylum seekers in Germany and the fact that many asylum seekers would have preferred (or still prefer) to go to the United States.

Economic opportunity was one of the six factors which the key informants were asked to rank order for importance and found to be somewhat more important than asylum policy, particularly in Belgium. The Belgian informants regarded economic opportunities as factor number one for asylum seekers from Lebanon and Ghana, as factor number two for Romanians, and as factor number three for Sri Lankans. The Dutch informants regarded this factor as factor number one for asylum seekers from Romania, and as factor number three for asylum seekers from Lebanon and

14 See also the Box on asylum seekers from India elsewhere in this Chapter. 
Ghana. In the UK, economic opportunities were considered to be important in the case of Turkey only (factor number two).

\section{Human-rights reputation}

The Dutch informants pointed out that The Netherlands is a small country and less well-known than Germany, France, Britain or Sweden. Many asylum seekers have never heard of The Netherlands or only know of it because of football or its monarchy. Nevertheless, several interviewees think that The Netherlands has a better human-rights reputation than Germany which is sometimes viewed as a racist or xenophobic country. Particularly Africans therefore prefer The Netherlands to Germany. The reputation of The Netherlands as a tolerant country may also attract specific groups from other countries: (Romanian) homosexuals, for example. The Dutch informants only see those asylum seekers who come to The Netherlands and not the larger numbers going to Germany, however.

The Belgian informants also emphasise that Belgium is a small country and less known than the other northern European countries including The Netherlands. According to several informants, Belgium has a rather poor human-rights reputation in Africa because of its colonial past in Zaire and particularly because of what happened shortly before and after independence of Zaire.

The United Kingdom is a much larger country than Belgium and The Netherlands. According to one of the UK informants,

'Britain is considered to be the most superior place, a great nation, a great race of people, they rule everyone and must be a fantastic country."

Another informant says (with regard to Bosnians):

'because of the media film industry, books and magazines, people are more aware of the influence of Britain on their culture than in other countries. But I'm talking of a specific social group, from urban areas.'

As to the country's human-rights reputation, several of the UK informants think Britain has a good reputation in Third World countries. As one informant put it, Britain is

'the mother of liberal democracy, parliamentary democracy and all of those human rights.'

The UK informants also point out that Germany and France have become particularly less attractive as a result of reports of racism and an antirefugee atmosphere in these countries. Britain has become accordingly more attractive, particularly for Africans. As cases in point, one of the informants mentions Algeria and Zaire: 
'Asylum seekers from these countries, whose first language is French, probably would not come to Britain if there were some more tolerant and liberal society in France and Belgium, if these countries would not have grown so racist and anti-foreigner in recent years.'

It is nevertheless possible that this predominantly positive image of the UK is more from the perspective of the key informants than the asylum seekers although many of the key informants are also themselves refugees.

\section{Events during the flight}

In addition to the factors already discussed (existing ties between the country of origin and the country of asylum; image and characteristics of the country of asylum), events during the flight from the country of origin may have an impact on the destination of the journey as well.

\section{Accessibility}

Some countries may be more easy to reach than other countries for a particular asylum seeker. Most of the UK informants stressed the fact that Britain is an island and for that reason less accessible.

'The UK is an island. You have to make a special effort to come here. Other countries are easier to get to.'

'Basically the people just walk over a border and move elsewhere in Europe. (...) I mean, we are an island and it still remains comparatively sewn up at the ports and the carrier's liability act has undoubtedly had a massive impact on these things.'

In line with this, some of the informants in the three countries pointed out that Germany is the first country fit for asylum for people travelling from Eastern Europe or the Middle East. Germany has a long land border. ${ }^{15}$ People travelling by cheap aeroplane to a country in Eastern Europe (former East Germany, Poland, Bulgaria) are likely to end up in Germany.

'Germany is the nearest to go to, that is quite clear. It is the most attractive and closest for Czechs and Hungarians and for Romanians too. Austria is not a country to receive you kindly, that is generally known. Germany is thus the first option and, what is more, a good country when you look at how the people live, how affluent they are. That makes Germany attractive. If people do not ask for asylum in Germany, if they go to The Netherlands, it is often in the last years because of the visible racism in Ger-

15 See the Boxes on asylum seekers from Romania and ex-Yugoslavia elsewhere in this Chapter. 
many. The threatening of foreigners. A general feeling which is luckily far less prominent here in the Netherlands.'

When people have to leave their country, they often go first to a neighbouring country. Iranians go to Turkey; Iraqis go to Jordan, Pakistan or Turkey; Somalis go to Djibouti or Kenya; and Zairians go to Zambia. In the neighbouring country, they then try to arrange the rest of their flight. Asylum seekers from Asian countries may travel via Moscow or Kiev.

For particular groups, our informants felt that direct air routes to the country of asylum were important. Schiphol is an international airport with direct air connections to Sri Lanka and many African countries (for example). It is also a transit airport to Canada and the United States. London has direct air connections to a lot of countries because of trade connections or colonial connections in the past. The Belgian airport $\mathrm{Za}$ ventem has far fewer international flights than the London and Amsterdam airports (but a direct air connection to Zaire). The importance of direct air connections is nevertheless limited by the fact that many asylum seekers start by crossing the border to a neighbouring country either by foot, by car, by bus, by train or by boat.

Just how easy a country is to reach also depends on the availability of visas and other travel documents and the checks at the borders for undocumented travellers.

The Belgian informants considered the accessibility of Belgium for Romanians to be the most important factor on their seeking asylum there. Both the Dutch and Belgian informants saw it as the second most important factor for asylum seekers from former Yugoslavia. The Belgian informants also considered accessibility to be the second most important for asylum seekers from Turkey. The Dutch informants considered accessibility to be the third mist important factor for asylum seekers from Romania, Turkey and Sri Lanka. For the other countries of origin, the accessibility of The Netherlands or Belgium was not seen as important. The British informants did not consider this factor to be important for any of the asylum seekers going to the UK.

\section{Chance}

In the opinion of most of the informants, chance is an important factor. An asylum seeker may arrive in a European country purely by chance. Travel documents may have been available for that country at the time or a plane for this destination could be boarded. A specific type of asylum is one who ended up here simply because he was not allowed to travel any further (due to false or missing travel documents). Many asylum seekers who want to go to Canada or the United States are stopped at either the Schiphol, Zaventem or London airports because they do not possess the required documents or visas. The only thing they can do then is ask for asylum in The Netherlands, Belgium or the United Kingdom. 
In some cases, the travel agent in the country of origin promised to get the asylum seeker to Canada but they end up somewhere else.

\section{Iran: Travel agents}

Rank order of Iran as country of origin

\begin{tabular}{|l|r|}
\hline EU-12 & 6 \\
\hline Belgium & 16 \\
\hline The Netherlands & 3 \\
\hline United Kingdom & 13 \\
\hline
\end{tabular}

The proportion of Iranians applying for asylum in The Netherlands has steadily increased. Up until 1989, The Netherlands received less than $10 \%$ of the total number of Iranian applications filed in the EU. In 1993, this proportion was over $40 \%$; in 1994 , it was almost $60 \%$. Belgium and the UK have received relatively small numbers of Iranian asylum seekers.

The informants in the UK draw attention to the role of travel agents. Iranian asylum seekers do not have much choice. They may prefer to come to the UK because of the language or relatives there; if the UK is not possible, however, they are satisfied with any other West European country. In contrast, the experience of several Belgian informants is that Iranian asylum seekers are mostly well informed and do not want to go to just any European country. If possible, they avoid Belgium. Most of them prefer the UK although that country is very difficult to enter.

Why does The Netherlands have such a large share of the total volume of Irani- an applications? The answers of the Dutch informants vary. Some informants point out that The Netherlands invited quite a number of Iranian refugees. This then induced other Iranians to seek asylum in The Netherlands as well. Others agree that in the last few years, the presence of Iranians already living in The Netherlands has become an important pull factor: many new arrivals have relatives here. However, they also draw attention to a number of other factors. Several informants point out that quite a number of Iranians end up in The Netherlands by chance. They were on their way to Canada but stopped during transit at Schiphol Airport. (One of the informants in the UK, reports many Iranians to be caught at the airports there as well.) Several other informants stress the role of travel agents. Every Iranian asylum seeker needs a travel agent, and these agents often determine their destination. According to one informant, many Iranians end up in The Netherlands because this is the cheapest destination. The prices demanded for Canada, the UK and other English-speaking countries which tend to be preferred by many Iranians are much higher. Finally, several informants think that The Netherlands has become more attractive in the past few years as a result of developments in Germany (new asylum law, assaults on asylum seekers).

\section{Travel agents}

The people whom we interviewed did not agree on the importance of travel agents in deciding the country of asylum. According to some, travel agents are by far the most important factor. ${ }^{16}$ For instance, a Sri Lankan social worker in the UK observed that:

'The most immediate reason as to why people come here or to any other European country is the relationship between the amount of danger they face and what their

16 For the influence of travel agents compare the Boxes on asylum seekers from Sri Lanka and Iran elsewhere in this Chapter. 
travel agent can do for them. That is the most overwhelming factor: which travel agent can get you out quickest and to where. This I have seen to be the most crucial issue in determining where a person goes.'

'In Iran you could get a complete package for about 6000 Dutch guilders, which includes the hike through the mountains to Turkey and the journey in Turkey to Istanbul where a package with your travel documents and an air ticket to a Western-European country lay ready. You could not choose, so in Iran you could not say 'I want to go to ...', that was too difficult. You went to whatever country was in stock, a Western country. Such an all-in package was $f 6000$,- at the time.'

According to other informants asylum seekers can make some choices even when they need the assistance of a travel agent.

'Interviewer: The travel agent chooses to send an asylum seeker to The Netherlands...? Informant: No, that is the choice of the asylum seeker himself.

Interviewer: That is the choice of the asylum seeker himself, he can choose from the menu of the travel agent?

Informant: He can say where he wants to go to, and together with the price...

Interviewer: Is The Netherlands expensive then?

Informant: It is the last country of the journey. If you start in Russia, you then have Poland, Czechoslovakia, East Germany, West Germany, and every time you are transferred to another travel agent... that costs more.'

The activities of the travel agent clearly vary. They may involve the complete organisation of an escorted flight from the country of origin to the country of asylum, or they may involve a single issue such as the selling of travel documents, guiding someone across a border or bribing an official to get someone out of the country. A Dutch informant describes a network helping refugees:

'Think of a network. An Ali in Iran knows a Hassan in Turkey; for the rest he knows no-one. Hassan in Turkey knows for instance a Yugoslav who helps them through Bosnia and he in turn knows a German in France and a Mark in Amsterdam. But they know of each other's existence. There is an invisible hand which can organise it all, a giant organiser.'

A Belgian informant distinguishes between helping a friend that is, using a network of friends based on solidarity), help crossing the border (that is, local people paid to get you across the border) and frontier-running organisations (that is, Mafia-like organisations which cover the complete flight). 17

Asylum seekers from Africa and Asia are generally said to make use of travel agents. Asylum seekers from European countries, in contrast, are said not to need the help of a travel agent.

17 The informant called these: 'vriendendiensten', 'passeurs' and 'traffikanten'. 
Sri Lanka: Existing communities and travel agents

Rank order of Sri Lanka as country of origin

\begin{tabular}{|l|r|}
\hline EU-12 & 5 \\
\hline Belgium & 21 \\
\hline The Netherlands & 4 \\
\hline United Kingdom & 1 \\
\hline
\end{tabular}

Just as Somalis, Sri Lankans have come in relatively large numbers to the UK and The Netherlands while the proportion of Sri Lankan applicants in Belgium has been rather small. Particularly in the years 1990-94, the UK and The Netherlands had a large share of the total volume of Sri Lankan asylum seekers in the EU-12. In The Netherlands, these peak years also followed a four-year period (1986-89) of relatively low numbers of Sri Lankan asylum seekers.

The Dutch informants regard travel agents as factor number one. One informant recalls how, in 1984, several thousand of Sri Lankan Tamils arrived in The Netherlands within a few weeks. Without intermediaries, this would not have been possible. Just why the intermediaries suddenly focussed their attention on The Netherlands, is not clear. Some of the Dutch informants assume the availability of direct (KLM) flights from Colombo to Amsterdam to be an important factor. Others do not agree, pointing out that the first group of Tamils did not arrive in The Netherlands by direct flight but via East Berlin. In 1985, the Dutch authorities introduced special reception facilities designed to make The Netherlands a less attractive destination for Tamil asylum seekers. Tamils no longer received so- cial welfare benefits and were housed in small towns or rural areas rather than in major cities. This may well explain the drop in the number of applications in 1986. An alternative explanation suggested by Bronkhorst (1990: 77), however, is that the recognition rates in France and the UK had become much higher than in The Netherlands.

To explain the increased influx of asylum seekers from Sri Lanka in 1990-94, several informants refer to family ties. Many new arrivals came to The Netherlands in these years because of relatives there. Most of the Dutch informants think that The Netherlands is otherwise not an attractive asylum country for $\mathrm{Ta}$ mils. Several informants pointed out that many of the Tamil asylum seekers actually move on to other countries (e.g., Switzerland) where there is a large Tamil community and they have better chances of finding employment. One informant observed that some Tamil asylum seekers intended go to Canada but were stopped at Schiphol Airport.

The UK informants also assume travel agents to play an important role. According to one informant, the Sri Lankan agents appear to be very well organised. Historical ties and the existence of settled communities are nevertheless considered more important. Several informants pointed out that the British poicy with regard to Tamil asylum seekers has also been important in a way. While only a few Tamils have obtained full refugee status, many of the rejected asylum seekers have been given an exceptional leave to remain. This means that they are not entitled to family reunion and that the only way to join their family in the UK for them is by applying for asylum there as well.

As one informant observed:

'it depends on the country they come from and on the countries they have to cross.'

The overall opinion of the informants is that travel agents have become more and more important over time. As a result of all kinds of measures 
by Western states to control immigration, it has become harder for a refugee to get to Europe without the help of others. This help has also become more professional in order to cope with the various difficulties. As one Belgian informant explained:

'It is stimulated indirectly by the government. An example. We refuse to give visas. That means visas are falsified. A Belgian visa in Kinshasa contains a hologram. You cannot carve that out of a potato. In order to falsify it, you need serious equipment and thus serious investment. Who can do this? Well-organised organisations such as the Mafia.'

When asked to rank order the importance of six factors, the Dutch informants considered travel agents to be most important for asylum seekers from Lebanon and Sri Lanka. The Belgian informants considered traffickers to be similarly important for asylum seekers coming from Sri Lanka. For asylum seekers from India and Ghana, they they considered travel agents to be the second most important. According to the UK informants, the presence of compatriots and historical/cultural ties with the UK are more important than travel agents for asylum seekers coming from both Sri Lanka and Ghana. Travel agents are considered least important by the Dutch and Belgium informants for asylum seekers from former Yugoslavia and Romania and also, according to the Belgian informants, for asylum seekers from Turkey and Zaire.

\section{Conclusion}

The results of the interviews draw attention to several factors. Almost all of the key informants consider the existence of an already established community in the country of destination or acquaintance with someone in that country to be of critical importance. The interviews corroborate the findings from the analyses of the statistics in the previous chapter which showed former colonial links and to a lesser extent language to explain some of the patterns of destination for asylum seekers. Such ties were found to have greater explanatory value for the arrival of asylum seekers in the United Kingdom than in Belgium and little or no explanatory value for The Netherlands.

In accordance with our expectations, it appears that no single factor or even a single group of factors is responsible for the destination of asylum movements. The factor considered most important for asylum seekers varies for the different countries of origin. Some of our informants also distinguished different types of asylum seekers or those coming first from a particular region and those following.

The interviews in the three countries revealed some clear differences. In the interviews in the United Kingdom, general consensus was express- 
ed on colonial ties, already established communities of compatriots and the English language as the most important reasons for asylum seekers to come the UK. Most of the UK informants do not believe that asylum seekers have much or any choice. Nevertheless, only one UK informant noted that asylum seekers (from Nigeria) would prefer to be in another country.

In the interviews in Belgium, the role of economic opportunities and the availability of work were far more frequently stressed than in the interviews in the other countries. Economic opportunities for asylum seekers in Belgium are particularly mentioned in relation to countries of origin with a disproportionately large representation in Belgium. According to the Belgian informants, social networks are also very important as many asylum seekers go to Belgium because of family ties.

In the interviews in The Netherlands, the factors considered most important widely varied across the countries of origin. Chance and the role of travel agents were considered most important for some groups; knowing someone in The Netherlands was considered most important for other groups. The Dutch informants generally considered the asylum policy of their country to be more important than the Belgian and British informants.

The effects of some factors on the country of destination are rather complicated and can be illustrated by the impact of colonial ties. Former colonial ties certainly influence the destinations of asylum seekers. Asylum seekers typically go to the former motherland. Other asylum seekers may nevertheless avoid the former motherland because they simply do not feel safe there. The former colonial tie between the country of origin and a particular country of destination usually implies friendly political relations. This need not be the case, however. Zairians frequently do not want to go to Belgium and arrive in The Netherlands or the United Kingdom instead. Looking at the statistics, moreover, we see a larger number of Zairian asylum seekers going to Belgium, which suggests that both positive and negative relations may never completely determine the pattern of destination. ${ }^{18} \mathrm{~A}$ former colonial tie means that some asylum seekers may go to the former mother country while others go elsewhere and some asylum seekers may even try to avoid the former mother country.

18 A large number of Zairian asylum seekers also go to France. Key informants considered France attractive for Zairians because of the French language. It is also said, however, that many Zairians do not feel safe in France either. 


$$
+
$$




\section{Chapter 5}

\section{Conclusion}

In this concluding chapter we will attempt to answer the central questions in this study. In doing this, three sources of information will be relied upon: existing literature, statistics on asylum applications in European Union countries provided by EUROSTAT and interviews with key informants in The Netherlands, Belgium and the United Kingdom. ${ }^{1}$

In the first section below, we will consider the question of the extent to which the country of destination appears to be the choice of the asylum seeker. The second, third and fourth sections will provide an answer to the question of how important the three distinguished groups of factors are in explaining the patterns of destination for asylum seekers. In the second section, the various linkages between the country of origin and the country of asylum will be considered. In the third section, the possible impact of the characteristics of the country of destination and the image asylum seekers have of that country will be considered. In the fourth section, the impact of events during the flight will be considered. In the end, we will attempt to draw some general conclusions with regard to which factors are most important under which conditions. Finally, some remarks on the implications of our study for policy and ongoing political discussions will be made.

\section{Country of asylum by choice or by chance?}

In the majority of cases, the choice of country for asylum is not a conscious, rational choice by the asylum seeker and certainly not based on a comparison of the advantages and disadvantages of various options. Occasionally, an asylum seeker does make a choice and decides on a particular country of destination. Certain (groups of) asylum seekers appear to have a preference for Canada or the United States, or for an Englishspeaking country. Worldwide, these countries appear to be where most asylum seekers dream of, if they dare to dream at all. Barsky (1995) elaborates on Canada as a favoured country for asylum seekers from the former Soviet Union because of the American dream.

1 See Chapter 1 for an outline of the study. 
The choice of a particular country of destination is often a choice to join a family member, friend or acquaintance and not for the country itself. An asylum seeker goes to Germany because his brother happens to be in Germany and not because he has a preference for Germany.

Asylum seekers do not have much choice. They decided to flee and decided to head to Europe or North America but the particular country does not particularly matter to many of them. The country of destination is often accidental for asylum seekers. In an unknown but probably large number of cases, moreover, someone else makes the decision. This can be a travel agent organising (part of) the trip or the person an asylum seeker relied on for information and advice. Under the circumstances, only certain travel connections and documents may be available. Rumours may also circulate suggesting a particular place. According to our key informants, most asylum seekers know little or nothing about the country in which they apply for asylum. Some people may also initially have little choice and later more choice during their stay in a transit country.

The finding that many asylum seekers do not deliberately choose the country of destination is in accordance with the conclusions of two Dutch studies based on the files of asylum applications and interviews with asylum seekers and a Canadian study based on interviews with asylum seekers (Doornhein and Dijkhoff 1995; Hulshof c.s. 1992; Barsky 1994, 1995). ${ }^{2}$

It is often remarked that the arrival of an asylum seeker in the Netherlands or any other country is accidental. This appears to be true from the perspective of the individual asylum seeker only, however. From a sociological perspective, this arrival is not so accidental and often fits in a particular pattern. This pattern can be explained by access to visas, travel connections, the decisions of travel agents, the existence of incidental contacts, border checks and the general flow of information. Put differently: Asylum seekers are dependent on certain fortuitous circumstances and these circumstances are structured by more general circumstances or opportunities which are not at all random.

The motives important for the individual asylum seeker at the microlevel are related to explanatory factors at the macro-level. Individual motives may be phrased differently than general factors but nevertheless related to such macro-level factors. For example, the various ties between countries are not, as such, a motive for an asylum seeker to go to that particular country. These ties may nevertheless shape the asylum seeker's motives indirectly. Take the former colonial bond between a country of origin and a country of asylum. Most asylum seekers do not go to the former mother country because of this colonial bond while others do and

2 See Chapter 2 for a brief description of these studies and their conclusions. 
claim a moral right to be there and be cared for. Most of the asylum seekers who actually go to the former mother country have other motives for doing so. They go there because there is a settled community of compatriots or because the language and culture are familiar or because frequent and regular transportation is available or simply because they know the country. These motives are all related to the former colonial link between the two countries.

\section{Links between the country of origin and country of destination}

\section{Three important links}

Three interconnected factors appear to be very important for explaining the patterns of destination for asylum seekers: existing communities of compatriots, colonial bonds and knowledge of the language.

Both our interviews and our analyses of the statistics with regard to asylum applications showed colonial links and to a lesser extent language to be important determinants of the destinations of asylum seekers. This combination of factors was more applicalabe in the United Kingdom than in Belgium and hardly applicable in The Netherlands. The interviews then drew particular attention to the significance of existing immigrant communities and personal acquaintances in the country of destination.

Just as labour migration, the migration of asylum seekers shows a pattern of chain migration. Asylum seekers try to go to a person they know (family, village). In organising their journey, they (or their helpers) make extensive use of friendship and kinship networks. The initial group of asylum seekers often just happens to have arrived in a particular country. When they are found to be successful, others will follow in order to join their families or because they used the same networks and routes and sometimes even the same passports.

Examples of well-established immigrant communities include those from former colonies (e.g., Somalis and Pakistanis in the United Kingdom, Algerians in France, Zairese in Belgium) or guest workers and other labour migrants from the past (Turks in Germany and The Netherlands, Yugoslavs in Germany). The recent arrival of asylum seekers can also be expected to result in chain migration. An example is the Sikhs in Belgium. In this case, the chain migration is limited to a specific region in the country of origin (India) and in the country of destination (Sint Truiden). Such migration is probably much more often the case than we know, but the relatively small number of asylum seekers involved in each instance makes an overall pattern in the general statistics difficult to discern. In the interviews, however, the presence of relatives or acquaintances in the country of destination was frequently mentioned. If the unit of analysis had been the region or clan instead of country of ori- 
gin, the effects of existing communities and chain migration would certainly have been more visible.

The patterns of asylum migration sometimes parallel those of labour migration because asylum seekers may use informal contacts with labour migrants during their flight and asylum seekers typically want to work in the country of destination. In public debates on asylum policy, the above facts are sometimes used to suggest that such asylum seekers are economic refugees and thus not real asylum seekers. It should be stressed, however, that these facts do not exclude a serious fear of persecution in the country of origin or an urgent need for protection.

\section{Political relations}

The political relationship between the governments of the country of origin and the country of asylum is not of particular importance in most cases. Sometimes it can be important, but often then for only part of the asylum seekers from that particular country of origin (see Zaire). This political relationship is presumably important when the country of origin has a powerful secret service also operating abroad and when a potential country of asylum is also part of the conflict in the country of origin causing a person to flee (an ally to a party in a civil war, for instance). In these cases, asylum seekers will prefer to go to another country.

Another type of political tie, the presence of representatives of the political opposition from the country of origin in the country of destination, plays a role in exceptional cases only. Some of the informants mentioned this for South Africans, Kurds, Northern Somalis, Nigerians and Ghanaians. We can expect this to be the case for asylum seekers of the activist-type (as distinguished by Zolberg c.s., 1989). Activists are probably only a small proportion of all asylum seekers, but many of the asylum seekers from a particular country of origin may be activists.

\section{Minimal importance of religion, cultural exchange and trade}

Religious ties appear to be unimportant. In a few exceptional cases only, the existence of a church or a priest from the same denomination as in the country of origin is reported as attractive. In such cases, however, a community also already exists in the country of destination and may very well be more important than the religious ties themselves. When explicitly asked, some of the key informants thought religious ties might be additionally important for Sikhs in Sint Truiden (Belgium) and in Amsterdam (The Netherlands), for Syrian-Orthodox-Christians in The Netherlands and for Ghanaians in Amsterdam.

When not associated with colonial and historical ties, cultural relations between the country of origin and the country of destination may be found to be important in individual cases. (Former) foreign students in 
particular may go to the country where they received their education for rather obvious reasons.

Trade contacts and the contacts of asylum seekers with Western visitors (development-aid projects, mission work, tourism) seem to be important in only a few exceptional cases.

\section{Characteristics and image of the countries of destination}

Asylum seekers prefer to go to countries which respect human rights, offer safety and provide a certain degree of wealth. Such considerations do not, however, differentiate much between West European asylum countries. They appear to determine, rather, the choice of Western or Northern Europe or North America. The characteristics of the country of asylum and the image which asylum seekers have of that country are not very important for explaining the general pattern of destination for asylum seekers within Western Europe. Such considerations nevertheless appear to be important for certain specific patterns. For example, when a country of asylum has a special policy with regard to asylum seekers from a particular country of origin. The characteristics of the country of asylum and the image which asylum seekers have of that country may be important for explaining changes in existing patterns. The links described in the previous section, in contrast, are rather permanent, do not disappear easily and cannot thus explain changing patterns of asylum. However, the arrival of asylum seekers from a particular country of origin can result in the establishment of a migrant community, and new links can arise.

\section{Rumours}

No single factor is responsible for the patterns of asylum movement. Asylum movements can be capricious and unexpected. One reason for this is that most asylum seekers are not well informed with regard to possible countries of asylum and are not travelling in accordance with a pre-arranged itinerary to a fixed destination which makes them very sensitive to rumours. A rumour that Somalis can get a residence permit in The Netherlands may spread through Europe, for instance, and induce a lot of Somalis to travel to The Netherlands to try their luck there. Conversely, the death of a Zairian asylum seeker at the Brussels airport can easily stop new asylum seekers from coming, at least temporarily. A rumour can cause asylum seekers to travel suddenly from one European country to another; a rumour can also cause people already on the run to direct their journeys to an alternative destination. The effecst of rumours are nevertheless hard to establish because one first needs to hear the rumours. It is often not the asylum policy as such but rumours about the 
policy that lead asylum seekers to go to a particular country of destination. The rumours about asylum policy can be partly true but also totally wrong. ${ }^{3}$

Compatriots living in European countries may also be a source of information for those still at home or under way. In the interviews, it was generally acknowledged that the stories that go home are often much more sunny than the reality. The same has been said with regard to labour migrants. No one wants to be a loser or to have failed. Even when negative stories about life in a country of destination reach people back in the country of origin, they may not be believed or impressive enough to keep people from trying to go there themselves. Despite all the problems which an asylum seeker may face in a European asylum country, he will have food and need not fear for his life.

\section{Democratic image}

The image of a country as democratic, tolerant and so forth is mentioned by many asylum seekers and thus seems to be a reason for requesting asylum in that country. Most of the Western European countries covered in this study do not differ in this respect, however, and many of the informants thought that this kind of statement was mere politeness on the part of the asylum seekers. In addition to a positive economic situation and the perspective of safety, a democratic image may nevertheless play a role in the decision to go to Western Europe or North America.

This finding is somewhat contradictory to the results of Barsky (1995). Barsky stresses the role of the American Dream and other idealised images in the decisions of asylum seekers from particularly the former Soviet Union to go to Canada. Canada and perhaps the United States should probably be compared to Europe and not a particular country, however. As Barsky (1994: 307) observes:

'with a very small number of exceptions, each claimant who actually made a choice simply chose Canada. The choice of Québec was related to either airline or overland routes, levels of acceptance, or availability of tickets.'

The difference is also partly due to the country of origin, the former Soviet Union. In the report of his complete study, Barsky (1994) shows that the image of Canada was not at all important for asylum seekers from Peru and Pakistan. Finally, Barsky is particularly interested in the specific manner in which refugees and asylum seekers relate their stories and reconstruct their past, which may also influence the results of such research.

3 Cf. Hovy (1993: 225) who concludes that ad hoc reasons, including unconfirmed reports about a country's lenient admission policy, should not be dismissed as factors influencing the process of asylum migration. 


\section{Asylum policy}

The asylum policy and reception of asylum seekers in the country of destination also does not appear to be a dominant factor in explaining the patterns of destination for asylum seekers. Just as for political ties, the asylum policy of some countries of destination may be very important at times. When there are special policies in favour of asylum seekers from a particular country of origin, we can expect a disproportionately high number of applications from this country. For instance, when the Dutch immigration authorities decided to grant a large number of Somali asylum seekers permission to stay in The Netherlands, many more Somali asylum seekers arrived in The Netherlands.

German asylum policy was very open for East Europeans. Up until 1987, they were allowed to remain in Germany even when their applications had been rejected and were allowed to work even when an employment ban for asylum seekers from other countries existed. Germany thus received large numbers of asylum seekers from Eastern Europe. When Germany changed this favourable treatment, regarded many East European countries as safe countries of origin, introduced an accelerated asylum procedure and implemented other restrictive measures, the number of asylum seekers from these countries dropped dramatically.

The fact that asylum seekers are allowed to work in Belgium probably caused such categories of asylum seekers as the Sikhs to go to Belgium. The moment Belgium prohibited asylum seekers from working, however, the number of Indian asylum seekers dropped.

Visa policy appears to be more important than asylum policy. In cases of a very restricted choice, the absence of a visa requirement or the availability of a visa may determine the destination of asylum seekers. The available visa may be a real visa due, for instance, to a liberal ambassador as in the case of the Dutch Ambassador to Romania at the time of the fall of the communist regime. The available visa may also be an irregularly issued (by a corrupt official) or a forged one. The introduction of a visa requirement generally has only a temporary effect in part because other countries often implement visa requirements as well.

Clear conclusions with regard to the impact of asylum and visa policies on the destinations of asylum seekers were difficult to draw. First, asylum policy often consists of a complex of different measures with different target groups, different dates of introduction and many changes in a short period of time. We quite often thought that we had reached a conclusion but had to revise the conclusion after checking it with the statistics and information from the interviews. For instance in 1989, Germany introduced an accelerated asylum procedure for asylum seekers from Poland. The number of Polish asylum applications dropped from 26,000 in 1989 to 10,000 in 1990, which suggested that this decline could be attributed to the accelerated procedure. Comparison showed the same 
measure to have been applied to asylum seekers from Turkey and Yugoslavia around that time but no drop in the number of asylum seekers from these countries, which suggests that an accelerated asylum procedure may be an important but not sufficient reason for a drop in asylum applications.

Second, it is hard to establish the effect of a particular measure on the patterns of destination within Europe because the major countries of asylum tend to introduce the same types of measures shortly after each other.

\section{Economic opportunities}

The analyses of the statistics showed that asylum seekers tend to go to the richest countries. This suggests that asylum seekers go to that country which offers the best economic opportunities for their future. Only partial support for this conclusion could be found, however. The research available in the literature suggests that economic opportunities are not very important. Our interviews suggest that such economic considerations may be important for specific groups of asylum seekers, including Sikhs, Romanians, Poles, Tamils and Ghanaians. These groups are often referred to as labour migrants in disguise. The demographic characteristics of these groups resemble those of traditional labour migrants who are typically single, young males. ${ }^{4}$ This does not imply that these groups are not real refugees or that they did not flee their country out of fear of severe persecution.

The situation of civil war in such countries or regions of origin as Sri Lanka, Somalia and Punjab makes the position of young men particularly difficult. They often find themselves caught between the devil and the deep blue sea. They either have to join the army of the government or the army of the opposition and joining one or the other party may give rise to the need to flee. We can only speculate on the reasons why groups of asylum seekers consisting of single men are attracted by opportunities to work in a particular country of destination. Perhaps they have families in need of financial support which makes work and an income abroad more urgent. Perhaps asylum seekers with a wife and children are less mobile and have other priorities such as housing and medical care.

In sum, it is not so much the characteristics of the countries of destination as the situation of the asylum seekers or the circumstances of the flight which appear to determine the destination of the asylum seeker's flight.

4 After some time, many of them may try to get their families to Europe. 


\section{Events during the flight}

\section{Geographical situation: Germany and the United Kingdom}

Asylum seekers from European countries such as former Yugoslavia, Romania and Poland tend to go to Germany. The same is true to a lesser extent for asylum seekers from Turkey. The explanation for this pattern is probably multifold. Asylum seekers from these countries travel over land. Germany is the first Western European country on the journey West to receive asylum seekers in a neutral or positive manner. For other asylum seekers, Austria may be easier to reach. Austria indeed receives large numbers of asylum applications from East Europeans but is also traditionally a transit country for asylum seekers from Eastern Europe (Fassman and Münz 1995:35-37).

Germany is not only geographically proximate but also attractive for East Europeans because of its affluence, employment opportunities, cultural affinity and political attitude which has been open and welcoming to East Europeans and asylum seekers from Eastern Europe in the past. For most of these European countries of origin, a (significant) immigration community does not already exist in a European or Western country. In the case of Yugoslavia, there are immigrant communities in several Western European countries but by far the largest community exists in Germany. The only major point making Germany less attractive recently, has been the xenophobe attitudes and concomitant lack of hospitality for asylum seekers. East Europeans are not the main target of these attitudes, however, Africans and Asians are. German asylum policy also became more restrictive since the end of the 1980 s although the same is true of other possible countries of asylum in Europe.

Unlike Germany, the United Kingdom is not easily accessible for East Europeans and asylum seekers in general because Britain is an island.

Asylum seekers from countries far away from Western Europe do not normally travel by land these days, which means that at least an important part of the journey is by plane or by boat. Other factors may thus be more important than geographical proximity. Entering a European country by air or by sea is more complicated than by land and often the help of a travel agent will be needed. The impact of geographical proximity may have been more significant if we had not limited our analysis to European countries of destination and in particular Northwestern European countries. Countries of first refuge in Africa and Asia have been excluded, for example. Similarly, North America, Scandinavia and Southern Europe have also been excluded.

Barsky (1994: 305) concludes that asylum seekers from Peru do not go to Canada because of geographical proximity and simple itineraries. Most of the asylum seekers travelled along complex routes because they were forced to rely upon Aeroflot as the principal means of transportation. In 
an era when many airline companies were carefully checking travel documents, Aeroflot planes were the most easy to secure passage on.

\section{Travel agents}

For a large but unknown number of asylum seekers, the country of destination is decided or highly influenced by travel agents. These can be people or organisations with either idealistic or commercial objectives. The choices travel agents make with regard to the country of destination are largely influenced by the same factors as the choices made by individual asylum seekers.

The existence of colonial or other historical links can make travelling easier because of existing networks, transportation, favoured treatment by immigration authorities, knowledge of the language and familiarity with the culture and organisation of the society. This is particularly the case when the travel agent has the same nationality as the asylum seeker. For the travel agent, accessibility, availability of required travel documents, air routes and border checks are also important. It may, in addition, be important for the travel agent that asylum seekers will not be sent back, as this could be bad for future business. Travel agents often specialise in a particular country of destination. For the travel agent, it is not important that the asylum seekers know somebody in a particular country.

Many asylum seekers from Asian and African countries come to Europe with the assistance of a travel agent. It is almost impossible to flee from a lot of countries of origin without some assistance in getting travel documents and tickets or bribing someone at the border or for an aeroplane to get out. Africans are often said to rely on networks of kinship, friends, political sympathisers, tribe and village. In contrast, asylum seekers from Asia and in particular Southern and Eastern Asia are said to more frequently use commercial organisations specialised in smuggling people out and in.

\section{Chance}

Quite a few asylum seekers arrive in the country of asylum simply by chance. They have not consciously decided where to go but in most of these cases the destination can be explained by such factors as border checks, transportation connections, immigration policy and the like. From the perspective of the individual asylum seeker, the impact of chance is fairly high; from a general sociological perspective, the impact is more limited.

The above conclusion is unfortunately not based on the results of our analyses of the statistical data. In our analyses, only a small amount of the variation in the statistics could be explained. Moreover, it was impossible to collect all of the quantitative data we needed. Certain informa- 
tion was not available at all or only for some countries of destination, some countries of origin and some years.

\section{Some closing theoretical considerations}

The destination of an asylum seeker is mainly influenced by the available possibilities. Even if an asylum seeker has a preferred country of destination, it is not always possible to go there from the country of origin and many things can happen to an asylum seeker on his or her way to that destination.

Which factors are most important depends on how much choice the asylum seekers have in their flight. We agree with Johansson (1990) that a distinction should be made between anticipatory refugee movements and acute refugee movements. This applies to the decision to flee and also, we assume, to where to flee. Just how much choice an asylum seeker will have, can be expected to depend on the answers to the following questions:

1. Is the flight acute and unanticipated? How much time and opportunity is there to prepare the flight?

2. Does the asylum seeker have information on the available options (how to organise his flight, where to go) or is this type of information simply unavailable to the asylum seeker?

3. How much money can the asylum seeker spend on his flight?

4. Is it possible to go to alternative countries? Does a choice of countries exist?

The more acute the situation, the less anticipated the flight, the less information on possible options, the less money the fewer the options means more importance for factors related to accessibility. These are: transport facilities; visa requirements; possibilities to obtain a (falsified) visa; prices of tickets, documents and other necessary services; checks at the borders; the possibilities offered by travel agents; geographical proximity; rumours and other elements of chance.

The less acute the situation, the more anticipated the flight, the more information on possible options, the more money and the greater the options mean more importance for factors related to the ties between the country of origin and the country of asylum. The main factors among these will be the existence of a settled community of compatriots in a country; friends, family or other people living in a country; colonial or other historical ties; familiar language; and political ties between the countries. These factors will be more important under such circumstances than factors related to accessibility. 
For a specific group of asylum seekers in a situation with a considerable degree of choice, it is not so much the ties between the countries but economic opportunities which may be decisive. These asylum seekers go to a country where they expect to be able to quickly work. This depends on the labour market, whether asylum seekers are allowed to work or not and the opportunities for illegal work. In the interviews, the key informants mentioned Romanians, Poles, Sikhs and Ghanaians) in particular and the demographic category of young, single males often sent by their families.

The distinction between acute and anticipated flights is more of a continuum than sharp. Many people at first flee to a neighbouring country and, from there, go to Europe. In the neighbouring country, the situation may be far less urgent; there may be more time to make arrangements. Common places of transit include Djibouti, Cyprus, Amman, Beirut, Istanbul, Moscow, Kiev and Karachi. Once again, however, people may get stuck in refugee camps or other places of transit. Although they may have made up their minds and prefer a country of destination, many may very well end up elsewhere as a result of jumping at any opportunity to get to Europe or North America.

\section{Some final remarks on policy}

The picture which emerges from this study is rather complex. No single or even restricted number of factors can explain the patterns of origin and destination discerned here. Some factors are generally not important but may nevertheless be very important for asylum seekers from a particular country of origin going to a particular country of destination at a particular time.

Many of the factors distinguished in this study cannot be influenced by the authorities. It is impossible to change the colonial history of a country. It is very difficult to change the presence of communities of migrants in a country of destination or the familiarity of a particular language.

Asylum policies and visa policies are more open to change. In political discussions, asylum policy is typically perceived as an instrument to reduce the influx of asylum seekers. Our study has shown the impact of asylum policy to be rather limited in the long run. Restrictive measures simply produce a shift in the destinations of asylum movements. Even then, these shifts may only occur for specific groups of asylum seekers and be very temporary. For example, some groups of asylum seekers are attracted to a specific country by the opportunities for work. Making it hard for asylum seekers to work during the asylum procedure may nevertheless not stop them from coming, as the case of The Netherlands demonstrates. Increased recognition rates may be important under particular 
circumstances and attract more asylum seekers from the same country of origin, as proved to be the case with Somalis in The Netherlands. In contrast, however, a low recognition rate does not guarantee a drop in the number of asylum applications.

The preceding considerations suggest that extreme care should be taken with measures introduced for the sole purpose of reducing the number of asylum applications. If European countries should succeed in becoming a real fortress, it will become more difficult for people seeking refuge to enter Europe. At the extreme, only rich people will be able to buy their way out of danger, which is clearly opposed to the ideals of the 1951 Refugee Convention. The asylum policy of the countries in Western Europe and associated visa requirements for major countries of origin, border controls, carrier liabilities, pre-flight checks have already played asylum seekers into the hands of travel agents and middlemen. Over time, it will become more difficult to leave your country and enter the Western world to apply for asylum.

Many asylum seekers do not make a consious choice for a particular country of refuge. They simply do not have the opportunity to make such a choice. They happen to end up in some country at the end of a long and insecure trip.

These observations open up a new perspective on the discussion of burden sharing and the desire to distribute asylum seekers evenly across the countries of the European Union. Whilst many asylum seekers do not have a clear preference for one European country over another, others have a definite preference. It is very important for them to go to that country where they have relatives, friends or compatriots. Otherwise they will feel lost. Someone familiar who talks their own language and knows the conditions at home can be very helpful and provide tremendous support. For the remainder of the asylum seekers, it may also be wise to take their preferences into account. Our study suggest that not all asylum seekers prefer the same country of asylum. In our view, a system of even distribution of asylum seekers should take the preferences of asylum seekers themselves into account. It should also not cause a long period of uncertainty with regard to the country of destination. It is, of course, difficult to decide on many, many applications for asylum in a short period of time and to find housing and employment for numerous refugees. Time has taken the edge off the problem - the number of applications for asylum seekers has declined in recent years. Moreover, it should be recalled that the largest number of refugees is not in Europe but in the poorer countries of Africa and Asia. 
, 
Table 1: Asylum applications in EU member states by country of nationality, 1985-1994

\begin{tabular}{|c|c|c|c|c|c|c|c|c|c|c|c|c|c|}
\hline $\begin{array}{l}\text { Country of } \\
\text { nationality }\end{array}$ & $\mathrm{D}$ & $\mathrm{F}$ & UK & NL & B & $\mathrm{DK}$ & $\mathrm{E}$ & I & GR & $\mathrm{P}$ & $\mathrm{I}$ & IRL & Total \\
\hline Europe & 931527 & 39251 & 17607 & 61530 & 31085 & 27312 & 18703 & 27265 & 90 & 2217 & 530 & & 1157117 \\
\hline Albania & & 1092 & 3 & 1395 & 555 & 33 & 26 & 20166 & 2 & 10 & 15 & & 23297 \\
\hline Bulgaria & 78785 & 1794 & 1072 & 2025 & 3246 & 566 & 1746 & 1116 & 1 & 42 & 64 & & 90457 \\
\hline Czechoslovakia & 15109 & 447 & 120 & 1766 & 163 & 240 & 308 & 7 & & 8 & 17 & & 18185 \\
\hline Hungary & 9088 & 451 & 91 & 1092 & 266 & 109 & 192 & 15 & & 16 & 9 & & 11329 \\
\hline Poland & 106447 & 5828 & 557 & 4437 & 2563 & 3491 & 9906 & 13 & & 66 & 62 & & 133370 \\
\hline Romania & 273052 & 17900 & 1956 & 9415 & 14213 & 1454 & 4971 & 5405 & 5 & 1898 & 138 & & 330407 \\
\hline (ex)USSR & 19455 & 2355 & 1041 & 8050 & 1271 & 1860 & 354 & 256 & 36 & 93 & 40 & & 34811 \\
\hline (ex)Yugoslavia & 400446 & 9287 & 12220 & 33267 & 8753 & 19303 & 1195 & 287 & 16 & 80 & 163 & & 485047 \\
\hline Rest Europe & 29145 & 97 & 547 & 83 & 55 & 256 & 5 & & & 4 & 22 & & 30214 \\
\hline Asia & 274991 & 102633 & 45753 & 33003 & 17372 & 8199 & 3843 & 614 & 94 & 196 & 121 & & 486819 \\
\hline Afghanistan & 44569 & 419 & 481 & 6210 & 211 & 662 & 70 & 28 & 5 & 3 & 3 & & 52661 \\
\hline Bangladesh & & 4079 & 708 & 1834 & 1387 & 237 & 383 & 13 & 2 & 23 & 2 & & 8668 \\
\hline Cambodia & & 8330 & & 2 & 68 & 9 & 2 & & & 1 & 4 & & 8416 \\
\hline China & 36.49 & 9963 & 1832 & 4085 & 767 & 326 & 2676 & 28 & 1 & 6 & 3 & & 23336 \\
\hline India & 37565 & 7241 & 9454 & 3640 & 8232 & 189 & 66 & 18 & 65 & 71 & 3 & & 66544 \\
\hline Laos & & 4278 & & 1 & 68 & 5 & & 1 & & & & & 4353 \\
\hline Pakistan & 28697 & 10131 & 10639 & 2278 & 5126 & 447 & 337 & 114 & 17 & 58 & 35 & & 57879 \\
\hline Sri Lanka & 58164 & 26510 & 19730 & 13481 & 496 & 5784 & 51 & 351 & 3 & 33 & 5 & & 124608 \\
\hline Vietnam & 45937 & 18528 & 18 & 699 & 705 & 205 & 29 & 52 & & & 48 & & 66221 \\
\hline Rest Asia & 56410 & 13154 & 2891 & 773 & 312 & 335 & 229 & 9 & 1 & 1 & 18 & & 74133 \\
\hline
\end{tabular}




\begin{tabular}{|c|c|c|c|c|c|c|c|c|c|c|c|c|c|}
\hline $\begin{array}{r}\text { Country of } \\
\text { nationality }\end{array}$ & D & $\mathrm{F}$ & UK & $\mathrm{NL}$ & $B$ & DK & $\mathrm{E}$ & I & GR & $\mathrm{P}$ & $\mathrm{L}$ & IRL & Total \\
\hline Africa & 208944 & 138513 & 76492 & 54481 & 35745 & 7863 & 11237 & 6152 & 1411 & 1881 & 234 & & 542953 \\
\hline Algeria & 18931 & 4688 & 341 & 2097 & 416 & 181 & 375 & 32 & 1 & 1 & 5 & & 27068 \\
\hline Angola & & 13852 & 8429 & 3063 & 1938 & 25 & 1954 & 139 & 2 & 1037 & 20 & & 30459 \\
\hline Cape Verde & & 4020 & & & 5 & & 6 & & & 4 & & & 4035 \\
\hline Ethiopia & 14376 & 462 & 6321 & 5791 & 249 & 220 & 78 & 2172 & 1378 & 6 & 1 & & 31054 \\
\hline Ghana & 32322 & 11074 & 8024 & 5888 & 7945 & 197 & 595 & 46 & & 111 & 13 & & 66215 \\
\hline Guinea & & 4506 & 1 & 184 & 842 & 25 & 221 & 2 & & 9 & 4 & & 5794 \\
\hline Liberia & & 504 & & 2029 & 1177 & 137 & 1091 & 39 & & 82 & 8 & & 5067 \\
\hline Mauritania & & 4383 & & 250 & 122 & 4 & 115 & 2 & & 1 & & & 4877 \\
\hline Mali & & 16639 & 2 & 57 & 52 & 4 & 102 & 1 & & 5 & 3 & & 16865 \\
\hline Nigeria & 28104 & 2354 & 5467 & 3000 & 3467 & 214 & 1122 & 23 & & 18 & 4 & & 43773 \\
\hline Senegal & & 5554 & 1 & 94 & 448 & 24 & 2675 & 1 & & 3 & 2 & & 8802 \\
\hline Somalia & & 1591 & 11494 & 20455 & 429 & 4696 & 141 & 3379 & 9 & 2 & 15 & & 42211 \\
\hline Sudan & & 120 & 2451 & 714 & 84 & 36 & 20 & 69 & 8 & & 7 & & 3509 \\
\hline Togo & 3488 & 395 & 2138 & 514 & 1389 & 178 & 27 & 19 & & 9 & 3 & & 8160 \\
\hline Uganda & & 15 & 6503 & 94 & 42 & 362 & & & & & 1 & & 7017 \\
\hline Zaire & 8305 & 38328 & 11800 & 7154 & 14383 & 75 & 589 & 133 & 7 & 443 & 92 & & 81309 \\
\hline Rest Africa & 103418 & 30028 & 13520 & 3097 & 2757 & 1485 & 2126 & 95 & 6 & 150 & 56 & & 156738 \\
\hline Middle East & 308143 & 67476 & 24578 & 40675 & 9189 & 20346 & 3136 & 906 & 13197 & 41 & 182 & & 487869 \\
\hline Iran & 76570 & 4350 & 5335 & 16394 & 1055 & 7653 & 1552 & 343 & 1744 & 20 & 138 & & 115154 \\
\hline Iraq & & 1299 & 4600 & 8607 & 322 & 5464 & 1445 & 204 & 10924 & 17 & 6 & & 32888 \\
\hline Lebanon & 56524 & 680 & 2913 & 4352 & 816 & 4587 & 87 & 242 & 4 & 1 & 9 & & 70215 \\
\hline Syria & & 145 & & 2814 & 382 & 280 & 20 & 16 & & 1 & 3 & & 3661 \\
\hline Turkey & 175048 & 60868 & 11670 & 8320 & 6483 & 1454 & 6 & 90 & 525 & 2 & 25 & & 264491 \\
\hline Rest Mid.East & 1 & 134 & 60 & 188 & 131 & 908 & 26 & 11 & & & 1 & & 1460 \\
\hline
\end{tabular}




\begin{tabular}{|c|c|c|c|c|c|c|c|c|c|c|c|c|c|}
\hline $\begin{array}{l}\text { Country of } \\
\text { nationality }\end{array}$ & $\mathrm{D}$ & $\mathrm{F}$ & UK & NL & $\mathrm{B}$ & $\mathrm{DK}$ & $\mathrm{E}$ & I & GR & $\mathrm{P}$ & $\mathrm{L}$ & IRL & Total \\
\hline America & 2418 & 14023 & 1778 & 4561 & 868 & 225 & 15479 & 92 & 2 & 10 & 28 & & 39484 \\
\hline Chile & & 1936 & 54 & 303 & 323 & 112 & 646 & 1 & & & 8 & & 3383 \\
\hline Colombia & & 1833 & 1127 & 38 & 187 & 5 & 786 & 5 & & & 1 & & 3982 \\
\hline Dominican $\operatorname{Re}$ & & 4 & & 2 & 14 & & 3115 & & & & & & 3135 \\
\hline Haiti & & 6943 & & 10 & 37 & & 6 & & 2 & 1 & & & 6999 \\
\hline Peru & & 1602 & 23 & 104 & 166 & 49 & 7106 & 31 & & 1 & 16 & & 9098 \\
\hline Surinam & & 20 & 6 & 3679 & 7 & & & & & & & & 3712 \\
\hline Rest America & 2418 & 1685 & 568 & 425 & 134 & 59 & 3820 & 55 & & 8 & 3 & & 9175 \\
\hline $\begin{array}{l}\text { Unspecified*/ } \\
\text { Stateless }\end{array}$ & 66407 & 1358 & 87469 & 3247 & 24567 & 10816 & 14582 & 25217 & 31536 & 42 & 1 & 674 & 265916 \\
\hline Total & 1792430 & 363254 & 253677 & 197497 & 118826 & 74761 & 66980 & 60246 & 46330 & 4387 & 1096 & 674 & 2980158 \\
\hline
\end{tabular}


Table 2: Distribution of the asylum applications across countries of nationality for the different EU member states (percentages). 1985-1994

\begin{tabular}{|c|c|c|c|c|c|c|c|c|c|c|c|c|c|}
\hline $\begin{array}{l}\text { Country of } \\
\text { nationality }\end{array}$ & $D$ & $\mathrm{~F}$ & UK & NL & $\mathrm{B}$ & $\mathrm{DK}$ & $\mathrm{E}$ & I & GR & $\mathrm{P}$ & $\mathrm{L}$ & IRL & Total \\
\hline Europe & 52.0 & 10.8 & 6.9 & 31.2 & 26.2 & 36.5 & 27.9 & 45.3 & .2 & 50.5 & 48.4 & & 38.8 \\
\hline Albania & & .3 & .0 & .7 & .5 & 0 & .0 & 33.5 & .0 & .2 & 1.4 & & .8 \\
\hline Bulgaria & 4.4 & .5 & .4 & 1.0 & 2.7 & .8 & 2.6 & 1.9 & .0 & 1.0 & 5.8 & & 3.0 \\
\hline Czechoslovakia & .8 & .1 & .0 & .5 & .1 & .2 & .5 & .0 & & .1 & 1.6 & & .5 \\
\hline Hungary & .5 & .1 & .0 & .6 & .2 & 1 & .3 & .0 & & .4 & .8 & & .4 \\
\hline Poland & 5.9 & 1.6 & .2 & 2.2 & 2.2 & 4.7 & 14.8 & .0 & & 1.5 & 5.7 & & 4.5 \\
\hline Romania & 15.2 & 4.9 & .8 & 4.8 & 12.0 & 1.9 & 7.4 & 9.0 & .0 & 43.3 & 12.6 & & 11.1 \\
\hline (ex)USSR & 1.1 & .6 & .4 & 4.1 & 1.1 & 2.5 & .5 & .4 & .1 & 2.1 & 3.6 & & 1.2 \\
\hline (ex)Yugoslavia & 22.3 & 2.6 & 4.8 & 16.8 & 7.4 & 25.8 & 1.8 & .5 & 1 & 1.8 & 14.9 & & 16.3 \\
\hline Rest Europe & 1.6 & .0 & .2 & .0 & .0 & .3 & .0 & & & .0 & 8.3 & & 1.0 \\
\hline Asia & 15.3 & 28.3 & 18.0 & 16.7 & 14.6 & 11.0 & 5.7 & 1.0 & .2 & 4.5 & 11.0 & & 16.3 \\
\hline Afghanistan & 2.5 & .1 & .2 & 3.1 & .2 & .9 & .1 & .0 & .0 & .1 & .3 & & 1.8 \\
\hline Bangladesh & & 1.1 & .3 & .9 & 1.2 & .3 & .6 & .0 & .0 & .5 & .2 & & .3 \\
\hline Cambodia & & 2.3 & & .0 & .1 & .0 & .0 & & & .0 & .4 & & .3 \\
\hline China & .2 & 2.7 & .7 & 2.1 & .6 & 4 & 4. & .0 & .0 & .1 & .3 & & .8 \\
\hline India & 2.1 & 2. & 3.7 & 1.8 & 6.9 & .3 & .1 & .0 & .1 & 1.6 & .3 & & 2.2 \\
\hline
\end{tabular}




\begin{tabular}{|c|c|c|c|c|c|c|c|c|c|c|c|c|c|}
\hline $\begin{array}{r}\text { Country of } \\
\text { nationality }\end{array}$ & 1) & $\mathrm{F}$ & UK & $\mathrm{NL}$ & B & I) K & $\mathrm{r}$ & I & GR & $P$ & L. & IIRI, & Total \\
\hline Laos & & 1.2 & & .0 & .1 & .0 & & .0 & & & & & .1 \\
\hline Pakistan & 1.6 & 2.8 & 4.2 & 1.2 & 4.3 & .6 & .5 & .2 & .0 & 1.3 & 3.2 & & 1.9 \\
\hline Sri Lanki & 3.2 & 7.3 & 7.8 & 6.8 & .4 & 7.7 & .1 & .6 & .0 & .8 & .5 & & 4.2 \\
\hline Vietnam & 2.6 & 5.1 & .0 & .4 & .6 & .3 & .0 & .1 & & & 4.4 & & 2.2 \\
\hline Rest Asia & 3.1 & 3.6 & 1.1 & .4 & .3 & .4 & .3 & .0 & .0 & .0 & 1.6 & & 2.5 \\
\hline Africa & 11.7 & 38.1 & 30.2 & 27.6 & 30.1 & 10.5 & 16.8 & 10.2 & 3. & 42.9 & 21.4 & & 18.2 \\
\hline Algeria & 1.1 & 1.3 & .1 & 1.1 & .4 & .2 & .6 & .1 & .0 & .0 & .5 & & .9 \\
\hline Angola & & 3.8 & 3.3 & 1.6 & 1.6 & .0 & 2.9 & .2 & .0 & 23.6 & 1.8 & & 1.0 \\
\hline Cape Verde & & 1.1 & & & .0 & & .0 & & & .1 & & & .1 \\
\hline Ethiopia & .8 & .1 & 2.5 & 2.9 & .2 & .3 & .1 & 3.6 & 3.0 & .1 & .1 & & 1.0 \\
\hline Ghana & 1.8 & 3.0 & 3.2 & 3.0 & 6.7 & .3 & .9 & .1 & & 2.5 & 1.2 & & 2.2 \\
\hline Guinea & & 1.2 & .0 & .1 & .7 & .0 & .3 & .0 & & .2 & .4 & & .2 \\
\hline Liberia & & .1 & & 1. & 1. & .2 & 1.6 & .1 & & 1.9 & .7 & & .2 \\
\hline Mauritania & & 1.2 & & .1 & .1 & .0 & .2 & .0 & & .0 & & & .2 \\
\hline Mali & & 4.6 & .0 & .0 & .0 & .0 & .2 & .0 & & .1 & .3 & & .6 \\
\hline Nigeria & 1.6 & .6 & 2.2 & 1.5 & 2.9 & .3 & 1.7 & .0 & & .4 & .4 & & 1.5 \\
\hline Senegal & & 1.5 & .0 & .0 & .4 & .0 & 4.0 & .0 & & .1 & .2 & & .3 \\
\hline Somalia & & .4 & 4.5 & 10.4 & .4 & 6.3 & .2 & 5.6 & .0 & .0 & 1.4 & & 1.4 \\
\hline Sudan & & .0 & 1.0 & .4 & .1 & .0 & .0 & .1 & .0 & & .6 & & .1 \\
\hline Togo & .2 & .1 & .8 & .3 & 1.2 & .2 & .0 & .0 & & .2 & .3 & & .3 \\
\hline Uganda & & .0 & 2.6 & .0 & .0 & .5 & & & & & .1 & & .2 \\
\hline Zaire & .5 & 10.6 & 4.7 & 3.6 & 12.1 & .1 & .9 & .2 & .0 & 10.1 & 8.4 & & 2.7 \\
\hline Rest Africa & 5.8 & 8.3 & 5.3 & 1.5 & 2.3 & 2.0 & 3.2 & .2 & .0 & 3.4 & 5.1 & & 5.3 \\
\hline
\end{tabular}




\begin{tabular}{|c|c|c|c|c|c|c|c|c|c|c|c|c|c|}
\hline $\begin{array}{r}\text { Country of } \\
\text { nationality }\end{array}$ & $\mathrm{D}$ & $\mathrm{F}$ & UK & NL & B & DK & $\mathrm{E}$ & I & GR & $\mathrm{P}$ & $\mathrm{L}$ & IRL & Total \\
\hline Middle East & 17.2 & 18.6 & 9.7 & 20.6 & 7.7 & 27.2 & 4.7 & 1.5 & 28.5 & .9 & 16.6 & & 16.4 \\
\hline Iran & 4.3 & 1.2 & 2.1 & 8.3 & .9 & 10.2 & 2.3 & .6 & 3.8 & .5 & 12.6 & & 3.9 \\
\hline Iraq & & .4 & 1.8 & 4.4 & .3 & 7.3 & 2.2 & .3 & 23.6 & .4 & .5 & & 1.1 \\
\hline Lebanon & 3.2 & .2 & 1.1 & 2.2 & .7 & 6.1 & .1 & .4 & .0 & .0 & .8 & & 2.4 \\
\hline Syria & & .0 & & 1.4 & .3 & .4 & .0 & .0 & & .0 & .3 & & .1 \\
\hline Turkey & 9.8 & 16.8 & 4.6 & 4.2 & 5.5 & 1.9 & .0 & .1 & 1.1 & .0 & 2.3 & & 8.9 \\
\hline Rest Mid.East & & .0 & .0 & .1 & .1 & 1.2 & .0 & .0 & .0 & .0 & .0 & & .0 \\
\hline America & .1 & 3.9 & .7 & 2.3 & .7 & .3 & 23.1 & .2 & .0 & .2 & 2.6 & & 1.3 \\
\hline Chile & & .5 & .0 & .2 & .3 & .1 & 1. & .0 & & & .7 & & .1 \\
\hline Colombia & & .5 & .4 & .0 & .2 & .0 & 1.2 & .0 & & & .1 & & .1 \\
\hline Dominican Re & & .0 & & .0 & .0 & & 4.7 & & & & & & 1 \\
\hline Haiti & & 1.9 & & .0 & .0 & & .0 & & .0 & .0 & & & .2 \\
\hline Peru & & .4 & .0 & .1 & .1 & .1 & 10.6 & .1 & & .0 & 1.5 & & .3 \\
\hline Surinam & & .0 & .0 & 1.9 & .0 & & & & & & & & .1 \\
\hline Rest America & .1 & .5 & .0 & .2 & .1 & .0 & 5.7 & .0 & & .1 & .0 & & .3 \\
\hline $\begin{array}{l}\text { Unspecified }{ }^{* /} \\
\text { Stateless }\end{array}$ & 3.7 & .4 & 34.5 & 1.6 & 20.7 & 14.5 & 21.8 & 41.9 & 68.1 & 1. & .1 & 100 & 8.9 \\
\hline Total & 100 & 100 & 100 & 100 & 100 & 100 & 100 & 100 & 100 & 100 & 100 & 100 & 100 \\
\hline
\end{tabular}

Based on data provided by EUROSTAT, 1995.

* Includes Australia \& Oceania (61), and unspecified applications in Belgium 1985-1987 (total), 1994 (large number); Greece 1985-1988 (total), 1989-1992 (large number); Ireland 1985-1994 (total); Italy 1985-1988 (total), 1989, 1994 (large number); Spain 1985-1987 (total), 1994 (large number); LK 1985-1994 (large numbers, include accompanying spouses and children). 


\section{Appendix 2 \\ Notes on the statistics used in this study}

In this study, we use the EUROSTAT data on asylum seekers by citizenship in the countries of the European Union. For our research, we needed the asylum applications specified by citizenship; that is, the country of nationality for the asylum seeker or what we call the country of origin. These figures are not available for all European Union countries in all years.

Table 1: Availability of information pertaining to country of nationality for asylum seekers per EU member state

\begin{tabular}{|c|c|c|c|c|c|c|c|c|c|c|c|c|}
\hline & $\mathrm{D}$ & $\mathrm{F}$ & $\mathrm{UK}^{*}$ & $\mathrm{NL}$ & $\mathrm{B}$ & $\mathrm{DK}$ & $\mathrm{E}$ & $\mathrm{I}$ & $\mathrm{GR} *$ & $\mathrm{P}$ & $\mathrm{L}$ & $\mathrm{IRL}$ \\
\cline { 2 - 10 } & + & + & + & + & - & + & - & - & - & + & + & - \\
1986 & + & + & + & + & - & + & - & - & - & + & + & - \\
1987 & + & + & + & + & - & + & - & - & - & + & + & - \\
1988 & + & + & + & + & + & + & + & - & - & + & + & - \\
1989 & + & + & + & + & + & + & + & + & $\mathrm{p}$ & + & + & - \\
1990 & + & + & + & + & + & + & + & + & $\mathrm{p}$ & + & + & - \\
1991 & + & + & + & + & + & + & + & + & $\mathrm{p}$ & + & + & - \\
1992 & + & + & + & + & + & + & + & + & + & + & + & - \\
1993 & + & + & + & + & + & + & + & + & $\mathrm{p}$ & + & + & - \\
1994 & $\mathrm{p}$ & + & $\mathrm{p}$ & + & $\mathrm{p}$ & $\mathrm{p}$ & $\mathrm{p}$ & + & - & + & + & - \\
\hline
\end{tabular}

$+=$ available $; \mathrm{p}=$ only available for some countries of nationality; $-=$ not available

* Not specified for accompanying partners and minor children.

** Only partly available for 1993 because these figures only include applications registered with the Greek authorities and not those registered with the UNHCR.

Although the German statistics on asylum applications are specified by country of nationality, many of the applications unfortunately have no specification. Over the years 1985-94 more than 250,000 applications in Germany are unspecified (see Table 1, Appendix 1). In particular, large numbers of asylum applications from African nationals are not further specified (some 100,000). In cases where the figures show Germany to not receive asylum seekers from a particular country, thousands of them may nevertheless be included in the unspecified numbers.

The counting behind specific figures may not be exactly the same in every country. Dependent children or accompanying partners are sometimes included and sometimes not. The same holds for invited refugees, asylum requests made abroad and requests rejected in a pre-screening procedure. 
Table 2: Which persons are included or excluded in the figures on asylum seekers 1

\begin{tabular}{|l|c|c|c|c|c|c|c|c|c|c|c|c|}
\hline & $\mathrm{D}^{2}$ & $\mathrm{~F}^{3}$ & $\mathrm{UK}^{4}$ & $\mathrm{NL}^{5}$ & $\mathrm{~B}^{6}$ & $\mathrm{DK}^{7}$ & $\mathrm{E}^{8}$ & $\mathrm{I}^{9}$ & $\mathrm{GR}^{10}$ & $\mathrm{P}^{11}$ & $\mathrm{~L}^{12}$ & $\mathrm{IRL}$ \\
\hline $\begin{array}{l}\text { Spouses } \\
\text { Dependent } \\
\text { children }\end{array}$ & $\mathrm{i}$ & $\mathrm{pe}$ & $\mathrm{pe}$ & $\mathrm{i}$ & $\mathrm{i}$ & $\mathrm{i}$ & $\mathrm{e}$ & $\mathrm{i}$ & $\mathrm{i}$ & $\mathrm{e}$ & $\mathrm{i}$ & $\mathrm{i}$ \\
$\begin{array}{l}\text { Rejected in } \\
\text { pre-screening }\end{array}$ & $\mathrm{i}$ & $\mathrm{i}$ & $\mathrm{i}$ & $\mathrm{i}$ & $\mathrm{i}$ & $\mathrm{pe}$ & $\mathrm{i}$ & $\mathrm{pe}$ & $\mathrm{e}$ & $\mathrm{e}$ & na & na \\
$\begin{array}{l}\text { Applications } \\
\text { abroad } \\
\text { Invited } \\
\text { refugees }\end{array}$ & $\mathrm{na}$ & $\mathrm{i}$ & $\mathrm{i}$ & $\mathrm{i}$ & $\mathrm{na}$ & $\mathrm{e}$ & $\mathrm{i}$ & $\mathrm{na}$ & $\mathrm{na}$ & $\mathrm{na}$ & na & na \\
\hline
\end{tabular}

$\mathrm{i}=$ included $; \mathrm{e}=$ excluded $; \mathrm{pe}=$ partly excluded $;$ na $=$ not applicable

1 This overview is based on NIDI 1994: Table 5.2.1 and on the notes to the tables supplied by EUROSTAT.

2 In Germany, dependent children are included if the parents requested asylum for them.

3 In France, children and some of the accompanying partners are excluded. Accompanying partners are included if they file a separate request for asylum. It is not known to what extent this actually happens. Applications made abroad are included at the moment OFRA receives the complete file. Resettled refugees (1991: 5,000) mainly originate from Vietnam, Sri Lanka and Cambodia.

4 In the UK, dependents (i.e., accompanying spouses and minor children) are not specified by citizenship but included in the category 'unspecified'. The numbers range from 1,400 in 1986 to 28,000 in 1991. For 1989,1992 and 1993, the figures are rounded to the nearest 5 . Applications made abroad and processed locally are excluded.

5 For The Netherlands, the number of applications made abroad is assumed to be small.

6 In Belgium, accompanying children under 18 are excluded.

7 In Denmark, asylum seekers rejected at the border are excluded (1,000-1,400 a year); manifestly unfounded cases are included. Applications outside Denmark are excluded (6,000-13,000 a year).

8 Spanish data refer to principal applicants, excluding dependents. The numbers of applications made abroad and the number of invited refugees are small.

9 In Italy, dependent children are excluded. In 1991, Albanian asylum seekers in particular were sent back without consultation.

10 The Greek figures for 1989-92 are the sum of the applications registered with the Greek authorities and those registered with the UNHCR. The extent of possible double counts is not known. Figures for 1993 include only applications registered with the Greek authorities. Albanian asylum seekers in particular were sent back without consultation.

11 In Portugal, manifestly unfounded requests have been excluded since the mid-1980s.

12 In Luxembourg, about 1,800 asylum requests from (ex-)Yugoslavs were excluded in 1992. 


\section{Appendix 3 \\ Results of the statistical analyses}

In a multivariate analysis, we tried to assess the effect of a number of variables on the pattern of origin and destination for asylum seekers. The analysis was confined to the 44 largest countries of origin and the following 10 destination countries: Germany, France, The Netherlands, United Kingdom, Belgium, Denmark, Spain, Italy, Greece and Portugal. For these EU countries, data pertaining to the country of origin (nationality) for the asylum seekers were available. Although such data were also available for Luxembourg, this country was not included because of the generally small number of asylum applications.

\section{Operationalisation of the dependent variable}

To start with, we had to operationalise our dependent variable. What we want to explain are the deviations from the overall patterns of origin and destination (i.e., cases where the actual number of applicants from a particular country of origin to a particular country of destination is either larger or smaller than the number which could be expected on the basis of the sending country's contribution to the EU and the receiving country's share of the EU as a whole). In other words, we had to obtain a measure of 'disproportionality' (relative over- or under-representation). It was decided to use the difference between the actual and expected proportion of applicants in a specific country of destination originating from a specific country of origin and to weight this difference inversely with the square root of the expected proportion. The following formula then applied

$$
\mathbf{D}_{\text {od }}=\frac{\mathbf{P}_{\mathrm{o} \mid \mathrm{d}}-\mathbf{P}_{\mathrm{o} \mid \mathrm{EU}}}{\sqrt{\mathbf{P}_{\mathrm{o} \mid \mathrm{EU}}}}
$$

with $\mathrm{P}_{\mathrm{o} / \mathrm{d}}$ representing the proportion of applicants in country d originating from country o (i.e., the number of applications filed in country $d$ by nationals from country o divided by the total number of applications filed in country d) and $\mathrm{P}_{\mathrm{ol}} \mathrm{EU}$ representing the total proportion of applicants from country $o$ in the $10 \mathrm{EU}$ countries (i.e., the total number of applications filed in the $10 \mathrm{EU}$ countries by nationals from country o divided by the total number of applications filed in the $10 \mathrm{EU}$ countries by nationals from the 44 largest countries of origin). 
The difference between the two proportions constitutes the numerator in the formula. The denominator consists of the square root of the expected (or 'marginal') proportion.

The measure defined by the above formula is commonly used in correspondence analysis, which is a technique for analysing the correspondence between the rows and columns in bivariate frequency tables. ${ }^{1}$ In our case, these are the numbers of asylum seekers by country of origin and country of destination (See Table 1 in Appendix 1). For each destination country in the table, the chi-square distance can be calculated. This distance indicates the degree to which a particular country of destination differs with regard to the countries of origin from the $10 \mathrm{EU}$ countries taken together. The chi-square distance for a particular destination country $d$ is the square root of the sum of the contributions of the individual countries of origin

$$
\partial^{2}=\sqrt{\sum \mathbf{D}_{\text {od }}{ }^{2}}
$$

and our measure of disproportionality $\left(D_{\text {od }}\right)$ indicates the contribution of the sending country o to the chi-square distance for the destination country d.

The measure $D_{\text {od }}$ has three important characteristics.

- A positive score for the combination of country of origin o and country of destination $d$ means that country $d$ receives a larger number of asylum seekers from country o than the number expected on the basis of the figures for the $10 \mathrm{EU}$ countries taken together. A negative score means a smaller number than expected.

- The score for a particular combination of country of origin and country of destination is inversely related to the 'marginal' proportion (i.e., the proportion expected on the basis of the figures for the $10 \mathrm{EU}$ countries taken together). In such a manner, larger differences between the observed and expected proportions for larger countries of origin are reduced and smaller differences between the observed and expected proportions for smaller countries are increased. The contributions of the larger and smaller countries of origin are thus equalised to a certain extent.

- The histogram for the measure defined in such a manner did not show a normal distribution but did show a reasonable degree of symmetry. This particular measure/variable was therefore suited for use in linear regression analyses.

Given these three characteristics, $D_{\text {od }}$ was considered an appropriate measure for the purposes of the present study.

1 For a discussion of this type of analysis, see Greenacre (1981). 
In the following table, the scores on the dependent variable $\mathrm{D}_{\text {od }}$ for each of the 44 largest countries of origin and the $10 \mathrm{EU}$ countries are presented. These scores range from -0.42 in the case of the Yugoslavia - Greece relation to 6.60 in the case of the Iraq - Greece relation.

Table 1: Scores for the different combinations of country of origin and country of destination on our measure of disproportionality $D_{o d}$ (relative over-or under-representation)

\begin{tabular}{|c|c|c|c|c|c|c|c|c|c|c|}
\hline & D & $\mathrm{F}$ & NL & UK & B & $\mathrm{E}$ & DK & GR & I & $P$ \\
\hline 1 Yugoslavia & .13 & -.36 & -.02 & -.25 & -.20 & -.37 & .29 & -.42 & -.40 & -.38 \\
\hline 2 Rom & .10 & -.21 & -.21 & -.32 & .08 & -.08 & -.28 & -.35 & .09 & .90 \\
\hline 3 Turl & .01 & .23 & -.17 & -.09 & -.09 & -.31 & -.24 & -.20 & -.30 & -.31 \\
\hline 4 Poland & .06 & -.15 & -.12 & -.21 & -.10 & .63 & .02 & -.22 & -.22 & -.15 \\
\hline 5 Sri Lanka & -.06 & .13 & .11 & .34 & -.19 & -.21 & .21 & -.21 & -.17 & -.18 \\
\hline 6 Iran & & -.15 & .20 & -.05 & -.15 & -.06 & .38 & .37 & -.16 & -.18 \\
\hline 7 Bulgaria & .07 & -.16 & -.13 & -.15 & & & -.13 & -.18 & & -.13 \\
\hline 8 Zaire & -.15 & .44 & .04 & .24 & .71 & -.11 & -.17 & -.17 & -.15 & .42 \\
\hline 9 Leb & .04 & -.15 & -.02 & -.05 & -.11 & -.15 & .29 & -.16 & -.12 & -.16 \\
\hline $10 \mathrm{In}$ & -.02 & -.03 & -.04 & .21 & .40 & -.15 & -.14 & -.13 & -.15 & -.05 \\
\hline $11 \mathrm{Vi}$ & .01 & .17 & -.13 & -.16 & -.11 & -.15 & -.14 & -.16 & -.15 & -.16 \\
\hline $12 \mathrm{G}$ & -.04 & .04 & .04 & .15 & .38 & -.08 & -.14 & -.16 & -.15 & \\
\hline $13 \mathrm{~Pa}$ & -.03 & .05 & -.07 & .29 & .23 & -.10 & -.10 & -.14 & -.12 & -.05 \\
\hline $14 \mathrm{Afg}$ & .05 & -.13 & .09 & -.12 & -.12 & -.13 & -.06 & -.14 & -.13 & -.13 \\
\hline $15 \mathrm{Ni}_{3}$ & & -.08 & & .13 & .16 & .04 & -.10 & -.13 & -.12 & -.09 \\
\hline $16 \mathrm{So}$ & -.12 & -.09 & .72 & .43 & -.09 & -.10 & .46 & -.12 & .65 & -.12 \\
\hline $17 \mathrm{US}$ & -.01 & -.06 & .25 & -.06 & & -.05 & .14 & -.09 & -.05 & .08 \\
\hline $18 \mathrm{Ir}$ & -.11 & -.08 & .29 & .14 & -.08 & .14 & .67 & 6.60 & -.06 & -.07 \\
\hline $19 \mathrm{Et}$ & -.03 & -.10 & .17 & .25 & -.08 & -.09 & -.07 & .76 & .47 & -.09 \\
\hline $20 \mathrm{An}$ & -.11 & .26 & .04 & .37 & .09 & .25 & -.10 & -.10 & -.07 & 2.15 \\
\hline $21 \mathrm{Alg}$ & & .03 & & -.08 & -.06 & -.03 & -.07 & -.10 & -.09 & -.10 \\
\hline $22 \mathrm{Cl}$ & -.07 & .20 & .13 & .03 & & .46 & -.04 & -.09 & -.08 & -.08 \\
\hline $23 \mathrm{Al}$ & -.09 & -.06 & -.02 & -.09 & -.03 & -.09 & -.09 & -.09 & 6.12 & -.07 \\
\hline $24 \mathrm{C}$ & .03 & -.07 & .03 & -.07 & -.06 & -.01 & -.04 & -.08 & -.08 & -.06 \\
\hline $25 \mathrm{M}$ & -.08 & .50 & -.08 & -.08 & -.07 & -.05 & -.08 & -.08 & -.08 & -.06 \\
\hline $26 \mathrm{~Hz}$ & .02 & -.05 & .02 & -.06 & -.02 & & -.04 & -.06 & -.06 & \\
\hline $27 \mathrm{Pe}$ & -.06 & .02 & -.05 & -.06 & -.03 & 2.28 & -.04 & -.06 & -.04 & -.05 \\
\hline $28 \mathrm{Se}$ & -.06 & .21 & -.05 & -.06 & .03 & .84 & -.05 & -.06 & -.06 & -.04 \\
\hline $29 \mathrm{~B}$ & .02 & .14 & .11 & .02 & .20 & .07 & & -.05 & -.05 & .04 \\
\hline $30 \mathrm{C}$ & -.06 & .36 & -.06 & -.06 & -.04 & -.05 & -.05 & -.06 & -.06 & -.05 \\
\hline $31 \mathrm{~T}$ & -.02 & -.03 & & .18 & .21 & -.05 & & -.05 & -.04 & -.02 \\
\hline $32 \mathrm{U}$ & -.05 & -.05 & -.04 & .72 & -.04 & -.05 & .06 & -.05 & -.05 & -.05 \\
\hline $33 \mathrm{Ha}$ & -.05 & .33 & -.05 & -.05 & -.04 & -.05 & -.05 & -.05 & -.05 & -.05 \\
\hline $34 \mathrm{Gu}$ & -.05 & .22 & -.03 & -.05 & .15 & .05 & -.04 & -.05 & -.04 & \\
\hline $35 \mathrm{Li}$ & -.04 & -.01 & .20 & -.04 & .25 & .44 & & -.04 & -.02 & .39 \\
\hline $36 \mathrm{M}$ & -.04 & .24 & -.01 & -.04 & -.01 & & -.04 & -.04 & -.04 & -.04 \\
\hline $37 \mathrm{La}$ & -.04 & .26 & -.04 & -.04 & -.02 & -.04 & -.04 & -.04 & -.04 & -.04 \\
\hline $38 \mathrm{Ca}$ & -.04 & .25 & -.04 & -.04 & -.04 & -.04 & -.04 & -.04 & -.04 & -.01 \\
\hline $39 \mathrm{Col}$ & -.04 & .09 & -.03 & .14 & .01 & .35 & -.04 & -.04 & -.03 & -.04 \\
\hline $40 \mathrm{Sz}$ & -.04 & -.04 & .48 & -.04 & -.03 & -.04 & -.04 & -.04 & -.04 & -.04 \\
\hline $41 \mathrm{Sy}$ & -.04 & -.03 & .36 & -.04 & .07 & -.03 & .08 & -.04 & -.02 & -.03 \\
\hline $42 \mathrm{Su}$ & -.04 & -.03 & .07 & .37 & -.01 & -.03 & -.02 & -.02 & .02 & -.04 \\
\hline $43 \mathrm{Ch}$ & -.04 & .12 & & -.03 & .06 & .31 & .01 & -.04 & -.03 & -.04 \\
\hline 44 Domin Rep & -.03 & -.03 & -.03 & -.03 & -.03 & 1.72 & -.03 & -.03 & -.03 & -.03 \\
\hline
\end{tabular}


For the regression analysis, each of the 440 (44 x 10) combinations of country of origin and country of destination was taken as a separate unit of analysis. A data matrix was created with the scores on the dependent variable $D$ together with the characteristics of the specific combination of country of origin and country of destination. Five outliers (cases with scores $>1$ ) were omitted from the analyses. These were the following five cases: Peru-Spain; Dominican Republic-Spain; Iraq-Greece; AlbaniaItaly; Angola-Portugal. Together, these five cases accounted for less than $2 \%$ of the total volume of asylum applications.

\section{Operationalisation of the independent variables}

The following variables were included in the analyses to explain the relative over- or under-representation of specific countries.

\section{Colonial ties}

For all 440 combinations of country of origin and destination, we examined whether the country of origin was a former colony, a protectorate or a mandated territory of the destination country or not.

\section{Language ties}

For all 440 combinations, we examined whether a shared (official) language between the country of origin and the country of destination existed or not.

\section{Geographical proximity}

We also examined whether or not the destination country shares a border with the country of origin or is easily reached by sea from the country of origin.

\section{Trade relations}

We examined whether the country of destination was among the two or three most important trade partners for the country of origin or not. As sources of information, we used The Statesman's Year-Book (1985-86 and 1990-91) and CIA World Fact Books (1992).

\section{Cultural ties}

This variable was operationalised as the number of nationals from the country of origin studying with a scholarship in the country of destination in the early 1980s. Data published by UNESCO (1986) were used for this purpose. Because of the skewed distribution observed for this variable, we constructed a number of dummy variables: NStu1 when the number of students was smaller than 11; NStu11 when the number of stu- 
dents was larger than 10 and smaller than 101; NStu 101 when the number of students was larger than 100 .

\section{Outcomes of the statistical analyses}

In a number of bivariate analyses, we initially examined the effects of the individual variables without controlling for the effects of other variables. The first three variables (colonial ties, language ties and geographic proximity) appeared to have a small but nevertheless significant effect. In the case of geographic proximity, an inverse relation contrary to our expectations was found. Multiple regression analysis, however, identified colonial ties as the most important predictor (Beta .318). The effects of language ties and geographic proximity were found to be much smaller, and the remaining variables were found to have hardly any effect at all. All five of the independent variables taken together explained no more than $17 \%$ of the total amount of variance ( $R$ Square .169).

Table 2: Results of the statistical analyses

\begin{tabular}{|l|r|r|r|}
\hline \multicolumn{1}{|c|}{ Variable } & $\begin{array}{c}\text { B uncontrolled } \\
\text { (bivariate analyis) }\end{array}$ & $\begin{array}{c}\text { B controlled } \\
\text { (multiple } \\
\text { regression } \\
\text { analysis) }\end{array}$ & Beta \\
\hline Colonial ties & .271 & .227 & .318 \\
\hline Language ties & .223 & .072 & .093 \\
\hline Trade relations & .091 & .027 & .051 \\
\hline Geographic proximity & -.175 & -.153 & -.108 \\
\hline NStu1 & .019 & .013 & .032 \\
\hline NStu11 & .009 & .033 & .079 \\
\hline NStu101 & .042 & .002 &. .006 \\
\hline
\end{tabular}

\section{Some remarks on the value of the analyses}

The results of the statistical analyses should be interpreted with caution. With the exception of colonial and language ties, the independent variables were operationalised in a rather rough manner. This was due to insufficient data. We were also not able to include the following variables in the analyses because of insufficient data: recognition rates (i.e., the proportion of asylum seekers receiving a positive decision on their application by country of origin and country of destination); migration ties (the size of already existing immigrant communities); and air connections (the presence or absence of regular flights between the countries of origin and destination). More sophisticated operationalisation of the variables and 
inclusion of a greater number of independent variables could conceivably produce more reliable results. 


\section{Appendix 4 \\ List of key informants and information on the interviews}

\section{In Belgium, we interviewed the following key informants.}

- The chairman of an interest group for asylum seekers in Belgium. He is a refugee from the Ivory Coast.

- A staff member of the UNHCR in Brussels.

- A staff member of Caritas, working with asylum seekers and refugees.

- A lawyer working at the Vaste Beroepscommissie voor Vluchtelingen which is an administrative court deciding on appeals in asylum proceedings.

- A social worker who has worked at a reception center for asylum seekers in Brussels. He is a Somalian refugee from Ethiopia.

- A staff member of an organisation which tries to further the integration of refugees. He is a refugee from Irak.

- A staff member of an organisation rendering assistance to rejected asylum seekers.

- A staff member of the International Organisation for Migration in Belgium and manager of a program for the repatriation of rejected asylum seekers.

- A lawyer working at the Commissariaat-Generaal voor de Vluchtelingen which decides on all asylum applications.

- A refugee from Lybia.

- A social worker working at a reception center for asylum seekers in Brussels. He is a refugee from Somalia.

- A staff member of an organisation which tries to further the integration of refugees. He is a refugee from Zaire.

- An educator who also works as an interpreter for Ethiopian refugees. In the past, he worked for an international organisation in refugee camps in Africa. He is from Ethiopia.

- A social worker who worked at a reception center for asylum seekers and who now works for an organisation rendering assistance to refugees.

- Joint interview with a Sikh asylum seeker who has been living in Belgium since 1992 together with the Belgian founder of an organisation rendering assistance to Sikhs in the Belgian fruit-growing region of Sint-Truiden.

- Joint interview with two pastoral workers at Zaventem airport. 


\section{In The Netherlands, we interviewed the following key inform- ants.}

- A solicitor specialised in asylum law practising from 1986 until 1992. His clients were in particular people from Iran, Tamils from Sri Lanka and people from Yugoslavia.

- A lawyer working in the legal aid agency helping asylum seekers with their applications (preparing people for the interview with the immigration officer).

- A woman working as a free lance interpreter Romanian and French; an active member of Amnesty International on refugee matters; and also president of the local branch of Vluchtelingenwerk (organisation for refugee assistance). Particularly familiar with the situation of Romanian asylum seekers.

- A sociologist specialised in refugees, asylum seekers and migrants, working as a free lance interpreter Farsi (Persian) since 1983. He is a refugee from Iran himself.

- A social worker assisting minor asylum seekers. She worked as an interpreter Somalian from 1989 until 1994. She is a refugee from Somalia herself.

- A person working in a reception centre for asylum seekers for almost five years. He came as a Tamil refugee from Sri Lanka.

- The chairman of an international network of churches working with asylum seekers. Special knowledge on Syrian-orthodox Christians and refugees from the Middle East.

- A staff member of the Dutch Refugee Council with long-standing experience on refugee issues.

- A staff member of a refugee association and interpreter Kurdish, Farsi and Arab for refugees and asylum seekers. $\mathrm{He}$ is a Kurdish refugee from Iraq.

- A staff member of a refugee association. He is a refugee from Ethiopia.

- A protestant pastor engaged in the reception of asylum seekers at Schiphol Airport. He is also president of the local branch of Vluchtelingenwerk (organisation for refugee assistance).

- A judge and, until 1995, solicitor specialised in asylum law.

- Joint interview with two immigration officers with years of experience in hearing asylum seekers as part of the application procedure.

- A staff member of the Dutch immigration agency.

- The president of the International Sikh Youth Federation Holland. He is a Sikh from India, not a refugee. 


\section{In the United Kingdom, we interviewed the following key in- formants.}

- A Chilean refugee working for the Refugee Council.

- A staff member of the Refugee Council.

- A refugee worker of an NGO assisting immigrants. She is a refugee from Sri Lanka herself.

- A staff member of an NGO providing services for refugees with years of experience in providing services to Vietnamese refugees. He is of Vietnamese origin.

- A staff member of an organisation providing advice to immigration detainees and foreign nationals who have immigration problems.

- A refugee working as Bosnia Liaison Worker for an NGO providing services for refugees.

- A Somalian refugee working for the Refugee Council.

- Joint interview with a manager together with a caseworker for an organisation providing legal assistance and representation for asylum seekers.

- Director of Refugee Services at a Roman Catholic Diocese.

- An Iranian administrative-advice worker for an NGO assisting Iranians regarding immigration, housing, education, health etc.

- A former staff member of the North of England Refugee Service currently working at the Refugee Council.

- A Nigerian refugee active in an organisation assisting Nigerians.

- A refugee worker of an organisation giving advice and information to Eritrean asylum seekers (immigration, housing, training, employment, other benefits), himself an Eritrean refugee.

- A solicitor in immigration law and particularly asylum seekers concentrating mainly on Sikhs and Chinese.

- An independent researcher and campaigner with a special interest in refugee rights and detained asylum seekers.

\section{The interviews}

The interviews in The Netherlands were conducted by Tetty Havinga and Thomas Hessels (Institute for the Sociology of Law, University of Nijmegen). The interviews in Belgium were organised and conducted by the Higher Institute for Labour Studies of the University of Leuven (Dr. Joan Ramakers). The interviews in the United Kingdom were organised by the Centre for Research in Ethnic Relations of the University of Warwick (Dr. Danièle Joly) and conducted by Mano Candappa. All of the interviews were audio-recorded. A literal protocol was made, and the interviews took between 1 and 3 hours.

Most of the people we asked for an interview were quite helpful. In The Netherlands, two persons from an organisation clearly sympathising with refugees refused to co-operate out of fear that the research might 
worsen the position of refugees. In the UK, some of the people from the minority organisations refused to be interviewed without financial compensation. 


\section{Appendix 5 \\ List of topics addressed in interviews with key informants}

\section{Informant's position and nature of his/her contacts with asylum seekers}

Selection of Belgium/The Netherlands/United Kingdom (B/NL/UK) as country of refuge

- Are asylum seekers as likely to arrive in B/NL/UK as in any other European country?

- Which country are they more/less likely to go to?

- Do you think that asylum seekers have a choice in the matter?

- Do asylum seekers have some knowledge of B/NL/UK upon their arrival in the country?

- What proportion of those applying for asylum in B/NL/UK wished to seek asylum in this country as their first or only choice?

- What proportion would have preferred to seek asylum in another country?

- What proportion of asylum seekers arriving in B/NL/UK are aware of other compatriots living in this country?

\section{Specific questions on asylum seekers in B/NL/UK}

- Statistics covering the past ten years indicate that asylum seekers from the following countries are proportionally overrepresented in B/NL/UK. (Countries relevant for B/NL/UK are mentioned.) Are you aware of any particular reasons for this?

- Asylum seekers from the following countries are proportionally underrepresented in $\mathrm{B} / \mathrm{NL} / \mathrm{UK}$. (Countries relevant for $\mathrm{B} / \mathrm{NL} / \mathrm{UK}$ are mentioned.) Are you aware of any reasons for this?

\section{The German case}

Of all countries in the European Union and taking such factors as population size, gross national product and geographic area into consideration, Germany gets by far the most requests for asylum. Are you aware of any reasons for this?

\section{Factors influencing the destination of asylum movement}

Can you tell me to what extent the following factors influence the direction of asylum flows and the selection of country of asylum for asylum seekers from different countries? 
- compatriots already living in the country

- colonial or other historical links

- language and other cultural ties (e.g., religion, scientific contacts)

- political links

- commercial or economic links

- country's asylum and immigration policy (e.g., recognition rates, rules relating to work and family reunification)

- ease of access (availability/price of transportation, airline connections)

- housing and living conditions

- other considerations (e.g., the country's reputation for fairness, tolerance, sport achievements)

- persons/organisations helping asylum seekers to leave their country of origin and enter this country

- other factors

\section{Specific questions on asylum and immigration policies}

Can you tell me to what extent the following measures or policies influence the final destination of asylum or selection of country of asylum for asylum seekers from different countries?

- visa requirements

- pre-boarding checks

- principle of safe countries of origin

- Schengen Treaty

- Dublin Treaty

- new Asylum Law in Germany

- other measures or policies

To what extent are asylum seekers aware of these measures and policies upon their arrival?

Can you tell me to what extent the folloing factors influenced asylum seekers from the countries shown below to flee to B/NL/UK rather than another European country? Could you please rank each factor in order of importance for each of the countries?

\begin{tabular}{|l|l|l|l|l|l|l|}
\hline $\begin{array}{l}\text { country of } \\
\text { origin }\end{array}$ & $\begin{array}{l}\text { presence } \\
\text { of fellow } \\
\text { country- } \\
\text { men }\end{array}$ & $\begin{array}{l}\text { ease of } \\
\text { access }\end{array}$ & $\begin{array}{l}\text { historical, } \\
\text { political, or } \\
\text { cultural } \\
\text { ties }\end{array}$ & $\begin{array}{l}\text { asylum } \\
\text { policy }\end{array}$ & $\begin{array}{l}\text { economic } \\
\text { opportuni- } \\
\text { ties }\end{array}$ & $\begin{array}{l}\text { travel } \\
\text { inter- } \\
\text { mediaries }\end{array}$ \\
\hline $\begin{array}{l}\text { ex-Yugo- } \\
\text { slavia }\end{array}$ & & & & & & \\
\hline Romania & & & & & & \\
\hline Turkey & & & & & & \\
\hline Sri Lanka & & & & & & \\
\hline Lebanon & & & & & & \\
\hline Ghana & & & & & & \\
\hline
\end{tabular}




\section{Appendix 6 Rank ordering of factors by key informants}

At the end of the interview, we asked the informants to rank order the following factors according to importance $(1=$ most important $\ldots ; 6=$ least important) for a select set of the countries of origin.

The six factors were: 1 ) the presence of fellow countrymen (compatriots) in the country of destination, 2) the country of destination is easy to reach, 3) historical, political or cultural ties of the country of destination with the country of origin, 4) asylum policy of the country of destination, 5) economic opportunities in the country of destination and 6) travel intermediaries (i.e., any person or organisation who helps asylum seekers to leave their country of origin, makes travel arrangements or, at the arrival point, plays a part in the process of seeking asylum). The informants were asked to rank the importance of the different factors for the following countries: Former Yugoslavia, Romania, Turkey, Sri Lanka, Lebanon, Ghana (and in Belgium: Zaire and India). Some of the informants did not have sufficient knowledge of a particular country to score the factors. Particularly in the UK, many of the informants felt they could only rank the factors for their own country of origin.

Although this ranking can only be seen as a rough indicator of the relative importance of the different factors, we computed a mean rank order per country of origin across the informants for each of the three countries of destination. This rank ordering should be used with care, as it is based on a small number of respondents and the informants made choices in some cases where they were not quite so sure. This rank ordering may nevertheless give the reader an impression of which factors our interviewees evaluated as most important for a particular country of origin. 
Table 1: Rank ordering of factors according to importance for determination of the country of asylum ( $1=$ most important ...; $6=$ least important according to key informants from the country of asylum)

\begin{tabular}{|c|c|c|c|c|c|c|c|}
\hline $\begin{array}{l}\text { Country of } \\
\text { origin }\end{array}$ & $\begin{array}{l}\text { Country of } \\
\text { asylum }\end{array}$ & $\begin{array}{c}\text { Presence } \\
\text { of fellow } \\
\text { country- } \\
\text { men } \\
\end{array}$ & $\begin{array}{l}\text { Easy to } \\
\text { reach }\end{array}$ & $\begin{array}{c}\text { Historic. } \\
\text { political } \\
\text { cultural } \\
\text { ties } \\
\end{array}$ & $\begin{array}{l}\text { Asylum } \\
\text { policy }\end{array}$ & $\begin{array}{l}\text { Econom. } \\
\text { opportu- } \\
\text { nities }\end{array}$ & $\begin{array}{l}\text { 'Travel } \\
\text { interme- } \\
\text { diaries' }\end{array}$ \\
\hline \multirow[t]{2}{*}{$\begin{array}{l}\text { Former } \\
\text { Yugoslavia }\end{array}$} & $\begin{array}{l}\text { Netherlands } \\
(\mathrm{n}=11)\end{array}$ & 1 & $2 / 3$ & 5 & $2 / 3$ & 4 & 6 \\
\hline & $\begin{array}{l}\text { Belgium } \\
(n=14)\end{array}$ & 3 & 2 & 4 & 1 & 5 & 6 \\
\hline \multirow[t]{2}{*}{ Romania } & $\begin{array}{l}\text { Netherlands } \\
(\mathrm{n}=10)\end{array}$ & 4 & 3 & 6 & 2 & 1 & 5 \\
\hline & $\begin{array}{l}\text { Belgium } \\
(\mathrm{n}=12)\end{array}$ & 4 & 1 & 5 & 3 & 2 & 6 \\
\hline \multirow[t]{3}{*}{ Turkey } & $\begin{array}{l}\text { Netherlands } \\
(n=11)\end{array}$ & 1 & 3 & 6 & 2 & $4 / 5$ & $4 / 5$ \\
\hline & $\begin{array}{l}\text { Belgium } \\
(\mathrm{n}=14)\end{array}$ & 1 & $2 / 3$ & $2 / 3$ & 5 & 4 & 6 \\
\hline & $\begin{array}{l}\mathrm{UK} \\
(\mathrm{n}=7) \\
\end{array}$ & 1 & 4 & $5 / 6$ & $5 / 6$ & 2 & 3 \\
\hline \multirow[t]{3}{*}{ Sri Lanka } & $\begin{array}{l}\text { Netherlands } \\
(n=11)\end{array}$ & 2 & 3 & 6 & $4 / 5$ & $4 / 5$ & 1 \\
\hline & $\begin{array}{l}\text { Belgium } \\
(\mathrm{n}=6)\end{array}$ & 2 & 6 & 5 & 4 & 3 & 1 \\
\hline & $\begin{array}{l}\mathrm{UK} \\
(\mathrm{n}=7) \\
\end{array}$ & 1 & 4 & 2 & 6 & 5 & 3 \\
\hline \multirow[t]{2}{*}{ Lebanon } & $\begin{array}{l}\text { Netherlands } \\
(\mathrm{n}=11)\end{array}$ & 2 & 5 & 6 & 4 & 3 & 1 \\
\hline & \begin{tabular}{|l}
$\begin{array}{l}\text { Belgium } \\
(\mathrm{n}=9)\end{array}$ \\
\end{tabular} & 2 & 5 & 6 & 3 & 1 & 4 \\
\hline \multirow[t]{3}{*}{ Ghana } & $\begin{array}{l}\text { Netherlands } \\
(\mathrm{n}=10)\end{array}$ & 1 & 5 & 6 & 2 & 3 & 4 \\
\hline & \begin{tabular}{|l|} 
Belgium \\
$(n=14)$
\end{tabular} & 3 & 5 & 6 & 4 & 1 & 2 \\
\hline & $\begin{array}{l}\mathrm{UK} \\
(\mathrm{n}=7) \\
\end{array}$ & 1 & 4 & 2 & 6 & 5 & 3 \\
\hline Zaire & $\begin{array}{l}\text { Belgium } \\
(n=14)\end{array}$ & 1 & 4 & 2 & 5 & 3 & 6 \\
\hline India & $\begin{array}{l}\text { Belgium } \\
(n=14)\end{array}$ & 3 & 5 & 6 & 4 & 1 & 2 \\
\hline
\end{tabular}




\section{References}

Adepoju, A. 1995, The Dynamics of Emigration: Sub-Saharan Africa, In: R. Van der Erf and L. Heering (eds), Causes of International Migration, Proceedings of a workshop, Eurostat, Luxembourg, 14-16 December 1994, Luxembourg: Office for the Official Publications of the European Commission, 187-200.

Barsky, R.F. 1994, "Why Canada? Why Québec?", Assessing the Convention Refugee's Choice of Québec and Canada as Host country in 1992 (unpublished interim report).

Barsky, R.F. 1995, Arguing the American Dream à la Canada: Former Soviet citizens' justification for their choice of host country, In: Journal of Refugee Studies 8/2, 127-141.

Bilsborrow, R.E. and H. Zlotnik 1995, The Systems Approach and the Measurement of the Determinants of International Migration, In: R. Van der Erf and L. Heering (eds), Causes of International Migration: Proceedings of a workshop, Eurostat, Luxembourg, 14-16 December 1994, Luxembourg: Office for the Official Publications of the European Commission, 61-76.

Black, R. 1993, Refugees and Asylum-seekers in Western Europe: New challenges, In: R. Black and V. Robinson (eds), Geography and Refugees: Patterns and processes of change, London/New York: Belhaven press, 88-103.

Blaschke, J. 1989, Refugees and Turkish Immigrants in West Berlin, In: D. Joly and R. Cohen (eds), Reluctant Hosts: Europe and its Refugees, Aldershot: Avebury, 96-103.

Böcker, A. 1995, Migration Networks: Turkish migration to Western Europe, In: R. Van der Erf and L. Heering (eds), Causes of International Migration: Proceedings of a workshop, Eurostat, Luxembourg, 14-16 December 1994, Luxembourg: Office for the Official Publications of the European Commission, 151-171.

Boyd, M. 1989, Family and Personal Networks in International Migration: Recent developments and new agendas, In: International Migration Review 23/ 3, 638-670.

Brink, M. and M. Pasariboe (eds) 1993, Asylum Seekers in the Netherlands, Amsterdam: Instituut voor Sociale Geografie, Universiteit van Amsterdam (abridged translation of Hulshof, M. [et al.], Asielzoekers in Nederland, 1992.).

Bronkhorst, D. 1990, Een Tijd van Komen: De geschiedenis van vluchtelingen in Nederland, Amsterdam: VON/Jan Mets. 
Caestecker, F. 1992, Vluchtelingenbeleid in de Naoorlogse Periode, Brussel: Balans.

Caestecker, F. 1995, Migratie is ook Re-migratie en Transit-migratie. Een gesprek met het reisagentschap voor de migranten, de IOM, In: Bareel 15/ 58, 12-13.

CIA 1992, The World Fact Book 1992, Washington, DC: CIA.

Daley, P. 1993, From the Kipande to the Kibali: The incorporation of refugees and labour migrants in Western Tanzania: 1900-87, In: R. Black and V. Robinson (eds), Geography and Refugees: Patterns and processes of change, London/New York: Belhaven press, 17-32.

Davies, J. 1990, Displaced Peoples and Refugee Studies: A resource guide, London etc: Hans Zell Publishers.

Doornhein, L. and N. Dijkhoff 1995, Toevlucht Zoeken in Nederland, Arnhem: Gouda Quint.

European Commission 1994, Pre-Feasibility Study on the Possible Establishment of a European Migration Observatory (working document), Brussels.

Fassmann, H. and R. Munz 1992, Patterns and Trends of International Migration in Western Europe, In: Population and Development Review $18 / 3,457-480$.

Fassmann, H. and R. Münz 1995, Einwanderungsland Österreich? Historische Migrationsmuster, aktuelle Trends und politische Maßnahmen, Wien: J\&V.

Flight Motivations of Refugees from Four Soviet Bloc Countries 1963, Munich: Audience Reserch Radio Free Europe.

Freund, P. and K. Kalumba 1986, Spontaneously Settled Refugees in Northwestern Province, Zambia, In: International Migration Review, 20/ 2, $299-312$.

Goodwin-Gill, G.S. 1990, Different Types of Forced Migration Movements as an International and National Problem, In: G. Rystad (ed), The Uprooted: Forced migration as international problem in the post-war era, Lund: Lund University Press, 15-45.

Gordenker, L. 1983, Refugees in Developing Countries and Transnational Organization, In: G.D.Loescher and J.A. Scanlan (eds), The Global Refugee Problem: U.S. and world response, (Special issue of the Annals of the Americal Academy of Political and Social Science vol 467), 62-77.

Grahl-Madson, A. 1983, Identifying the World's Refugees, In: G.D. Loescher and J.A. Scanlan (eds), The Global Refugee Problem: U.S. and worla response, (Special issue of the Annals of the Americal Academy of Political and Social Science vol 467), 11-23. 
Greenacre, M.J. 1981, Practical correspondence analysis. In: V. Barnett (ed.), Interpreting multivariate data, Chicester: John Wiley and Sons, 119-146.

Hailbronner, K. (ed) 1992, Asyl-und Einwanderungsrecht im europäischen Vergleich (Comparative law of asylum und immigration in Europe), Köln: Bundesanzeiger.

Hailbronner, K. 1994, Reform des Asylrechts: Steuerung und Kontrolle des Zuzugs von Ausländern,Konstanz: Universitätsverlag Konstanz.

Hakovirta, H. 1986, Third World Conflicts and Refugeeism: Dimensions, dynamics and trends of the world refugee problem, Helsinki: Finnish Society of Sciences and Letters.

Hakovirta, H. 1991, The World Refugee Problem, Tsmpere: Hillside.

Hammar, T. 1993, The 'Schweden-wide Strategy' of Refugee Dispersal, In: R. Black and V. Robinson (eds), Geography and Refugees: Patterns and processes of change, London/New York: Belhaven press, 104-117.

Hansen, A. 1981, Refugee Dynamics: Angolans in Zambia, 1966 to 1972, In: International Migration Review 15/ 1,2, 175-194.

Hovy, B. 1993, Asylum Migration in Europe: Patterns, determinants and the role of East-West movements, In: R. King (ed), The New Geography of European Migrations, London/New York, Belhaven Press, 207-227.

Hulshof, M., L. De Ridder and P. Krooneman 1992, Asielzoekers in Nederland, Amsterdam: Instituut voor Sociale Geografie, Universiteit van Amsterdam.

IGC 1995, Overview of Asylum Appications as Reported by Participating States, Revised Version.

Johansson, R. 1990, The Refugee Experience in Europe after Worl War II: Some theoretical and empirical considerations, In: G. Rystad (ed), The Uprooted: Forced migration as international problem in the postwar era, Lund: Lund University Press, 227-269.

Joly, D. 1988, Refugees in Britain: An annotated bibliography, Warwick: Centre for Research and ethnic relations.

Kay, D. and R. Miles 1992, Refugees or Migrant Workers? European volunteer workers in Britain 1946-1951, London/New York: Routledge.

King, R. 1993, Why Do People Migrate? The geography of departure, In: R. King (ed), The New Geography of European Migrations, London/ New York, Belhaven Press, 17-46.

Koser, K. 1995a, Asylum Migration in Europe: A systems approach, Paper presented to the COST A2 Workshop on Refugees in Europe: Research Issues, Amsterdam, 25-28 May 1995. 
Koser, K. 1995b, Social Networks and the Asylum Cycle: The case of Iranians in the Netherlands, Paper presented to the 2nd European Sociological Association Conference, Budapest 30 August-2 September 1995.

Koser, K. 1996, Out of the Frying Pan and Into the Fire: A case study of illegality of asylum seekers, Paper presented to the 2nd Ercomer International Conference New Migration in Europe, Utrecht April 1996.

Kritz, M.M., L.L.Lim and H. Zlotnik (eds) 1992, International Migration Systems: A global appraoch, Oxford: Clerendon Press.

Kuhlman, T. 1994, Asylum or Aid? The economic integration of Ethiopian and Eritrean refugees in the Sudan [Ph.D. dissertation Vrije Universiteit Amsterdam].

Kuiper, H.L. 1992, Een Eeuw Ruimhartig Beleid: Een vergelijkend onderzoek naar de gasturijheid van Nederland ten aanzien van vluchtelingen en asielzoekers, Arnhem: [eigen beheer].

Kunz, F. E. 1973, The Refugee in Flight: Kinetic models and forms of displacement, In: International Migration Review 7 , 125-146.

Kunz, F. E. 1981, Exile and Resettlement: Refugee theory, In: International Migration Review 15 / 1,2, 42-51.

Liebkind, K. 1993, Self-Reported Ethnic Identity: Depression and anxiety amoung young Vietnamese refugees and their parents, In: Journal of Refugee Studies 6/ 1, 26.

Loescher, G.D. and J.A. Scanlan (eds) 1983, The Global Refugee Problem: $U . S$. and world response, (Special issue of the Annals of the Americal Academy of Political and Social Science vol 467).

Massey, D.S., R. Alarcón, J. Durand and H. González 1987, Return to Aztlan: The social process of international migration from Western Mexico, Berkeley: University of California Press.

Melander, G. 1990,. Refugee Policy Option - Protection or Assistance?, In: G. Rystad (ed), The Uprooted: Forced migration as international problem in the post-war era, Lund: Lund University Press, 137-156.

Menjívar, C. 1993, History, Economy and Politics: Macro and micro-level factors in recent Salvadorean migration to the US, In: Journal of Refugee Studies 6/ 4, 351-371.

NIDI 1994, Asylum-seekers and Refugees: A statistical report, Volume 1: EC Member States, European Commission, Luxembourg: Office for Official Publications of the European Comminities.

Peterson, W. 1970, A General Typology of Migration, In: C.J. Jansen (ed), Readings in the Sociology of Migration, Oxford: Pergamon Press, 4968. 
Portes, A. and J. Böröcz 1989, Contemporary Immigration: Theoretical perspectives on its determinants and modes of incorporation, In: International Migration Review 23/ 3, 606-630.

Postel, A.A. and P.F.M. Boekhoorn 1993, Een Wereld van Verschil: Ervaringen van vluchtelingen in Nederland, Nijmegen.

Ramakers, J. 1995, Migranten en Ontwikkeling: Enkele elementen uit de discussie tussen eigenbelang en humanitaire principes, In: Bareel 15/ $58,16-18$.

Richmond, A.H. 1993, Reactive Migration: Sociological perspective on refugee movements, In: Journal of Refugee Studies 6/ 1, 7-24.

Rystad, G. 1990, Victims of Oppression or Ideological Weapons?, Aspects of US refugee policy in the post-war era, In: G. Rystad (ed), The Uprooted: Forced migration as international problem in the post-war era, Lund: Lund University Press, 195-226.

Scanlan, J.A. and G.D.Loescher 1983, U.S. Foreign policy 1959-1980: Impact on refugee flow from Cuba, In: G.D.Loescher and J.A. Scanlan (eds), The Global Refugee Problem: U.S. and world response, (Special issue of the Annals of the American Academy of Political and Social Science vol 467), 116-137.

Scheinman, R.S. 1983, Refugees: Goodby to the Good Old Days, In: G.D. Loescher and J.A. Scanlan (eds), The Global Refugee Problem: U.S. and world response, (Special issue of the Annals of the Americal Academy of Political and Social Science vol 467), 78-88.

Schilling, S. R. 1995, Refugees and Immigration in Europe and the Third World, In: F. Heckmann and W. Bosswick (eds), Migration Policies: A comparative perspective, 263-266.

Schoorl, J. 1995, Determinants of International Migration: Theoretical approaches and implications for survey research, In: R. Van der Erf and L. Heering (eds), Causes of International Migration: Proceedings of a workshop, EUROSTAT, Luxembourg, 14-16 December 1994, Luxembourg: Office for the Official Publications of the European Commission, 3-14.

Sik, E. 1992, Transylvanian Refugees in Hungary and the Emergence of Policy Networks to Cope with Crisis, In: Journal of Refugee Studies 5/ 1, 16-28.

Snowden, L.L. 1993, Preventing Asylum Flows in Southern Italy and Sicily, In: Journal of Refugee Studies 6/ 2, 158-170.

The Statesman's Year Book: statistical and historical annual of the states of the world for the year 1985-86, 1986, London: Macmillan.

The Statesman's Year Book: statistical and historical annual of the states of the world for the year 1990-91, 1991, London: Macmillan. 
Stepick, A. and A. Portes 1986, Flight into Despair: A profile of recent Haitian refugees in South Florida, In: International Migration Review 20/2, 329-350.

Suhrke, A. 1995, Analyzing the Causes of Contemporary Refugee Flows, In: R. Van der Erf and L. Heering (eds), Causes of International Migration: Proceedings of a workshop, Eurostat, Luxembourg, 14-16 December 1994, Luxembourg: Office for the Official Publications of the European Commission, 201- 221.

Sutter, V. O'Connor 1990, The Indochinese Refugee Dilemma, Baton Rouge/London: Louisiana State University Press (Political Traditions in Foreign Policy Series).

Ten Doesschate, J.W. 1993, Asielbeleid en Belangen: Het Nederlandse vluchtelingenbeleid ten aanzien van vluchtelingen in de jaren 19681982, Hilversum: Verloren.

Tenhula, J. 1991, Voices from Southeast Asia: The refugee experience in the United States, New York/London: Holmes \& Meier.

UNESCO 1986, Statistical Yearbook 1985, Paris: UNESCO .

UNHCR 1993, The State of the World's Refugees: The challenge of protection, New York: Penguin.

UNHCR 1994, Populations of Concern to UNHCR: A statistical overview, Geneva: United Nations High Commissioner for Refugees.

United Nations 1990, Statistical Yearbook 1988-'89, New York: United Nations.

Van der Erf, R. and L. Heering (eds) 1995, Causes of International Migration: Proceedings of a workshop, Eurostat, Luxembourg, 14-16 December 1994, Luxembourg: Office for the Official Publications of the European Commission.

White, F.E. and R.I. Woods (eds) 1980, The Geographical Impact of Migration, London: Longman.

Widgren, J. 1989, Asylum Seekers in Europe in the Context of SouthNorth Movements, In: International Migration Review 17/ 3, 599-605.

WVC 1991, Vluchtelingen en Asielzoekers (LL941): Een keuze uit de literatuur, Rijswijk: Ministerie van Welzijn, Volksgezondheid en Cultuur, afdeling Documentatie en bibliotheek.

WVC 1992, Vluchtelingen en Asielzoekers (vervolg 1) (LL941): Een keuze uit de literatuur, Rijswijk: Ministerie van Welzijn, Volksgezondheid en Cultuur, afdeling Documentatie en bibliotheek. 
Zolberg, A.R., A. Suhrke and S. Aguayo 1989, Escape from Violence: Conflict and the refugee crisis in the developing world, New York etc.: Oxford University Press.

Zucker, N.L. 1993, Refugee Resettlement in the United States: Policy and Problems, In: G.D.Loescher and J.A. Scanlan (eds), The Global Refugee Problem: U.S. and world response, (Special issue of the Annals of the American Academy of Political and Social Science vol 467), 172-186. 

European Commission

\section{Asylum migration to the European Union: Patterns of origin and destination}

Document

Luxembourg: Office for Official Publications of the European Communities

$1998-X, 121$ pp. $-21 \times 29.7 \mathrm{~cm}$

ISBN 92-828-3306-2

Price (excluding VAT) in Luxembourg: ECU 20.50

\begin{tabular}{|c|c|c|c|}
\hline \multirow{5}{*}{ 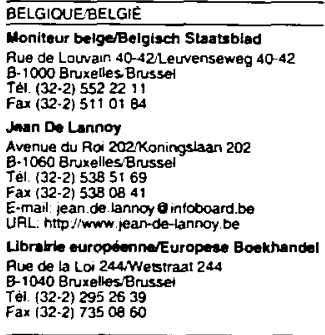 } & NEDERLAND & CYPRUS & INDIA \\
\hline & 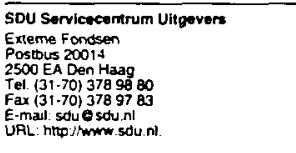 & 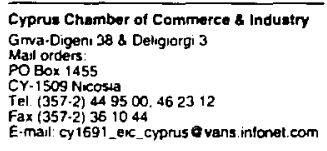 & 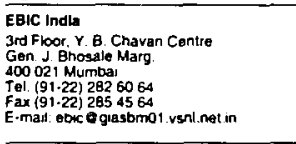 \\
\hline & \multirow{4}{*}{ 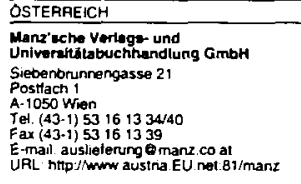 } & MAGYAROASZAG & \multirow{6}{*}{ 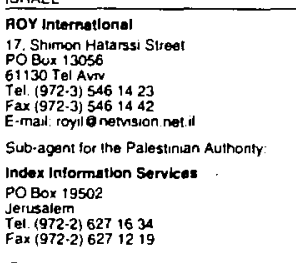 } \\
\hline & & Euro Info Sorvioo & \\
\hline & & 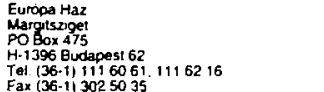 & \\
\hline DANMAAK & & 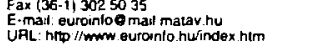 & \\
\hline \multirow{3}{*}{ 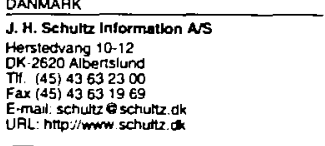 } & \multirow{2}{*}{ 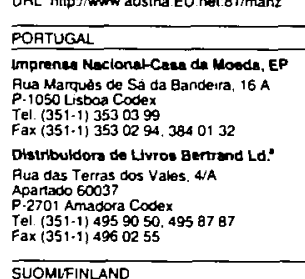 } & MALTA & \\
\hline & \multirow{4}{*}{ 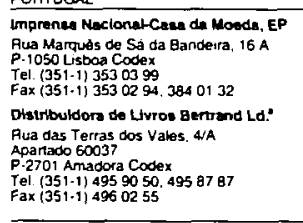 } & \multirow{3}{*}{ 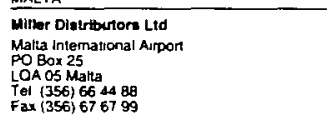 } & \\
\hline & & & \multirow{3}{*}{ 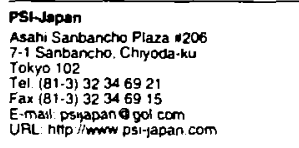 } \\
\hline \multirow{4}{*}{ 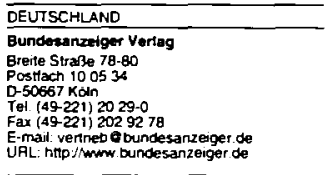 } & & & \\
\hline & & \multirow{3}{*}{ 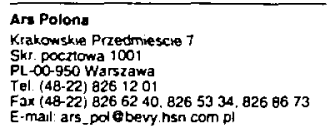 } & \\
\hline & & & \\
\hline & \multirow{4}{*}{ 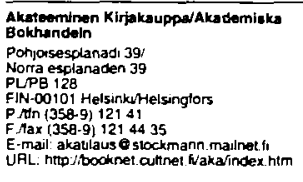 } & & \multirow{3}{*}{ 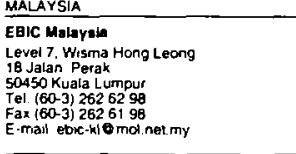 } \\
\hline \multirow{3}{*}{ 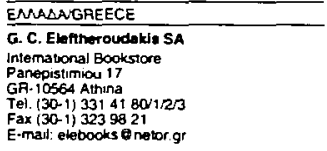 } & & \multirow{3}{*}{$\begin{array}{l}\text { ROMANIA } \\
\text { Euromeds } \\
\text { Str. Grat Bermelot Nr } 41 \\
\text { RO-70749 Bucuresti } \\
\text { Tel (40-1)2104401. } 8140664 \\
\text { Fax }(40-1) 2104401.3129646\end{array}$} & \\
\hline & & & \\
\hline & & & PHILIPPINES \\
\hline ESPANA & SVEAIGE & SLOVAKLA & \multirow{2}{*}{ 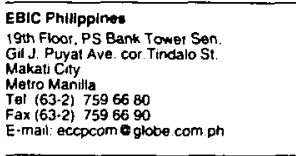 } \\
\hline 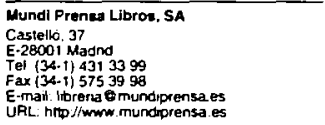 & 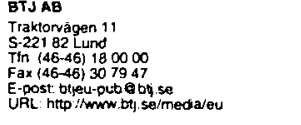 & 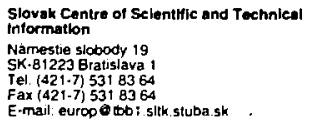 & \\
\hline \multirow{3}{*}{ 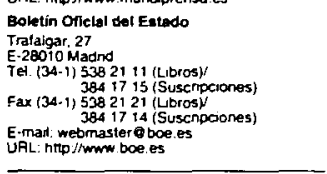 } & \multirow{4}{*}{ 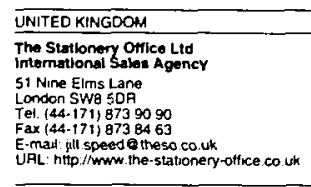 } & SLOVENIA & \multirow{2}{*}{ 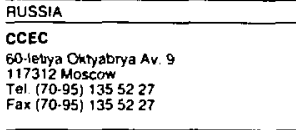 } \\
\hline & & 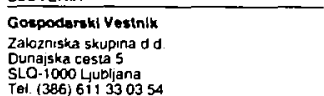 & \\
\hline & & 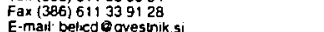 & SOUTH AFAICA \\
\hline \multicolumn{2}{|r|}{ 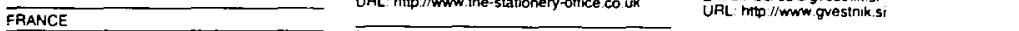 } & & \multirow{3}{*}{ 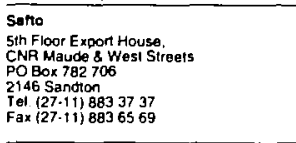 } \\
\hline Jourmal otriciel & \multirow[b]{2}{*}{ 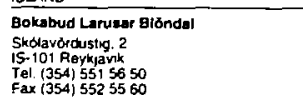 } & TURKIYE & \\
\hline 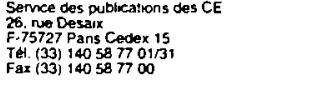 & & 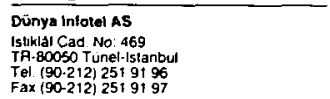 & \\
\hline RELAND & NORGE & & \multirow[b]{2}{*}{ 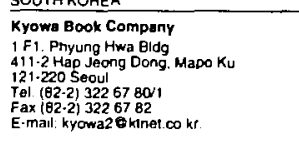 } \\
\hline 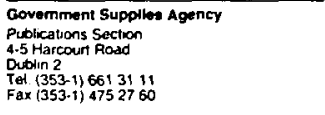 & 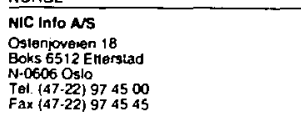 & 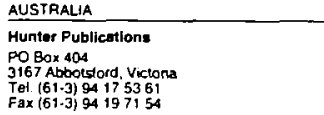 & \\
\hline TALIA & SCHWEIZJSUISSESSVIZZERA & $\overline{\text { CANADA }}$ & \multirow[b]{2}{*}{ 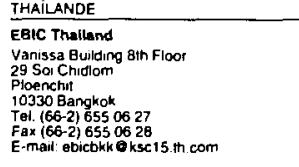 } \\
\hline \multirow[t]{2}{*}{ 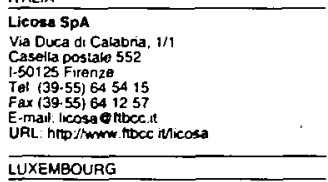 } & 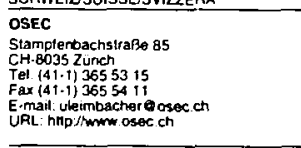 & 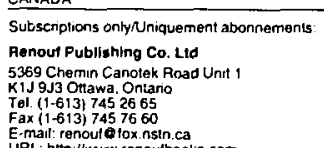 & \\
\hline & BALGARUA & & UNITED STATES OF AMEAICA \\
\hline 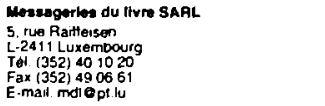 & 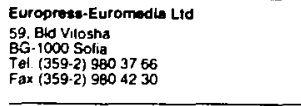 & $\begin{array}{l}\text { EGYPT } \\
\text { The Middle Esat Observer } \\
41 \text {, Sherit Siseet } \\
\text { Carro } \\
\text { Tel. (20-2) } 3939732\end{array}$ & 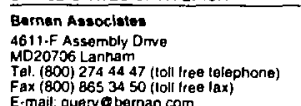 \\
\hline Abornementis: & CESKÁ REPUELIXA & $\operatorname{Fax}\{20.2\} 3939732$ & 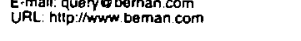 \\
\hline 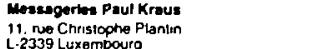 & $\begin{array}{l}\text { NIS CH - prodojns } \\
\text { Komvikiska } 5 \\
\text { CZ-11357 Pratal }\end{array}$ & HAVATSKA & $\begin{array}{l}\text { ANDERE LANDERYTHER COUNTTIES } \\
\text { AUTRES PAYS }\end{array}$ \\
\hline 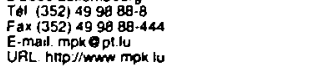 & 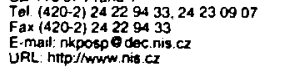 & $\begin{array}{l}\text { Pavla Haza } 1 \\
\text { HR-10000 Zagreb } \\
\text { Tal. (385-1)430392 } \\
\text { Fax (385-1) } 430392\end{array}$ & 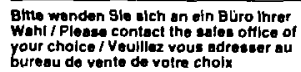 \\
\hline
\end{tabular}


Price (excluding VAT) in Luxembourg: ECU 20.50

ISBN ㄹ-8ㄹ- $3306-2$

$\begin{array}{ll}*{ }^{\star} \star & \text { OFFICE FOR OFFICIAL PUBLICATIONS } \\ * \text { EUA } & \text { OF THE EUROPEAN COMMUNITIES }\end{array}$

$\star \frac{\text { EUR }}{\text { (P }}{ }^{\star}$ OF THE EUROPEAN COMMUNITIES 